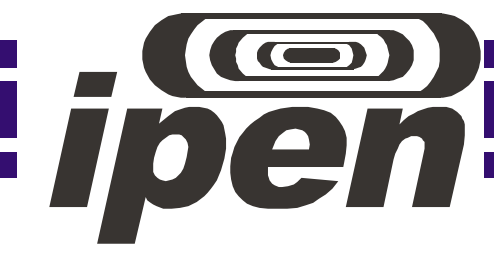

AUTARQUIA ASSOCIADA À UNIVERSIDADE DE SÃO PAULO

\title{
PROJETO, CONSTRUÇÃO E CARACTERIZAÇÃO DE CÂMARAS DE IONIZAÇÃO ESPECIAIS PARA MONITORAÇÃO DE FEIXES DE RADIAÇÃO X
}

\author{
MAÍRA TIEMI YOSHIZUMI
}

\author{
Tese apresentada como parte \\ dos requisitos para obtenção do Grau \\ de Doutor em Ciências na Área \\ de Tecnologia Nuclear - Aplicações \\ Orientadora: \\ Profa. Dra. LINDA V.E. CALDAS
}


INSTITUTO DE PESQUISAS ENERGÉTICAS E NUCLEARES

Autarquia associada à Universidade de São Paulo

\section{PROJETO, CONSTRUÇÃo E CARACTERIZAÇÃO DE CÂMARAS DE IONIZAÇÃO ESPECIAIS PARA MONITORAÇÃO DE FEIXES DE RADIAÇÃO X}

MAÍRA TIEMI YOSHIZUMI

Tese apresentada como parte dos requisitos para obtenção do Grau de Doutor em Ciências na Área de Tecnologia Nuclear - Aplicações.

Orientadora:

Profa. Dra. LINDA V.E. CALDAS

SÃO PAULO

2010 


\section{AGRADECIMENTOS}

À Dra. Linda V. E. Caldas, pela orientação, não somente deste trabalho, mas também em outros aspectos de minha vida pessoal e profissional. Agradeço pelo carinho, atenção, amizade, dedicação, confiança e paciência. Obrigada por todo o incentivo e apoio.

À Dra. Maria da Penha Albuquerque Potiens e ao Dr. Vitor Vivolo, pelos valiosos conselhos e ensinamentos, principalmente no início deste projeto, e também pelas conversas sempre estimulantes.

Ao Sr. Marcos Xavier, pelo apoio técnico e sugestões que muito contribuíram no desenvolvimento deste projeto.

Aos Srs. Claudinei Cescon e Rafael Elias Diniz, pelo apoio técnico sempre atencioso.

Ao Sr. Salvio Soares, pelo suporte em LTEX.

À Sra. Donata Celicea de Oliveira Zanin, pela ajuda em assuntos administrativos, mas principalmente pela amizade, carinho e tantos bons momentos passados juntos.

Ao Sr. José Carlos Sabino, por todos os serviços realizados na Oficina Mecânica do IPEN.

Às queridas amigas Christianne Cobello Cavinato, Patrícia de Lara Antonio e Priscilla Roberta Tavares Leite Camargo, minhas novas amigas de infância. Obrigada pela amizade, carinho, apoio e paciência. Agradeço por tantas conversas francas e tantos momentos felizes, que ficarão sempre guardados em minhas melhores lembranças. Às amigas Lizandra de Souza Pereira e Lúcia Helena da Silva Santos, por serem tão especiais mesmo nos encontrando tão pouco.

Aos amigos e colegas do IPEN Ana Paula Perini, Eric Alexandre Brito da Silva, Fernanda Beatrice Conceição Nonato, Gustavo Barretto Vila, Jonas Oliveira da Silva e Lúcio Pereira Neves, pelo carinho, atenção e pela convivência harmoniosa, agradável e divertida. 
Ao Instituto de Pesquisas Energéticas e Nucleares (IPEN), pela infraestrutura e por possibilitar o desenvolvimento deste projeto.

Ao Conselho Nacional de Desenvolvimento Científico e Tecnológico (CNPq), pelo suporte financeiro.

Aos meus pais, Marisa e Carlos, meu irmão, Bruno, e à Jujú, pelo amor e carinho que sempre me incentivaram a continuar nesta batalha que é a vida acadêmica. Aos meus sogros, Tereza e Ioshinori, meus cunhados, Erika e Márcio, pelo carinho e incentivo inestimáveis.

Ao meu noivo e futuro esposo, Maurício Ioshihiro Fucuda, pelo amor, carinho, dedicação, paciência, incentivo, amizade e companheirismo. Obrigada por compreender essa vida sem horários e com tantos prazos a cumprir. 


\title{
PROJETO, CONSTRUÇÃO E CARACTERIZAÇÃO DE CÂMARAS DE IONIZAÇÃO ESPECIAIS PARA MONITORAÇÃO DE FEIXES DE RADIAÇÃO X
}

\author{
Maíra Tiemi Yoshizumi
}

\begin{abstract}
RESUMO
Os equipamentos de radiação $\mathrm{X}$, por estarem ligados à rede elétrica, podem apresentar flutuações na intensidade de seus feixes de radiação. Essas variações na intensidade, podem, por sua vez, modificar a taxa de kerma no ar produzida por este feixe de radiação. Em um laboratório de calibração de instrumentos, onde são realizadas calibrações de diversos equipamentos detectores de radiação, utilizados principalmente em clínicas ou hospitais, essa possível variação na intensidade do feixe de radiação pode causar um erro na determinação da dose absorvida. As câmaras de ionização monitoras são utilizadas para verificar a constância da intensidade de feixes de radiação, e fornecer uma correção para possíveis oscilações. Neste trabalho foram projetadas, construídas e caracterizadas câmaras de ionização monitoras para feixes de radiação X. As câmaras de ionização desenvolvidas possuem formato inovador, anelar, com eletrodos de alumínio ou de grafite. Essas câmaras de ionização anelares apresentam a vantagem de não interferirem no feixe direto de radiação. Foi ainda construída uma câmara de ionização com volume duplo e eletrodos de grafite, similar à câmara de ionização monitora comercial utilizada no Laboratório de Calibração de Instrumentos do Instituto de Pesquisas Energéticas e Nucleares. Essas câmaras de ionização foram testadas em diversos feixes de radiação padronizados e seus desempenhos foram comparados aos de câmaras de ionização comerciais. Os resultados obtidos mostram que duas dentre as quatro câmaras de ionização desenvolvidas apresentaram desempenho comparável ao das câmaras de ionização comerciais testadas. Além de apresentarem bons resultados, as câmaras de ionização desenvolvidas foram feitas artesanalmente e utilizando materiais de baixo custo, que são facilmente encontrados no mercado.
\end{abstract}




\title{
DESIGN, CONSTRUCTION AND CHARACTERIZATION OF SPECIAL IONIZATION CHAMBERS FOR X RADIATION BEAMS MONITORING
}

\author{
Maíra Tiemi Yoshizumi
}

\begin{abstract}
$\mathrm{X}$ radiation equipment may show fluctuations in the radiation beam intensity, as they are connected to the power net. These intensity variations can, in turn, modify the air kerma rate produced by this radiation beam. In a calibration laboratory, where radiation detectors (from clinics and hospital services) are calibrated, variations in the radiation beam intensity may cause an error in the absorbed dose determination. The monitor ionization chambers are used to verify the radiation beam intensity constancy, and to provide a correction for possible fluctuations. In this work, monitor ionization chambers for $\mathrm{X}$ radiation beams were designed, assembled and characterized. The developed ionization chambers have an innovative design, ring-shaped, with aluminium or graphite electrodes. These ring-shaped ionization chambers have the advantage of not interfering in the direct radiation beams. A double-volume ionization chamber with graphite electrodes was also developed. This ionization chamber is similar to the commercial monitor ionization chamber used in the Calibration Laboratory of the Instituto de Pesquisas Energéticas e Nucleares. All developed ionization chambers were tested in several standardized radiation beams and their performances were compared with those of commercial ionization chambers. The results show that two of the four ionization chambers developed showed performance comparable to that of the commercial ionization chambers tested. Besides presenting good results, the ionization chambers were designed and manufactured using low cost materials, which are easily found on the Brazilian market.
\end{abstract}




\section{Sumário}

1 Introdução 17

2 Fundamentação Teórica 21

2.1 Grandezas Dosimétricas . . . . . . . . . . . . . . 21

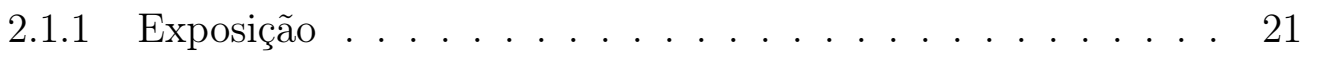

2.1 .2 Dose absorvida . . . . . . . . . . . . . . . . . . . 22

2.1 .3 Kerma . . . . . . . . . . . . . . . . 22

2.2 Medidores de Radiação Ionizante . . . . . . . . . . . . . . . . . . . 23

2.3 Teoria Cavitária . . . . . . . . . . . . . . . . . 24

2.4 Câmaras de Ionização . . . . . . . . . . . . . . . . . . . . . . . . 25

2.5 Câmaras de Ionização do Tipo Dedal . . . . . . . . . . . . . . . . . 28

2.6 Câmaras de Ionização de Placas Paralelas .......... 28

2.7 Câmaras Monitoras . . . . . . . . . . . . . . . . . . . . . 29

2.7.1 Qualidade de um feixe de radiação X . . . . . . . . . . . 30

2.7.2 Determinação da camada semirredutora . . . . . . . . . 31

2.7.3 Filtração adicional . . . . . . . . . . . . . . . 33

2.8 Calibração de Instrumentos e Sistemas Padrões . . . . . . . . . . . 33

2.8 .1 Intercomparação . . . . . . . . . . . . . . 35

2.8.2 Qualidades metrológicas para radiação X de energias baixas e médias e radiação gama . . . . . . . . . . . . . 36

2.9 Rastreabilidade . . . . . . . . . . . . . . . 37 
3 Revisão Bibliográfica 38

4 Materiais e Métodos 41

4.1 Características dos Equipamentos de Radiação . . . . . . . . . . . . 43

4.1.1 Equipamento de radiação X . . . . . . . . . . . . . 43

4.1 .2 Irradiador gama . . . . . . . . . . . . . . . . . 49

4.1.3 Sistema padrão secundário de radiação beta . . . . . . . . . 50

4.2 Testes de Caracterização e de Controle de Qualidade . . . . . . . 51

4.2 .1 Curva de saturação . . . . . . . . . . . . . . . . 52

4.2 .2 Efeito de polaridade . . . . . . . . . . . 52

4.2 .3 Eficiência de coleção de íons . . . . . . . . . . . . . 52 52

4.2.4 Linearidade de resposta . . . . . . . . . . . 5 52

4.2 .5 Calibração . . . . . . . . . . . . . . . 553

4.2 .6 Testes de estabilidade . . . . . . . . . . . . . 553

5 Desenvolvimento de Câmaras de Ionização Monitoras 55

5.1 Câmara Monitora Anelar com Eletrodo Coletor de Alumínio (Primeiro

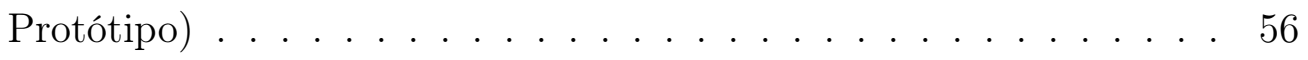

5.2 Câmara Monitora Anelar com Eletrodo Coletor de Alumínio (Segundo Protótipo) . . . . . . . . . . . . . 58

5.3 Câmara Monitora Anelar com Eletrodo Coletor de Grafite . . . . . 59

5.4 Câmara Monitora de Transmissão com Volume Duplo . . . . . . . . 60

6 Desempenho das Câmaras Monitoras Comerciais 63

6.1 Testes de Caracterização . . . . . . . . . . . . . . . . . 64

6.1.1 Curva de saturação, efeito de polaridade e eficiência de coleção de íons . . . . . . . . . . . . . . . . . . . . 64 64

6.1 .2 Linearidade de resposta . . . . . . . . . . . . 65 65

6.2 Testes de Estabilidade de Resposta utilizando Fontes de Controle . 66

6.2 .1 Tempo de estabilização . . . . . . . . . . . . . . 67 
6.2.2 Teste de corrente de fuga . . . . . . . . . . . . 68

6.2.3 Testes de repetitividade e reprodutibilidade . . . . . . . 68 68

6.3 Testes de Estabilidade de Resposta em Feixes de Radiação X . . . . 69

6.4 Calibração das Câmaras de Ionização Comerciais . . . . . . . . . . 70

6.4.1 Calibração em feixes de radiação X . . . . . . . . . . . . . 72

6.4.2 Calibração em feixes de radiação beta e gama . . . . . . . . 79

7 Desempenho das Câmaras de Ionização Desenvolvidas

7.1 Testes de Caracterização . . . . . . . . . . . . . . . . . . . . 82

7.1.1 Curva de saturação, efeito de polaridade e eficiência de coleção de íons . . . . . . . . . . . . . . . . . . . . . . . 82

7.1.2 Linearidade de resposta . . . . . . . . . . . . 84

7.2 Testes de Estabilidade de Resposta utilizando uma Fonte de Controle 85

7.2 .1 Tempo de estabilização . . . . . . . . . . . . . 87

7.2 .2 Teste de corrente de fuga . . . . . . . . . . . . 88

7.2.3 Testes de repetitividade e reprodutibilidade . . . . . . 88

7.3 Testes de Estabilidade de Resposta em Feixes de Radiação X . . . . 89

7.4 Calibração e Transferência do Coeficiente de Calibração do Instrumento Padrão para as Câmaras de Ionização Desenvolvidas . . . . . 92

7.4.1 Transferência do coeficiente de calibração do instrumento padrão utilizando feixes de radiação X . . . . . . . . . 9 95

7.4.2 Calibração em feixes de radiação beta e gama . . . . . . . . 105

7.5 Comparação entre as Câmaras de Ionização Desenvolvidas e as Câmaras Comerciais . . . . . . . . . . . . . . . . . . . . 108

7.6 Estabelecimento de um Sistema Tandem para Avaliação das Camadas Semirredutoras . . . . . . . . . . . . . . . . . . . . . . 110

8 Discussão 
A Artigos Publicados 


\section{Lista de Figuras}

2.1 Câmaras de ionização. . . . . . . . . . . . . . . . . . . . 27

2.2 Arranjo experimental e gráfico para determinação da camada semirredutora. . . . . . . . . . . . . . . . . 32

4.1 Equipamento de radiação X Pantak/Seifert. . . . . . . . . . . . . . 44

4.2 Esquema do aparato experimental utilizado, para as normas IEC

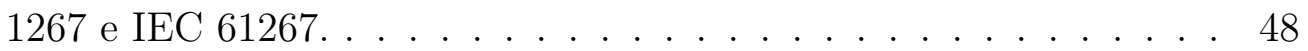

4.3 Irradiador gama Steuerungstechnik Strahlenschutz GmbH, modelo 0B85, Alemanha. . . . . . . . . . . . . . 50

4.4 Sistema de radiação beta padrão secundário Beta Sekundär Standard BSS2, AEA Technology QSA, Alemanha. . . . . . . . . . 51

5.1 Sistema de colimação de feixes de raios X utilizado no sistema Pantak/Seifert do LCI. . . . . . . . . . . . . . . . . . . . . . 56

5.2 Diagrama e fotografia do primeiro protótipo de câmara de ionização anelar. . . . . . . . . . . . . . . . 5 57

5.3 Diagrama e fotografia da câmara de ionização anelar A desenvolvida. 58

5.4 Câmara de ionização monitora anelar com eletrodo coletor de grafite. 60

5.5 Diagrama e fotografia da câmara de ionização de transmissão com volume duplo. . . . . . . . . . . . . . . . . . . . . 61 61

6.1 Câmaras de ionização comerciais de transmissão e do tipo BaldwinFarmer. . . . . . . . . . . . . . . . . 63 
6.2 Curvas de saturação das câmaras de ionização. . . . . . . . . . . . 65

6.3 Linearidade das respostas das câmaras de transmissão e Farmer. . . 66

6.4 Arranjos experimentais para os testes de estabilidade de resposta das câmaras comerciais . . . . . . . . . . . 67

6.5 Reprodutibilidade da resposta das câmaras de transmissão e Farmer, utilizando-se fontes de controle. . . . . . . . . . . . . . . . .69

6.6 Reprodutibilidade da resposta das câmaras monitoras comerciais para as qualidades de radiação RQR5, RQR7, RQA5 e RQA7. . . . 70

6.7 Fatores de correção da resposta da câmara de transmissão para as qualidades de radiodiagnóstico da norma IEC 1267 [35]. . . . . . . . 74

6.8 Fatores de correção da resposta da câmaras Farmer para as qualidades de radiodiagnóstico da norma IEC 1267 [35] . . . . . . . . . . . 75

6.9 Fatores de correção da resposta das câmaras monitoras para as novas qualidades nível radiodiagnóstico $[36] \ldots \ldots$. . . . . . . . . . . . 76

6.10 Fatores de correção da resposta das câmaras monitoras para as novas qualidades nível mamografia $\mid 54]$. . . . . . . . . . . . . . . 78

6.11 Dependência com a distância fonte-detector da câmara de ionização Farmer. . . . . . . . . . . . . . . . . . . 81

7.1 Curva de saturação das câmaras A, G e T. . . . . . . . . . . . 83

7.2 Linearidade da resposta das câmaras A, G e T. . . . . . . . . 8 85

7.3 Suporte de acrílico confeccionado para posicionamento da fonte de controle nos testes de estabilidade das câmaras desenvolvidas. . . . 86

7.4 Câmara de ionização A com a fonte de controle disposta na posição 1 do suporte. . . . . . . . . . . . . . . . 86

7.5 Reprodutibilidade da resposta da câmara A para as posições 1, 2, 3 e 4 do suporte, com fonte de controle de ${ }^{90} \mathrm{Sr}+{ }^{90} \mathrm{Y}$. . . . . . . . . . 89

7.6 Reprodutibilidade da resposta da câmara $\mathrm{G}$ para as posições 1, 2, 3 e 4 do suporte para fonte de controle. . . . . . . . . . . . . . . . . 90 
7.7 Reprodutibilidade da resposta da câmara T para a posição 5 do suporte para fonte de controle. . . . . . . . . . . . . . . . 91

7.8 Reprodutibilidade da resposta da câmara A para as qualidades RQR5, RQR7, RQA5 e RQA7 da norma IEC 1267 de 1994 [35]. . . 92

7.9 Reprodutibilidade da resposta da câmara G para as qualidades RQR5, RQR7, RQA5 e RQA7 da norma IEC 1267 de 1994 [35]. . . 93

7.10 Reprodutibilidade da resposta da câmara $\mathrm{T}$ para as qualidades RQR3, RQR5, RQA3 e RQA5 da norma IEC 61267 de 2005 [36]. . . 94

7.11 Fatores de correção das câmaras A, G e T, utilizando as qualidades definidas na norma IEC 1267 de 1994 [35]. . . . . . . . . . . . . . . 96

7.12 Fatores de correção das câmaras A, G e T, utilizando as novas qualidades definidas na norma IEC 61267 de $2005[36]$. . . . . . . . 101

7.13 Fatores de correção das câmaras A, G e T, utilizando as qualidades de mamografia recomendadas pelo PTB [54]. . . . . . . . . . . . . 103

7.14 Dependência energética das câmaras A, G e T utilizando feixes de radiação beta. . . . . . . . . . . . . . . . . . . . . . . . . . 106

7.15 Dependência com a distância da fonte da resposta das câmaras A, G e T utilizando feixes de radiação beta. . . . . . . . . . . . . . 107

7.16 Curvas tandem obtidas da razão entre as respostas das câmaras G e $\mathrm{T}$, utilizando as qualidades de radiação RQR, RQA e mamografia. . 113 


\section{Lista de Tabelas}

4.1 Qualidades de radiodiagnóstico convencional de acordo com a publicação IEC 1267 de $1994[35] . \ldots \ldots$. . . . . . . . . . . . . . 45

4.2 Características dos feixes padronizados de radiação X para radiodiagnóstico convencional implantadas no equipamento Pantak/Seifert, de acordo com a publicação IEC $1267[35] . . . . . . . . . .46$

4.3 Qualidades de radiodiagnóstico convencional recomendadas pela nova publicação IEC 61267 de $2005[36]$. . . . . . . . . . . . . . . . . . 47 47

4.4 Características dos feixes padronizados de radiação X para radiodiagnóstico convencional implantadas no equipamento Pantak/Seifert, de acordo com a nova publicação IEC 61267 de 2005 [36]. . . . . . . . . . . . . . 48

4.5 Características dos feixes padronizados de radiação X para mamografia implantadas no equipamento de radiação X do LCI, de acordo com certificado emitido pelo PTB $[54] . \ldots \ldots$. . . . . . . . . . . . 49

4.6 Características das fontes de radiação gama. . . . . . . . . . . . . . . . 49

4.7 Características das fontes de radiação beta. . . . . . . . . . . . . . 50

6.1 Tempo de estabilização da câmara de ionização Farmer. . . . . . . . . . 68

6.2 Coeficientes de equivalência e fatores de correção da câmara de transmissão, para as qualidades de diagnóstico, de acordo com a norma IEC 1267 [35]. 74

6.3 Coeficientes de calibração e fatores de correção da câmara Farmer, para as qualidades de diagnóstico, de acordo com a norma IEC 1267 [35] . . . 75 
6.4 Coeficientes de equivalência e fatores de correção da câmara de transmissão, para as qualidades de diagnóstico, de acordo com a norma IEC 61267 [36]. 76

6.5 Coeficientes de calibração e fatores de correção da câmara de ionização Farmer, para as qualidades de diagnóstico, de acordo com a norma IEC 61267 [36 . . . . . . . . . . . . . . . . . . . . . . . . 77

6.6 Coeficientes de equivalência e fatores de correção da câmara de transmissão para as qualidades de mamografia $[54] \ldots \ldots$. . . . . . . . 77

6.7 Coeficientes de calibração e fatores de correção da câmara de ionização Farmer para as qualidades de mamografia [54] . . . . . . . . . . . 77

6.8 Coeficientes de calibração da câmara Farmer para feixes de radiação beta. 79

6.9 Coeficientes de calibração da câmara Farmer para feixes de radiação gama. 80

7.1 Teste de polaridade e eficiência de coleção de íons das câmaras de ionização desenvolvidas. . . . . . . . . . . . . . . . . . . 84

7.2 Tempo de estabilização da resposta das câmaras de ionização desenvolvidas A e G. . . . . . . . . . . . . . . . . . 87

7.3 Tempo de estabilização da câmara T. . . . . . . . . . . . . . . 87

7.4 Teste de corrente de fuga das câmaras de ionização desenvolvidas. . . . . 88

7.5 Coeficientes de equivalência e fatores de correção da câmara A para as qualidades de diagnóstico, de acordo com a norma IEC 1267 [35]. . . . . 95

7.6 Coeficientes de equivalência e fatores de correção da câmara G para as qualidades de diagnóstico, de acordo com a norma IEC 1267 [35]. . . . . 97

7.7 Coeficientes de equivalência e fatores de correção da câmara T para as qualidades de diagnóstico, de acordo com a norma IEC 1267 [35] . . . . . 98

7.8 Coeficientes de equivalência e fatores de correção da câmara A para as qualidades de diagnóstico, de acordo com a norma IEC 61267 [36]. . . . . 99

7.9 Coeficientes de equivalência e fatores de correção da câmara G para as qualidades de diagnóstico, de acordo com a norma IEC $61267[36]$. . . . 99

7.10 Coeficientes de equivalência e fatores de correção da câmara T para as qualidades de diagnóstico, de acordo com a norma IEC $61267[36]$. . . . 100 
7.11 Coeficientes de equivalência e fatores de correção da câmara A para as qualidades de mamografia, de acordo com as qualidades de radiação

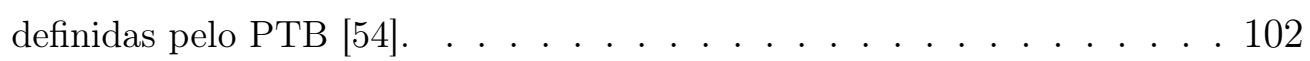

7.12 Coeficientes de equivalência e fatores de correção da câmara G para as qualidades de mamografia, de acordo com qualidade de radiação definidas

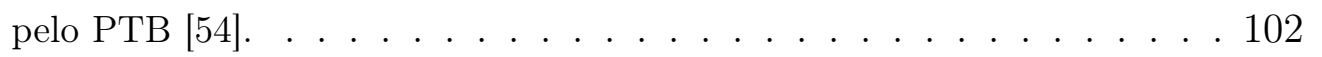

7.13 Coeficientes de equivalência e fatores de correção da câmara T para as qualidades de mamografia, de acordo com as qualidades de radiação

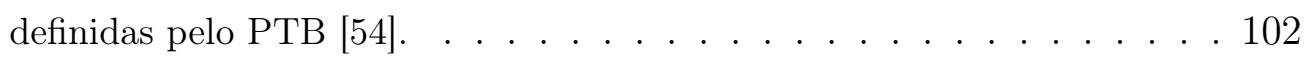

7.14 Coeficientes de calibração das câmaras desenvolvidas para feixes de radiação beta. . . . . . . . . . . . . . . . . . . 105

7.15 Coeficientes de calibração para as fontes de radiação gama. . . . . . . . 106

7.16 Comparação do desempenho entre as câmaras de ionização Farmer, A e G. Os valores em vermelho indicam resultados fora dos limites recomendados

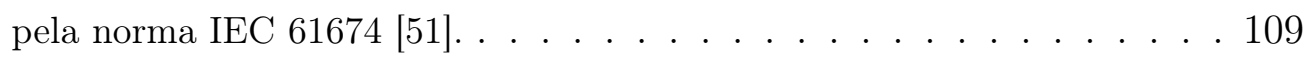

7.17 Comparação do desempenho entre as câmaras de ionização de transmissão e T. . . . . . . . . . . . . . . . . . . . . 1110

7.18 Respostas e razão entre as respostas das câmaras G e T para qualidades de radiação RQR e RQA, nível radiodiagnóstico [36], e WMV, nível mamografia $54 . \ldots \ldots \ldots \ldots$ 


\title{
Lista de Abreviaturas
}

\author{
AAPM AMERICAN ASSOCIATION OF PHYSICISTS IN MEDICINE \\ BIPM BUREAU INTERNATIONAL DES POIDS ET MESURES \\ CNEN COMISSÃO NACIONAL DE ENERGIA NUCLEAR \\ CSR CAMADA SEMIRREDUTORA \\ DAP DOSE AREA PRODUCT \\ IAEA INTERNATIONAL ATOMIC ENERGY AGENCY \\ ICRP INTERNATIONAL COMMISSION ON RADIOLOGICAL PROTEC- \\ TION \\ ICRU INTERNATIONAL COMMISSION ON RADIATION UNITS AND \\ MEASUREMENTS \\ IEC INTERNATIONAL ELECTROTECHNICAL COMMISSION \\ INMETRO INSTITUTO NACIONAL DE METROLOGIA, NORMALIZAÇÃO \\ E QUALIDADE INDUSTRIAL \\ ISO INTERNATIONAL ORGANIZATION FOR STANDARDIZATION \\ LCI LABORATÓRIO DE CALIBRAÇÃO DE INSTRUMENTOS
}


NCRP NATIONAL COUNCIL ON RADIATION PROTECTION AND MEASUREMENTS

NIST NATIONAL INSTITUTE OF STANDARDS AND TECHNOLOGY

PSDL PRIMARY STANDARD DOSIMETRY LABORATORY

PTB PHYSIKALISCH-TECHNISCHE BUNDESANSTALT

PTW PHYSIKALISCH-TECHNISCHE WERKSTÄTTEN

SSDL SECONDARY STANDARD DOSIMETRY LABORATORY

VIM VOCABULÁRIO INTERNACIONAL DE TERMOS FUNDAMENTAIS E GERAIS DE METROLOGIA 


\section{Introdução}

As radiações transportam energia e, dependendo desta energia, ela pode excitar ou ionizar os átomos da matéria. Quando a energia é suficiente para arrancar elétrons dos átomos, ela é chamada radiação ionizante e quando a energia não é suficiente para arrancar elétrons ela é chamada radiação não ionizante. As radiações ionizantes podem ser ondas eletromagnéticas, como a radiação X e gama, partículas carregadas, como elétrons e partículas alfa, ou ainda, podem ser nêutrons.

A radiação ionizante interage com a matéria de forma complexa e pode causar efeitos deletérios ao organismo. Existem vários estágios dessa interação. Primeiramente ocorre o estágio físico, no qual ocorre a deposição da energia na matéria. Depois ocorre a quebra das ligações iônicas, como a hidrólise da água, com a formação dos radicais livres que, em seguida, irão interagir formando produtos estáveis que podem ser tóxicos. Neste estágio começam a ocorrer quebras celulares e interrupção de processos bioquímicos dando origem aos efeitos biológicos.

A dosimetria das radiações ionizantes refere-se à medição dessas radiações, avaliando a energia depositada para tentar quantificar o efeito no organismo, seja ele danoso ou não. A quantidade de radiação totalmente inócua ao ser humano ainda não é conhecida e o efeito a longo prazo, que pode resultar de exposições crônicas, mesmo para baixos níveis de exposição, está longe de ser determinado. Várias teorias foram elaboradas para descrever esses efeitos, mas devido à complexidade da interação da radiação com a matéria, estas teorias não são suficientes para descrever todos os seus aspectos. Existem ainda métodos computacionais (p. ex. método de Monte Carlo) que simulam essa interação permitindo avaliar tanto a deposição 
quanto a distribuição dessa energia na matéria. Apesar disso, as regulamentações de proteção radiológica são baseadas em um modelo muito mais simples que considera que não há dose de limiar e que o risco aumenta linearmente com a dose [1].

Em qualquer serviço médico, seja em hospitais ou em clínicas, que utiliza radiações ionizantes, é necessária muita cautela para se garantir a qualidade dessas radiações. Esses cuidados começam na determinação da dose absorvida, ou da exposição, pelos Laboratórios de Dosimetria Padrões Primários, passando pela calibração dos padrões secundários pertencentes aos Laboratórios de Dosimetria Padrões Secundários, depois pela calibração dos equipamentos utilizados em campo e terminam nos programas de garantia e controle da qualidade realizados nos serviços médicos [2].

Diversos protocolos para determinação da dose absorvida e/ou para calibração tanto do feixe de radiação como dos instrumentos detectores de radiação já foram publicados e recomendados pela International Commission on Radiation Units and Measurements (ICRU) [3, 4], pela American Association of Physicists in Medicine (AAPM) [5, 6], pela International Atomic Energy Agency (IAEA) [7 -9 e, também, pela International Organization for Standardization (ISO) [10. Todos esses protocolos demonstram uma grande preocupação quanto aos efeitos da radiação.

A medição da quantidade de radiação é realizada por meio da utilização de equipamentos denominados medidores de radiação. O medidor de radiação mais comumente utilizado é a câmara de ionização. A câmara de ionização contém um volume sensível no qual a energia depositada pela radiação é convertida em corrente elétrica, que é medida e apresentada por um sistema de medição eletrônico, o eletrômetro.

As câmaras de ionização são formadas, basicamente, por um eletrodo de polarização, um eletrodo coletor e um volume preenchido por gás, que normalmente é o próprio ar do ambiente no qual se encontra, sendo necessárias correções para as condições de temperatura e pressão de referência. A radiação ionizante, ao interagir com o gás do volume sensível da câmara, irá ionizá-lo, sendo que os elétrons pro- 
duzidos serão coletados devido a um campo elétrico aplicado entre os eletrodos da câmara de ionização. Dependendo de sua aplicação, cada câmara apresenta um tipo de geometria, tamanho e composição dos seus materiais constituintes. Essa variação depende do tipo da radiação, de sua energia, e da taxa de dose a ser medida.

Um tipo especial de câmara de ionização é a câmara de transmissão. Estas câmaras de transmissão têm eletrodos de placas paralelas e um volume sensível grande. São utilizadas no monitoramento da intensidade dos feixes de radiação, principalmente dos feixes que não são constantes com o tempo devido a flutuações no fornecimento de energia elétrica.

No grupo de pesquisa do Laboratório de Calibração de Instrumentos (LCI) do IPEN foram desenvolvidos vários sistemas de referência compostos por câmaras de ionização de placas paralelas para radiação X de energias baixas e beta [11 13], e para elétrons de energias altas [14], uma câmara de extrapolação para radiação X e beta 15,17 e câmaras de ionização de dupla face (sistema Tandem) 18, 19. Foram ainda desenvolvidas duas mini-câmaras de extrapolação 20, 21 para dosimetria de fontes planas e côncavas de ${ }^{90} \mathrm{Sr}+{ }^{90} \mathrm{Y}$, e uma câmara de ionização de referência para feixes de tomografia computadorizada em laboratórios de calibração de instrumentos [22]. No Instituto de Radioproteção e Dosimetria, Comissão Nacional de Energia Nuclear (CNEN), Rio de Janeiro, foi desenvolvida uma câmara de transmissão de grafite com características comparáveis ao esperado de um equipamento padrão secundário 23].

Nos sistemas de raios $\mathrm{X}$ dos laboratórios de calibração de instrumentos há necessidade da utilização de câmaras monitoras, que podem ser do tipo câmara de transmissão (posicionada no feixe direto) ou do tipo câmara cilíndrica (posicionada fora do feixe direto), para controle da taxa de kerma no ar (devido a uma possível falta de estabilidade dos feixes de radiação X) durante os procedimentos de calibração de instrumentos. 
O objetivo principal deste trabalho é o desenvolvimento de uma câmara de ionização, de placas paralelas, de forma anelar, a ser utilizada como câmara monitora em feixes de radiação $\mathrm{X}$.

Este tipo de câmara apresenta a vantagem, em relação às câmaras de transmissão comerciais, de não alterar as características dos feixes de radiação, pois, apesar de estar localizada no banco óptico, entre o ponto focal do tubo de raios X e o detector de radiação (a ser calibrado, por ex.) ela não intercepta o feixe direto, por ser anelar. Em relação às câmaras cilíndricas, de volume sensível igual a $0,6 \mathrm{~cm}^{3}$, utilizadas como monitoras, a câmara anelar apresenta a vantagem de ter uma resposta mais sensível devido ao seu volume de gás ser grande.

Além disso, um outro objetivo é a construção de uma câmara de ionização com volume duplo, para comparação com as câmaras de transmissão disponíveis no mercado. 


\section{Fundamentação Teórica}

\subsection{Grandezas Dosimétricas}

As grandezas relacionadas à dosimetria das radiações foram definidas pela ICRU 2427 e mais recentemente a International Commission on Radiological Protection (ICRP), em sua publicação 103, novamente definiu essas grandezas entre outras 28. Essas grandezas dosimétricas quantificam a radiação ionizante e são especificadas a partir de grandezas físicas mensuráveis, tais como as grandezas radiométricas de caracterização de um campo de radiação e os coeficientes de interação entre a radiação e a matéria [29].

\subsubsection{Exposição}

Ao contrário da dose absorvida, o roentgen foi motivo de grande discussão pelo fato de ser utilizado ora como grandeza, ora como unidade. Somente em 1968, com a publicação do relatório ICRU 11 [30], o termo exposição foi utilizado com o significado de "estar exposto a campos de radiação", ou seja, foi criada a grandeza exposição cuja unidade era o roentgen.

A exposição $(X)$ foi definida como sendo o quociente do valor absoluto da carga total de íons de um mesmo sinal produzidos no ar quando todos os elétrons liberados pelos fótons num volume de ar são completamente freados $(d Q)$ pela massa desse volume de ar $(d m) \mid 26]$, ou seja:

$$
X=\frac{d Q}{d m}
$$


Como a exposição, de uma forma simplificada, representa a carga total relacionada com a ionização produzida no ar por fótons, a grandeza exposição é somente definida para radiações X e gama, em condições normais de temperatura e pressão.

Atualmente a unidade da exposição segue o Sistema Internacional de Unidades, sendo denotada por $\mathrm{C} \cdot \mathrm{kg}^{-1}[26]$. A equivalência da nova unidade com o roentgen é: $1 \mathrm{R}=2,58 \times 10^{-4} \mathrm{C} \cdot \mathrm{kg}^{-1}$.

\subsubsection{Dose absorvida}

A radiação ionizante pode interagir com a matéria por meio da transferência de energia. Esta energia transferida pode excitar ou ionizar átomos, ou pode ainda produzir radiação de Bremsstrahlung (radiação de freamento),ou seja, nem toda energia transferida é absorvida ou depositada na matéria.

Em 1950, a ICRU recomendou que a dose fosse expressa em termos da quantidade de energia absorvida por unidade de massa do material irradiado. Somente em 1953, a grandeza dose absorvida foi estabelecida [24], sendo definida como a relação entre a energia média depositada em um volume e a massa desse volume, ou seja:

$$
D=\frac{d \bar{E}}{d m}
$$

sendo, inicialmente, sua unidade chamada de rad (radiation absorbed dose), equivalendo a 100 ergs por grama, ou seja, 1 rad é igual à dose absorvida pelo tecido mole quando exposto a 1 roentgen de exposição em feixes de radiação X.

Posteriormente [25], a unidade da dose absorvida foi modificada para o gray, sendo que, no Sistema Internacional, 1 Gy equivale a $1 \mathrm{~J} \cdot \mathrm{kg}^{-1}$. Apesar dessa modificação, a definição de dose absorvida continua a mesma até os dias atuais [26].

\subsubsection{Kerma}

Assim como a grandeza dose absorvida, o kerma (kinetic energy released per unit of mass) também está relacionado à energia. Ele é definido como sendo o quociente 
da energia cinética inicial total de todas as partículas carregadas provindas de partículas não carregadas em um volume de massa $d m\left(d E_{t r}\right)$ pela própria massa de material $(d m)$ [26]:

$$
K=\frac{d E_{t r}}{d m}
$$

A unidade da grandeza kerma é a mesma da dose absorvida, $\mathrm{J} \cdot \mathrm{kg}^{-1}$, que recebe o nome especial de Gray, no Sistema Internacional.

Por suas definições, o kerma e a dose absorvida são equivalentes quando: a) existe o equilíbrio de partículas carregadas? b) as perdas por processos radiativos são desprezíveis; e c) a energia das partículas carregadas é grande quando comparada com a energia de ligação das partículas carregadas [26].

\subsection{Medidores de Radiação Ionizante}

Os medidores de radiação, ou dosímetros, são equipamentos, sistemas ou mesmo materiais que, em conjunto com o sistema de leitura, medem a radiação ionizante, seja de forma direta ou indireta. Essa medição pode ser feita de diversas formas, tais como por: mudança de cor, temperatura ou potencial, indução de corrente elétrica, luminescência, entre outras.

Para a utilização de um dosímetro, ele deve possuir ao menos uma propriedade física que seja relacionada às grandezas físicas mensuráveis e, ainda, apresentar algumas características importantes. Nem todos os dosímetros atendem a todas essas características; dessa forma, a escolha de um dosímetro depende de sua aplicação. As características mais importantes na escolha de um dosímetro são 31:

- Acurácia e precisão

- Linearidade

\footnotetext{
${ }^{1}$ A condição de equilíbrio de partículas carregadas é alcançada quando a quantidade de elétrons que deixam o volume sensível da câmara é compensada com a mesma quantidade de elétrons de mesmas características que entram neste volume.
} 
- Dependência com a taxa de dose

- Dependência energética

- Dependência angular

- Resolução espacial e tamanho físico

- Conveniência de manuseio, leitura e uso

Para cada aplicação existe um dosímetro mais recomendado. Normalmente este dosímetro possui as características mais importantes para sua finalidade, principalmente quanto à facilidade de utilização e custo. A determinação da dose em radiodiagnóstico e, principalmente, em radioterapia é de fundamental importância e, por isso, as câmaras de ionização são amplamente utilizadas, devido ao fato de serem versáteis, com resposta em tempo real e de funcionamento simples.

\subsection{Teoria Cavitária}

A teoria da cavidade busca contornar o problema de descontinuidade do meio causada pela introdução de um dosímetro, ou de uma cavidade, para a medição. Esta teoria é de suma importância na dosimetria das radiações, pois qualquer medição realizada sofre a interferência do próprio dosímetro.

W.H. Bragg e L.H. Gray, citados por Attix [32], foram os primeiros a estabelecer uma teoria da cavidade, baseada em duas condições. A primeira é que a cavidade seja pequena em relação ao alcance das partículas carregadas geradas pela interação da radiação com a cavidade; a segunda condição é que a energia depositada na cavidade seja exclusivamente devido às partículas que a atravessam. Sob estas duas condições, Gray enunciou o "Princípio de Equivalência", citado por Attix [32], onde afirmava que: "a energia cedida pelos elétrons, por unidade de volume, na cavidade, é $1 /{ }_{\mathrm{m}} S_{\text {meio }}^{\text {cav }}$ vezes a energia cedida pela radiação gama, por unidade de volume, no 
meio adjacente", sendo $1 /{ }_{\mathrm{m}} S_{\text {meio }}^{\text {cav }}$ o inverso da razão dos poderes de freamento dos elétrons na cavidade e no meio, ou seja:

$$
D_{\text {meio }}=\frac{1}{{ }_{\mathrm{m}} S_{\text {meio }}^{\text {cav }}} D_{\text {cav }},
$$

sendo $D_{\text {meio }}$ a dose absorvida no meio de interesse e $D_{\text {cav }}$ a dose absorvida na cavidade.

Muitos aprimoramentos foram propostos para esta teoria pelo fato de que as condições de Bragg-Gray nem sempre podem ser atendidas na prática. Uma dessas propostas foi feita por Spencer e Attix, citadas por Attix 32]. Eles consideraram as perdas de energia devido aos raios $\delta$ e introduziram uma energia de corte $\triangle$. Burlin foi o primeiro a considerar a atenuação dos elétrons gerados no meio e o aumento de elétrons gerados na cavidade [32]. A teoria da cavidade de Burlin pode ser aplicada para cavidades pequenas, intermediárias ou grandes e é dada pela equação:

$$
D_{\text {meio }}=\left[d \times{ }_{\mathrm{m}} S_{\text {meio }}^{\text {cav }}+(1-d) \frac{\left(\mu_{\mathrm{en}} / \rho\right)_{\text {cav }}}{\left(\mu_{\mathrm{en}} / \rho\right)_{\text {meio }}}\right]^{-1} D_{\text {cav }},
$$

sendo ${ }_{\mathrm{m}} S_{\text {meio }}^{\text {cav }}$ a razão dos poderes de freamento dos elétrons na cavidade e no meio; $\left(\mu_{\mathrm{en}} / \rho\right)_{\mathrm{cav}}$ e $\left(\mu_{\mathrm{en}} / \rho\right)_{\text {meio }}$ os coeficientes de absorção de energia de massa da cavidade e do meio, respectivamente; $D_{\text {cav }}$ e $D_{\text {meio }}$ as doses absorvidas na cavidade e no meio, respectivamente; e $d$ um fator que depende do tamanho da cavidade. O fator $d$ é igual a 1 para cavidades pequenas, com relação ao alcance dos elétrons, e igual a zero para cavidades maiores que o alcance dos elétrons.

\subsection{Câmaras de Ionização}

As câmaras de ionização são medidores de radiação que se baseiam nos efeitos produzidos pela passagem de uma partícula carregada dentro de um volume preenchido por gás.

Dependendo de sua finalidade, as câmaras de ionização se apresentam em diversas geometrias, materiais e tamanhos. De uma forma bem ampla, pode-se 
considerar que as câmaras de ionização podem ser divididas em dois tipos [32]: as câmaras cavitárias e as de ar livre. As câmaras cavitárias são muito mais simples e versáteis permitindo seu uso rotineiro. As câmaras cavitárias consistem, basicamente, de um eletrodo central circundado por uma parede, delimitando o seu volume preenchido pelo gás. A radiação, ao entrar na câmara de ionização através de sua janela de entrada, interage com o material da janela, com a parede ou com o próprio gás, causando principalmente ionizações e excitações. Com a aplicação de um campo elétrico entre o eletrodo central e a parede, os elétrons gerados nas ionizações migram em direção ao eletrodo central, sendo coletados, enquanto que os íons positivos migram para a parede, gerando, assim, uma variação na carga do circuito. Essa variação gera um sinal elétrico que é medido por um circuito eletrônico e sua intensidade depende do número de pares de íons produzidos. As câmaras cavitárias são muito compactas, se comparadas com as câmaras de ar livre, pelo fato de a condição de equilíbrio de partículas carregadas ser facilmente assegurada com a utilização de um material sólido como a parede da câmara de ionização e/ou a janela de entrada. A Figura 2.1 mostra dois tipos muito comuns de câmaras de ionização cavitárias, cilíndrica e de placas paralelas, e uma câmara de ar livre.

As câmaras de ar livre apresentam o mesmo princípio de funcionamento das câmaras cavitárias. Como seu próprio nome sugere, elas não possuem janela de entrada, sendo muito grandes para que o equilíbrio de partículas carregadas seja alcançado. Por esse motivo, as câmaras de ar livre são utilizadas somente para radiação X gerados com tensão de até $300 \mathrm{kV}$. São detectores absolutos, não necessitando de coeficientes de calibração, pois medem grandezas físicas básicas (carga e massa) diretamente e assim a exposição pode ser determinada.

Normalmente as câmaras de ionização são abertas, isto é, não seladas, principalmente em diagnóstico, utilizando o ar do próprio ambiente como o gás de seu volume sensível. Como a resposta da câmara depende da densidade do gás de preenchimento, a leitura obtida pela câmara aberta deve ser corrigida. Essa 


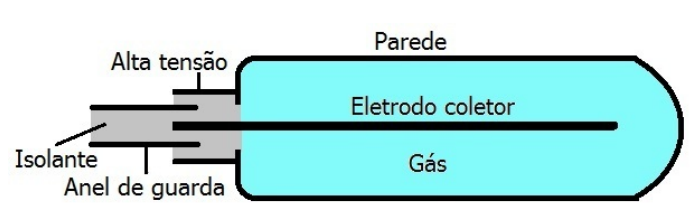

(A) Câmara de ionização cilíndrica

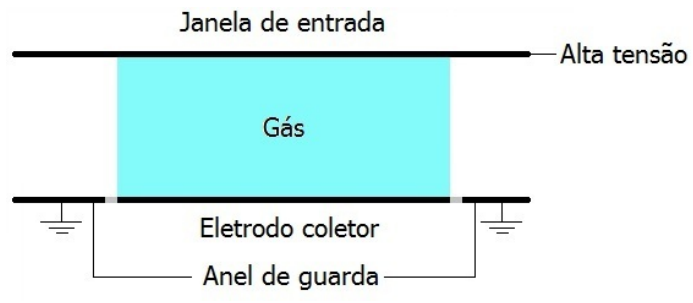

(в) Câmara de ionização de placas paralelas

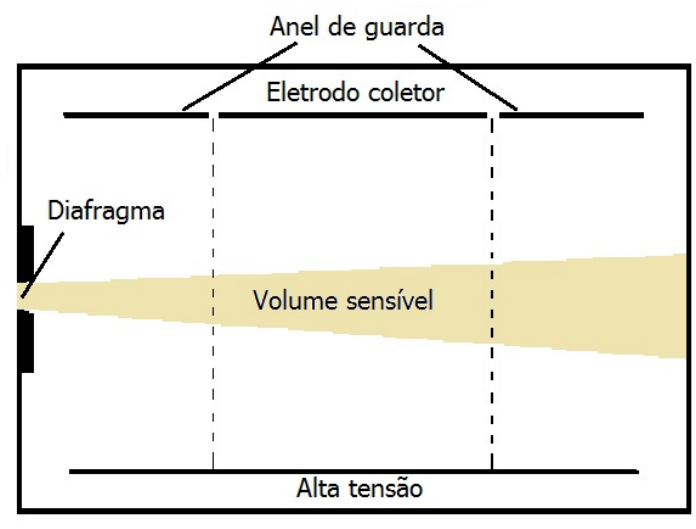

(c) Câmara de ar livre

Figura 2.1 - Câmaras de ionização.

correção é feita em relação às condições normais de temperatura e pressão e pode ser obtida pela seguinte equação [32]:

$$
f_{T, p}=\frac{p_{c}}{p} \times\left(\frac{273,15+T}{273,15+T_{c}}\right)
$$

sendo $p_{c}$ e $T_{c}$ a pressão atmosférica e a temperatura, respectivamente, sob condições normais e iguais a $101,325 \mathrm{kPa}$ e $20^{\circ} \mathrm{C}$; e $p$ e $T$ são, respectivamente, a pressão atmosférica e a temperatura do laboratório no momento da medição.

As câmaras de ionização podem ser utilizadas para a detecção e medição das radiações X, alfa, beta, gama e fragmentos de fissão. Por isso, as câmaras podem ser construídas com os mais diversos tipos de materiais, dimensões e formas. São normalmente utilizadas para se determinar a dose absorvida em um meio que não 
seja necessariamente de mesmo material que o do seu volume. Esta relação é obtida pela teoria da cavidade.

Eletrômetros são equipamentos que podem ser utilizados para medição de correntes baixas da ordem de $10^{-9} \mathrm{~A}$ ou menos e, quando utilizados em conjunto com uma câmara de ionização, medem, com alto ganho, a corrente ou a carga coletada por um intervalo de tempo 31.

\subsection{Câmaras de Ionização do Tipo Dedal}

As câmaras cilíndricas, ou do tipo dedal, são fabricadas em diversos tamanhos e com volume sensível variando entre 0,1 e $1 \mathrm{~cm}^{3}$. O tipo mais comum de câmara de ionização dedal é a câmara de $0,6 \mathrm{~cm}^{3}$, também conhecida por câmara BaldwinFarmer, em homenagem ao seu inventor, Frank T. Farmer.

Tipicamente, as câmaras cilíndricas têm comprimento interno de até $25 \mathrm{~mm}$ e diâmetro interno de até $7 \mathrm{~mm}$. O material da parede normalmente é de material equivalente a tecido ou ar, ou seja, de baixo número atômico. A parede deve ainda ser pouco espessa, menor que $0,1 \mathrm{~g} / \mathrm{cm}^{2}$ [31]. Sua construção deve ser a mais homogênea possível para evitar dependência energética de sua resposta.

Como toda câmara cavitária, as câmaras cilíndricas devem ser calibradas em relação a sistemas de referência.

\subsection{Câmaras de Ionização de Placas Paralelas}

As câmaras de ionização de placas paralelas possuem duas paredes planas que atuam como: a) janela de entrada e eletrodo de polarização; e b) anel de guarda e eletrodo coletor [31]. O eletrodo coletor nestas câmaras é isolado do anel de guarda. Nesta configuração de placas paralelas, o anel de guarda atua primariamente na definição do volume sensível, provendo um campo elétrico uniforme. Porém, em 
algumas câmaras, o anel de guarda também previne contra o surgimento de corrente de fuga do eletrodo polarizado 32 .

A camada de ar entre suas placas pode ser muito estreita, da ordem de $0,5 \mathrm{~mm}$, permitindo boa resolução em profundidade durante as medições, especialmente nas regiões onde a dose varia rapidamente com a distância. Por esta característica, as câmaras de placas paralelas são recomendadas para dosimetria de feixes de elétrons com energia abaixo de $10 \mathrm{MeV}$ e em medições de doses superficiais e profundas na região de equilíbrio eletrônico em feixes de fótons de megavoltagem [31].

\subsection{Câmaras Monitoras}

As câmaras monitoras são câmaras de ionização utilizadas quando não é possível ter-se a garantia de que o fornecimento de energia para o gerador de radiação é constante com o tempo; estas câmaras de ionização permitem corrigir o resultado de uma medição qualquer pela sua medição. Isto ocorre porque elas são fixas e cobrem todo o feixe de radiação. Elas não precisam, necessariamente, de calibração, já que não será medida nenhuma grandeza tal como dose absorvida ou exposição. Porém é necessário conhecer muito bem suas características, como estabilidade, dependência energética, saturação, entre outras.

As câmaras monitoras próprias para aplicações em feixes de raios X são as câmaras de ionização de placas paralelas, chamadas de câmaras de transmissão. Essas placas podem ser de Lucite recobertas com grafite. Devem, ainda, possuir um anel de guarda para separar os eletrodos do corpo da câmara e definir seu volume sensível. Os contatos elétricos com os cabos coaxiais podem ser feitos de bronze [32], assim como, de cobre recoberto com prata ou ouro. O problema de se utilizar o grafite como revestimento é por ele não ser um material "transparente" à radiação e acaba por produzir uma atenuação do feixe que não é desejável nesse tipo de câmaras 33. 
As câmaras monitoras disponíveis comercialmente podem, em sua maioria, ser conectadas a eletrômetros comuns. Elas fornecem medições da variação da corrente ou da carga elétrica com o tempo ou podem, ainda, fazer a medição do acúmulo de carga durante um certo período de tempo.

Existe um tipo especial de câmara de ionização que é conhecida como câmara DAP (dose area product). Este tipo de câmara mede o produto da dose absorvida no ar (ou exposição) pela área útil do feixe. Como esta câmara é fixa, sua resposta varia de acordo com alterações eventuais na intensidade do feixe de radiação $\mathrm{X}$. Assim, essa câmara pode também ser utilizada como câmara monitora, mas ela tem ainda outras finalidades, como determinar a energia transferida ao paciente [34].

Uma câmara dedal também pode ser utilizada como câmara de ionização monitora [32]. Para isto deve-se simplesmente posicioná-la em um local fixo fora do feixe direto. Porém, uma câmara de ionização plana, na qual o feixe de radiação passe através dela, tem a vantagem de poder ser instalada permanentemente no arranjo experimental e monitorar um segmento do feixe de maior interesse, ou todo o feixe.

Os geradores de raios X modernos possuem uma estabilidade alta e a utilização de uma câmara monitora nem sempre é imprescindível. Mesmo assim, as câmaras monitoras são recomendadas para garantir a qualidade, ou seja, para verificar se o feixe de radiação está ou não presente e se a filtração e o tamanho do campo escolhidos estão corretos [33]. Com relação aos equipamentos de radiação X utilizados em laboratórios de calibração, diversas normas recomendam a utilização de câmaras monitoras $8,9,33$.

\subsubsection{Qualidade de um feixe de radiação $X$}

A qualidade de um feixe de radiação foi primeiramente utilizada para definir sua capacidade de penetração na matéria. Atualmente sua definição é mais ampla e relativa à distribuição espectral de energia 32. 
A espectrometria de um feixe de radiação é um processo que requer mão-deobra especializada [33 e equipamentos sofisticados; em diversas aplicações clínicas a determinação do espectro do feixe não se faz necessária. Uma descrição mais simplificada da qualidade do feixe pode ser feita por meio do conhecimento da tensão do tubo de raios X e de sua camada semirredutora (CSR). A camada semirredutora é definida como sendo a espessura de um absorvedor necessária para reduzir em $50 \%$ a intensidade ou a taxa de kerma no ar de um feixe estreito, a uma certa distância de referência.

A qualidade de feixes monoenergéticos, que possuem espectro discreto e conhecido, pode ser descrita a partir da energia efetiva do feixe de radiação. Como todos os feixes de raios X não são monoenergéticos, suas qualidades são normalmente descritas em termos da CSR. Esta heterogeneidade é devido à variação na tensão de pico, no material do alvo e na filtração total do feixe. Porém, a energia efetiva de um feixe de radiação X heterogêneo é a mesma energia efetiva de um feixe monoenergético de mesma CSR 31.

É definida, ainda, a segunda camada semirredutora, que corresponde à espessura adicional necessária para reduzir a taxa de kerma no ar a $25 \%$ de seu valor inicial. O valor da razão entre a primeira CSR e a segunda CSR é denominado coeficiente de homogeneidade.

Para cada um dos níveis de utilização da radiação X (radiodiagnóstico, radioproteção e radioterapia), existem várias qualidades de feixes de radiação. Essas qualidades possíveis são geralmente caracterizadas pela diferença de potencial aplicado ao tubo gerador de raios X e pela filtração adicional. Essas características são descritas em normas internacionais [10, 35, 36] e estabelecem a padronização dos campos de radiação X.

\subsubsection{Determinação da camada semirredutora}

As qualidades de radiação para o estabelecimento dos campos padrões, como já dito anteriormente, são definidas pelas diferentes CSR obtidas para cada configuração 
de tensão e filtração adicional. Para a determinação da CSR utiliza-se uma câmara de ionização para a medição da taxa de kerma no ar do feixe de radiação. São utilizadas diferentes espessuras de material absorvedor, de alta pureza, posicionadas à meia distância entre o ponto focal do tubo e a câmara de ionização, e realizadas as medições de taxa de kerma no ar. Os dados representam a intensidade da radiação transmitida através dos absorvedores de espessuras variáveis, mas de material conhecido. A seguir, para se determinar a CSR, deve ser construído um gráfico linear ou semi-logarítmico das medições versus a espessura do material absorvedor. A primeira CSR é a espessura na qual a taxa de kerma no ar é reduzida a $50 \%$. A Figura 2.2 mostra o arranjo experimental recomendado pela norma IEC 61267 [36] e um exemplo de gráfico construído para a determinação da CSR.

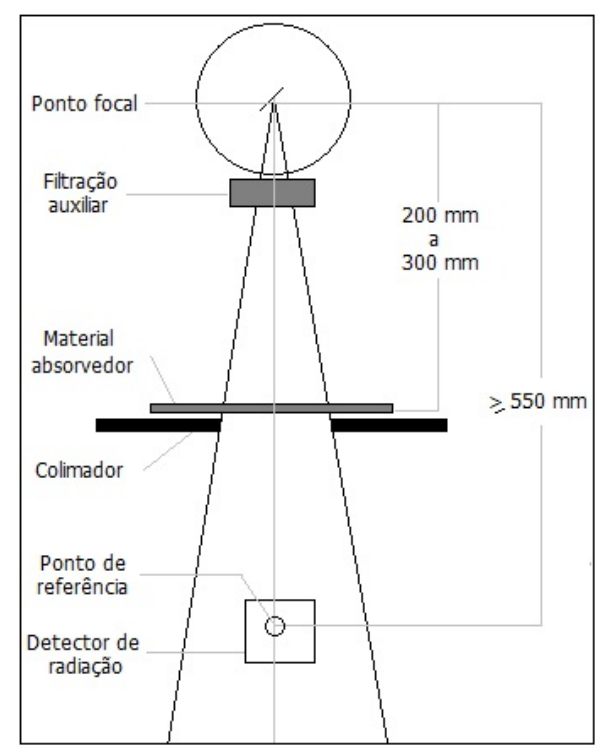

(A) Arranjo experimental.

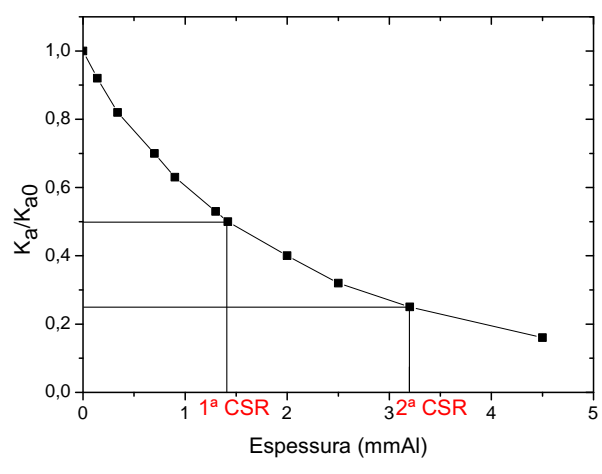

(в) Gráfico para determinação da CSR.

Figura 2.2 - Arranjo experimental e gráfico para determinação da camada semirredutora. 


\subsubsection{Filtração adicional}

O feixe produzido por um equipamento de raios $\mathrm{X}$ apresenta um espectro heterogêneo em energia, sendo que essa energia varia desde zero até a energia cinética dos elétrons do tubo. Com a utilização dos filtros adicionais, os fótons menos energéticos são absorvidos, não contribuindo para a formação do feixe de radiação útil.

O objetivo da utilização de filtros é eliminar os fótons menos energéticos, que normalmente não contribuem para a formação da imagem. Esses fótons de energias mais baixas contribuem para o aumento da dose superficial, pois muitas vezes são totalmente absorvidos nas primeiras camadas de pele.

Desta forma, um feixe de radiação com filtração adicional apresenta, em relação a um feixe sem filtração, uma distribuição energética menor, sendo esta radiação mais penetrante e com um valor de camada semirredutora maior, mas com intensidade menor. Isto significa que com a filtração adicional, o feixe é constituído somente pelos fótons com energia suficiente para atravessar a filtração.

Os filtros adicionais são em geral de alumínio ou de cobre de alta pureza (99,9\%), dependendo da faixa de energia do feixe de radiação 36.

\subsection{Calibração de Instrumentos e Sistemas Padrões}

Os instrumentos de medição, comumente utilizados nos procedimentos da área médica ou industrial, não fornecem os valores reais das grandezas como dose absorvida ou exposição. Para que este tipo de instrumento possa ser devidamente utilizado, é necessário submetê-lo à calibração em um laboratório autorizado ou acreditado por uma autoridade competente.

De acordo com o Vocabulário Internacional de Termos Fundamentais e Gerais de Metrologia do INMETRO (VIM) [37], calibração é um "conjunto de operações que estabelece, sob condições especificadas, a relação entre os valores indicados por um instrumento de medição, ou sistema de medição, ou valores representados por uma 
medida materializada, ou um material de referência, e os valores correspondentes das grandezas estabelecidos por padrões."

O sistema padrão primário é o sistema de referência de mais alta qualidade metrológica [7], pois determina uma grandeza a partir de grandezas físicas básicas. Estes sistemas são mantidos em laboratórios de dosimetria de padronização primária (Primary Standard Dosimetry Laboratory — PSDL) e são utilizados para calibração de instrumentos do tipo padrão secundário, para pesquisas e intercomparações. Cada PSDL é, então, responsável por desenvolver, manter e aperfeiçoar os sistemas padrões primários, além de realizar a calibração de sistemas padrões secundários e promover intercomparações.

O sistema padrão secundário é aquele cuja resposta é comparada diretamente com um sistema padrão primário, determinando-se o coeficiente de calibração [7]. Dessa comparação com um padrão primário origina-se um certificado de calibração para se garantir a rastreabilidade. Um laboratório de dosimetria de padronização secundária (Secondary Standard Dosimetry Laboratory — SSDL) é um laboratório que oferece serviços de calibração de instrumentos. Este tipo de laboratório deve possuir pelo menos um padrão secundário para cada faixa de energia (e tipo de radiação) para a qual o serviço de calibração é oferecido.

O sistema padrão terciário é aquele cujo coeficiente de calibração foi determinado a partir de sua comparação com um padrão secundário. Normalmente estes são os instrumentos utilizados no trabalho de campo, rotineiramente, pois possuem qualidade metrológica menos refinada.

De uma maneira geral, existem dois métodos de calibração: utilização de um instrumento padrão calibrado (método da substituição) e utilização de campos de radiação com propriedades bem conhecidas [7].

Quando o campo de radiação tem propriedades bem conhecidas não é necessário o uso de um instrumento padrão para o serviço rotineiro de calibração de instrumentos. A calibração é feita posicionando-se o instrumento a ser calibrado no campo de radiação e comparando-se o valor medido deste instrumento com o valor conhecido 
previamente da intensidade do feixe de radiação em termos da grandeza em questão (obtido por meio da dosimetria de feixe com um sistema padrão, por exemplo).

No método da substituição, os campos de radiação podem ter propriedades menos bem conhecidas. O sistema padrão e o instrumento a ser calibrado são posicionados sequencialmente no campo de radiação sob as mesmas condições de geometria. O coeficiente de calibração é obtido por comparação entre as medições dos dois instrumentos. Neste método pode-se utilizar ou não câmaras monitoras. O fator de calibração do equipamento será:

$$
N=\frac{M^{*} \cdot k_{T}^{*} \cdot k_{p}^{*} \cdot k_{c}^{*}}{M \cdot k_{T} \cdot k_{p}},
$$

sendo M a média das medições, $k_{T}$ e $k_{p}$ os fatores de correção para temperatura e pressão ambientais de referência, respectivamente, e $k_{c}$ o coeficiente de calibração da câmara padrão. O símbolo $(*)$ refere-se aos termos da câmara padrão secundário.

O instrumento a ser calibrado geralmente é submetido a diversos campos de radiação com diferentes energias, pois o equipamento pode apresentar dependência energética de sua resposta. No caso dos feixes de radiação X, são utilizadas qualidades diferentes de feixes, a pedido do cliente e de acordo com as características das câmaras de ionização. No certificado de calibração não são apresentados todos os coeficientes de calibração obtidos diretamente. Esses coeficientes são normalizados para uma dada qualidade de radiação obtendo-se fatores de correção para as demais qualidades. Essa é uma maneira bastante simples para se visualizar a dependência energética da resposta do instrumento.

\subsubsection{Intercomparação}

Os programas de intercomparação são realizados pelos laboratórios a fim de se comparar o desempenho de seus instrumentos padrões dentro dos sistemas de controle da qualidade. A intercomparação permite assegurar a qualidade das medições de cada laboratório, e pode ser nacional ou internacional. A intercomparação mantém a qualidade metrológica das câmaras de ionização comparadas. 
Estes programas são de grande importância, pois permitem também a troca de experiência entre especialistas de vários laboratórios (às vezes de países diferentes).

\subsubsection{Qualidades metrológicas para radiação $\mathrm{X}$ de energias baixas e médias e radiação gama}

Os laboratórios de dosimetria de padronização primária e secundária devem possuir equipamentos que atendem às qualidades metrológicas exigidas para calibração de instrumentos de medição. Como exemplo, serão relatadas aqui algumas características dos laboratórios do Bureau International des Poids et Mesures (BIPM) (primário) e da IAEA (coordenador da rede internacional de laboratórios secundários).

O Bureau International des Poids et Mesures (BIPM), localizado em Paris, França, é um laboratório de dosimetria de padronização primária. O sistema padrão primário para radiação X de $10 \mathrm{kV}$ a $50 \mathrm{kV}$ é uma câmara de ionização de ar livre de placas paralelas com volume sensível de $1,2004 \mathrm{~cm}^{3}$. Para radiação $\mathrm{X}$ de energias médias, que compreende potenciais de $100 \mathrm{kV}$ a $250 \mathrm{kV}$, o sistema padrão primário deste laboratório também é uma câmara de ionização de ar livre de placas paralelas, mas com volume sensível de 4,6554 $\mathrm{cm}^{3}$. O sistema padrão para medição do kerma no ar em um campo de radiação gama é uma câmara de placas paralelas de grafite com volume sensível de $6,8 \mathrm{~cm}^{3}$ [38.

A IAEA possui um laboratório de dosimetria de padronização secundária, que coordena a rede de laboratórios secundários dos países membros. Neste laboratório são realizados vários tipos de calibrações de instrumentos de medição em diversos níveis de energia [38]. Para isso, este laboratório secundário possui vários equipamentos, tais como: duas câmaras de ionização cilíndricas com volume sensível de $1000 \mathrm{~cm}^{3}$, para radiação X e gama com rastreabilidade ao BIPM e ao laboratório de dosimetria de padronização primária (Physikalisch-Technische Bundesanstalt) (PTB), situado na Alemanha; uma câmara de ionização esférica com volume sensível 
de $1000 \mathrm{~cm}^{3}$ somente para radiação gama com rastreabilidade ao PTB; uma câmara de ionização de $6 \mathrm{~cm}^{3}$ para radiação $\mathrm{X}$ de energias baixas com rastreabilidade ao laboratório de dosimetria de padronização primária National Institute of Standards and Technology (NIST), localizado nos Estados Unidos da América; uma câmara monitora; um irradiador gama de ${ }^{60} \mathrm{Co}$ e ${ }^{137} \mathrm{Cs}$; e uma unidade de radiação X de até $160 \mathrm{kV} 39$.

\subsection{Rastreabilidade}

O termo rastreabilidade, de acordo com o Vocabulário Internacional de Termos Fundamentais e Gerais de Metrologia (VIM) [37, diz respeito à "propriedade do resultado de uma medição ou do valor de um padrão estar relacionado a referências estabelecidas, geralmente a padrões nacionais ou internacionais, através de uma cadeia contínua de comparações, todas tendo incertezas estabelecidas."

Para que essa cadeia contínua tenha validade, é necessário que todos os instrumentos utilizados para calibração de outros detectores de radiação sejam também calibrados com relação a um instrumento de qualidade superior [7], sendo essa calibração rastreável a um laboratório padrão de dosimetria autorizado ou acreditado [40]. Os equipamentos devem ser periodicamente recalibrados, segundo normas nacionais [2] e internacionais [7], para garantir a estabilidade do coeficiente de calibração, assegurando assim a confiabilidade da medição. 


\section{Revisão Bibliográfica}

No relatório da National Council on Radiation Protection and Measurements (NCRP) [41, foi feito um levantamento da exposição da população dos Estados Unidos da América. De acordo com este levantamento, o público em geral nos Estados Unidos foi exposto principalmente à radiação natural (raios cósmicos, radônio, radiação terrestre, entre outros), que correspondia a $82 \%$ da exposição total. Os outros $18 \%$ correspondiam à radiação produzida pelo homem (radiação X e medicina nuclear, entre outros). Dentre esses 18\%, 11\% eram somente devido ao uso de raios X da área médica. Em 2009, a NCRP lançou um novo relatório com dados atualizados de 2006 [42]. Neste novo relatório os números relativos à exposição da população à radiação são mais alarmantes. De acordo com o relatório, a população dos Estados Unidos está exposta a uma quantidade de radiação sete vezes maior do que no começo dos anos 1980. A contribuição para essa exposição também sofreu mudanças, como por exemplo, a radiação natural, que agora contribui com 50\% da radiação total. Mas os números que mais surpreendem são os relacionados às modalidades médicas de imagem, principalmente a tomografia computadorizada e medicina nuclear, com contribuições de $24 \%$ e $12 \%$, respectivamente.

Por esses números e, ainda, considerando o crescente número de equipamentos e procedimentos que utilizam radiação ionizante nos países em desenvolvimento, é possível perceber a importância de se assegurar a precisão da dose administrada ao paciente. Um dos meios de assegurar essa medição é pelo controle de qualidade de todos os equipamentos envolvidos nessa área. O uso de câmaras monitoras nos feixes de radiação X de laboratórios de calibração é um exemplo de controle de 
qualidade, pois assegura maior precisão na calibração de equipamentos que serão utilizados em serviços clínicos e hospitalares.

Shrimpton e Wall [43 avaliaram a resposta do produto exposição-área de uma câmara de transmissão Diamentor-D, Physikalisch-Technische Werkstätten (PTW), Alemanha, em exames de radiodiagnóstico. Eles avaliaram várias câmaras e concluíram que com alguns cuidados e com a utilização de um fator de correção de cada instalação, essas câmaras apresentaram bons resultados com pouca interferência no diagnóstico. Confirmaram ainda, após várias medições, a distribuição não uniforme da intensidade do feixe de raios $\mathrm{X}$ utilizado.

Gfirtner et al.44 testaram uma versão nova da câmara Diamentor, modelo M4KDK, PTW, que apresentou dependência energética e variação da resposta com o tamanho do campo de radiação. Pelo fato desta câmara de ionização determinar o produto do kerma no ar pela área do campo de radiação e apresentar dependência com o tamanho do campo de radiação, ela necessita portanto, de um fator de calibração para cada sistema de radiação.

Utilizando os resultados de uma câmara do tipo DAP (dose area produt), McParland 45] conseguiu obter estimativas da dose de entrada na pele de pacientes. A câmara utilizada é parte integrante de um equipamento médico de radiação X para angiografia.

Utilizando uma tela de radiofrequência, disponível comercialmente como material da parede da câmara, Sankaran [46] construiu uma câmara de placas paralelas para ser utilizada como dosímetro em feixes de radiodiagnóstico, ou seja, para medição e controle da dose absorvida em pacientes. Um eletrômetro é utilizado para a medição da corrente de resposta desta câmara de ionização. Apesar da simplicidade e do baixo custo de sua produção, a câmara demonstrou bons resultados. De acordo com a publicação da AAPM [47], a incerteza total associada à medição da dose em diagnóstico médico não deve ultrapassar 10\%, considerando um intervalo de confiança de $99 \%$. A câmara proposta apresentou uma incerteza total de $11 \%$ na medição da dose incidente no paciente. 
As câmaras de transmissão podem ser construídas também para monitoramento em tratamentos de radioterapia. Pallwal et al. [48] utilizaram uma câmara, do mesmo tipo utilizado em radiodiagnóstico (para medição do produto exposiçãoárea), à meia distância entre o isocentro de um acelerador linear e o alvo. Verificaram uma grande sensibilidade da resposta da câmara de ionização a pequenas variações tanto da área do campo de radiação como dos parâmetros de ajuste do feixe de radiação e também no uso de acessórios como compensadores e blocos. Além disso, Poppe et al. 49] projetaram e implementaram o sistema DAVID que consiste de uma câmara de transmissão com múltiplos eletrodos coletores. Essa multiplicidade propicia a verificação in vivo do perfil do campo de tratamento radioterápico, devido a sua resolução espacial alcançada pelo posicionamento dos eletrodos coletores exatamente na linha de projeção de um par de lâminas do colimador de múltiplas lâminas (multileaf collimator).

No Instituto de Radioproteção e Dosimetria da Comissão Nacional de Energia Nuclear (CNEN), Rio de Janeiro, foi construída uma câmara de transmissão de grafite altamente puro. Austerlitz et al. 23] verificaram em 1987 uma resposta melhor da câmara de transmissão de grafite em comparação com a resposta de uma câmara de ionização dedal do tipo Baldwin-Farmer, utilizada no local como câmara monitora. Sua dependência energética baixa, pouca corrente de fuga e muito boa estabilidade em curto prazo tornaram o seu desempenho comparável àquele esperado de uma câmara de ionização padrão secundária.

No Instituto de Pesquisas Energéticas e Nucleares foram testadas duas câmaras de ionização planas, PTW, para utilização como câmaras monitoras no sistema de radiação X, por Miranda e Potiens [50|. Foram realizados os testes de estabilidade a curto e longo prazo, e fuga de corrente. Os resultados obtidos para todos os testes se mantiveram de acordo com a recomendação da norma IEC 61674 [51. 


\section{Materiais e Métodos}

Neste trabalho foram utilizados um equipamento de radiação X, um irradiador gama, um sistema padrão secundário de radiação beta, câmaras de ionização comerciais e eletrômetros. Toda a infraestrutura necessária encontra-se disponível no Laboratório de Calibração de Instrumentos do IPEN (LCI):

- Sistemas de radiação

- Equipamento de radiação X industrial, marca Pantak/Seifert, modelo ISOVOLT 160HS, que opera até $160 \mathrm{kV}$;

- Irradiador gama Steuerungstechnik Strahlenschutz GmbH, modelo 0B85, Alemanha, com fontes de radiação de ${ }^{137} \mathrm{Cs} \mathrm{e}{ }^{60} \mathrm{Co}$;

- Sistema de radiação beta padrão secundário Beta Sekundär Standard BSS2, AEA Technology QSA, Alemanha, com três fontes de radiação $\left({ }^{90} \mathrm{Sr}+{ }^{90} \mathrm{Y},{ }^{85} \mathrm{Kr}\right.$ e $\left.{ }^{147} \mathrm{Pm}\right)$;

- Fontes de controle de ${ }^{90} \mathrm{Sr}+{ }^{90} \mathrm{Y}$, PTW, modelos 8921, S1253 e 48002, com atividades de $33 \mathrm{MBq}$ (1994), 0,3 mCi (1976) e 33,3 MBq (1996), respectivamente;

- Sistemas de medida e acessórios

- Câmara de ionização padrão secundário, PTW, modelo 77334, com certificado de calibração do PTB;

- Câmara de ionização padrão secundário, Radcal, modelo RC6, com certificado de calibração do PTB; 
- Câmara de ionização padrão secundário, Radcal, modelo RC6M, com certificado de calibração do PTB;

- Câmara de ionização de transmissão, PTW, modelo 34014-0031;

- Câmara de ionização cilíndrica do tipo Baldwin-Farmer, Nuclear Enterprises (NE), modelo 1229;

- Eletrômetros PTW, modelos UNIDOS e UNIDOS E e Keithley, modelo $6517 \mathrm{~A}$;

- Suportes de acrílico para fonte de controle, fabricados na Oficina Mecânica do IPEN, sendo que, para as câmaras de ionização desenvolvidas, o suporte possui 5 posições diferentes para a fonte;

- Barômetros, termômetros, higrômetros, desumidificadores e climatizadores de ambiente, etc.

Todos os resultados de corrente de ionização foram corrigidos para as condições normais de temperatura e pressão e as incertezas foram estimadas de acordo com a norma ISO [52, 53], que define as incertezas em Tipo A e Tipo B.

As incertezas do Tipo A são aquelas associadas à análise estatística de uma série de observações [52]. Neste trabalho foram utilizadas médias aritméticas de séries de medições em mesmas condições e desvios padrões experimentais da média, ou seja,

$$
\bar{x} \pm \delta_{\bar{x}}
$$

sendo

$$
\bar{x}=\frac{1}{N} \sum_{i=1}^{N} x_{i}
$$

e

$$
\delta_{\bar{x}}=\sqrt{\frac{1}{N(N-1)} \sum_{i=1}^{N}\left(x_{i}-\bar{x}\right)^{2}}
$$


As incertezas do Tipo B são aquelas não associadas à análise estatística [52]. Dentre as incertezas do Tipo B estão as incertezas atribuídas a equipamentos de medidas, dados fornecidos em certificados de calibração, especificações dos fabricantes, entre outros.

Neste trabalho foi utilizada a incerteza combinada expandida, considerando as incertezas do Tipo A e B e um fator de abrangência $k$ igual a 2. Em alguns casos, a incerteza estimada foi tão pequena que a barra de incerteza não é visualizada nas Figuras.

\subsection{Características dos Equipamentos de Radiação}

\subsubsection{Equipamento de radiação $\mathrm{X}$}

No equipamento de radiação X, Pantak/Seifert (Figura 4.1), estão implantadas as qualidades de feixes de radiação específicas de radioterapia, radiodiagnóstico convencional, mamografia e radioproteção, de acordo com as recomendações internacionais. Neste trabalho, foram utilizadas as qualidades de radiodiagnóstico convencional recomendadas pela norma IEC 1267 [35] e que estão descritas na Tabela 4.1. Estas qualidades foram implantadas no equipamento de radiação X Pantak/Seifert utilizando a câmara de ionização padrão secundário, PTW, modelo 77334, calibrada no PTB. A Tabela 4.2 mostra as qualidades de radiodiagnóstico implantadas no equipamento de radiação X do LCI.

Para a implantação dos feixes padronizados, foram utilizadas as tensões e filtrações auxiliares e adicionais recomendadas pela publicação IEC 1267 [35] e assim obtidas as camadas semirredutoras. As filtrações auxiliares e adicionais foram posicionadas na saída do tubo de radiação X (em contato com a blindagem do tubo), portanto antes da câmara de transmissão.

Recentemente foram implantadas as novas qualidades de diagnóstico convencional recomendadas pela publicação IEC 61267 de 2005 [36 neste mesmo equipa- 


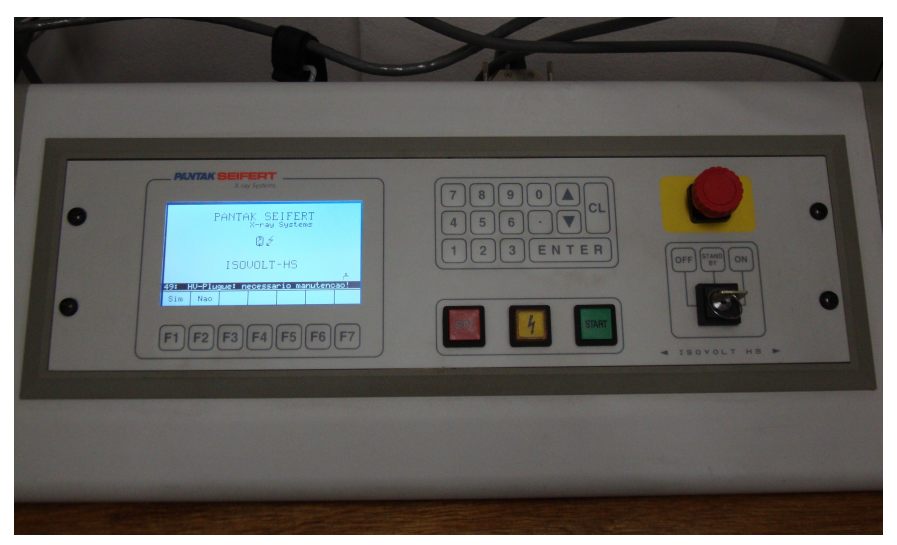

(A) Painel de controle.

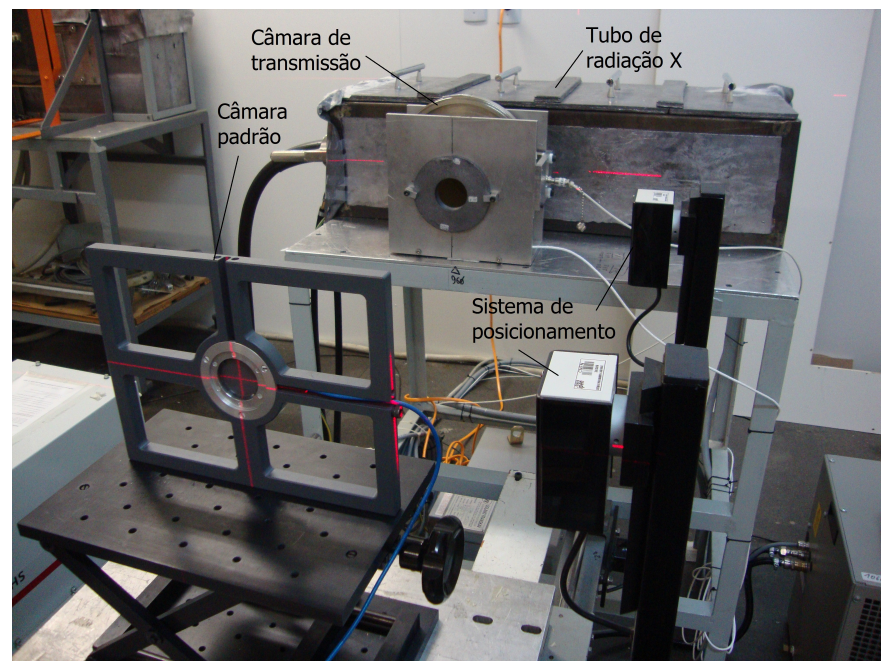

(B) Conjunto de tubo de radiação X, câmara monitora e colimadores; câmara de ionização padrão secundário PTW modelo 77334 posicionada a $100 \mathrm{~cm}$.

Figura 4.1 - Equipamento de radiação X Pantak/Seifert.

mento de raios X. Estas novas qualidades podem ser vistas na Tabela 4.3. As diferenças principais entre as publicações de 1994 e a de 2005 serão descritas mais adiante. A câmara de ionização modelo RC6 foi calibrada no laboratório padrão primário PTB, Alemanha, em algumas qualidades de radiodiagnóstico da nova publicação da IEC 61267 [36]. A partir da calibração dessa câmara de ionização foram 
TABela 4.1 - Qualidades de radiodiagnóstico convencional de acordo com a publicação IEC 1267 de 1994 [35].

\begin{tabular}{|c|c|c|c|c|}
\hline \multicolumn{2}{|c|}{$\begin{array}{l}\text { Qualidade } \\
\text { da } \\
\text { Radiação }\end{array}$} & $\begin{array}{c}\text { Tensão } \\
\text { do Tubo } \\
(\mathrm{kV})\end{array}$ & $\begin{array}{c}\text { Filtração Auxiliar } \\
+ \text { Adicional } \\
(\mathrm{mmAl})\end{array}$ & $\begin{array}{c}\text { Camada } \\
\text { Semirredutora } \\
(\mathrm{mmAl})\end{array}$ \\
\hline \multirow{9}{*}{ 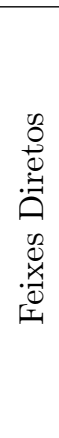 } & RQR2 & 40 & 2,5 & 1,0 \\
\hline & RQR3 & 50 & 2,5 & 1,5 \\
\hline & RQR4 & 60 & 2,5 & 2,0 \\
\hline & RQR5 & 70 & 2,5 & 2,5 \\
\hline & RQR6 & 80 & 2,5 & 2,9 \\
\hline & RQR7 & 90 & 2,5 & 3,3 \\
\hline & RQR8 & 100 & 2,5 & 3,7 \\
\hline & RQR9 & 120 & 2,5 & 4,5 \\
\hline & RQR10 & 150 & 2,5 & 5,7 \\
\hline \multirow{9}{*}{ 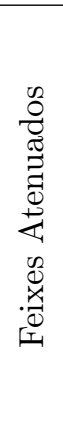 } & RQA2 & 40 & 6,5 & 2,4 \\
\hline & RQA3 & 50 & 12,5 & 4,0 \\
\hline & RQA4 & 60 & 18,5 & 5,7 \\
\hline & RQA5 & 70 & 23,5 & 7,1 \\
\hline & RQA6 & 80 & 28,5 & 8,4 \\
\hline & RQA7 & 90 & 32,5 & 9,1 \\
\hline & RQA8 & 100 & 36,5 & 9,9 \\
\hline & RQA9 & 120 & 42,5 & 11,5 \\
\hline & RQA10 & 150 & 47,5 & 12,8 \\
\hline
\end{tabular}

implantadas essas mesmas qualidades no equipamento de radiação X Pantak/Seifert. Essas qualidades estão descritas na Tabela 4.4 .

Pelas Tabelas 4.4 e 4.3 pode-se notar que não foram implantadas todas as qualidades apresentadas na publicação IEC 61267 [36]. Isso ocorreu porque a câmara de ionização padrão secundário RC6 foi calibrada somente para as qualidades mais utilizadas no LCI.

Ocorreram algumas mudanças na implantação dessas novas qualidades em relação às antigas. A primeira mudança foi com relação às filtrações utilizadas. Pela Tabela 4.3 pode-se notar que para as qualidades RQR os valores das filtrações auxiliar e adicional não são fornecidos. Isso ocorreu porque eles foram determinados experimentalmente para se obter os valores de camadas semirredutoras recomenda- 
TABela 4.2 - Características dos feixes padronizados de radiação X para radiodiagnóstico convencional implantadas no equipamento Pantak/Seifert, de acordo com a publicação IEC 1267 [35].

\begin{tabular}{|c|c|c|c|c|c|c|}
\hline \multicolumn{2}{|c|}{$\begin{array}{l}\text { Qualidade } \\
\text { da } \\
\text { Radiação }\end{array}$} & $\begin{array}{c}\text { Tensão } \\
\text { do Tubo } \\
(\mathrm{kV})\end{array}$ & $\begin{array}{c}\text { Filtração Auxiliar } \\
+ \text { Adicional } \\
(\mathrm{mmAl})\end{array}$ & $\begin{array}{c}\text { Camada } \\
\text { Semirredutora } \\
(\mathrm{mmAl})\end{array}$ & $\begin{array}{c}\text { Energia } \\
\text { Efetiva } \\
(\mathrm{keV})\end{array}$ & $\begin{array}{c}\text { Taxa de Kerma } \\
\text { no Ar } \\
(\mathrm{mGy} / \mathrm{min})\end{array}$ \\
\hline \multirow{8}{*}{ 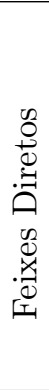 } & RQR3 & 50 & 2,5 & 1,79 & 27,15 & $23,37 \pm 0,04$ \\
\hline & RQR4 & 60 & 2,5 & 2,09 & 28,80 & $34,50 \pm 0,07$ \\
\hline & RQR5 & 70 & 2,5 & 2,35 & 30,15 & $46,39 \pm 0,09$ \\
\hline & RQR6 & 80 & 2,5 & 2,65 & 31,65 & $59,62 \pm 0,12$ \\
\hline & RQR7 & 90 & 2,5 & 2,95 & 33,05 & $74,16 \pm 0,14$ \\
\hline & RQR8 & 100 & 2,5 & 3,24 & 34,40 & $89,14 \pm 0,17$ \\
\hline & RQR9 & 120 & 2,5 & 3,84 & 37,05 & $121,66 \pm 0,23$ \\
\hline & RQR10 & 150 & 2,5 & 4,73 & 40,75 & $175,06 \pm 0,34$ \\
\hline \multirow{8}{*}{ 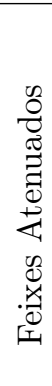 } & RQA3 & 50 & 12,5 & 3,91 & 37,30 & $3,46 \pm 0,01$ \\
\hline & RQA4 & 60 & 18,5 & 5,34 & 43,25 & $3,11 \pm 0,01$ \\
\hline & RQA5 & 70 & 23,5 & 6,86 & 49,40 & $3,45 \pm 0,01$ \\
\hline & RQA6 & 80 & 28,5 & 8,13 & 54,75 & $4,04 \pm 0,01$ \\
\hline & RQA7 & 90 & 32,5 & 9,22 & 59,70 & $4,99 \pm 0,01$ \\
\hline & RQA8 & 100 & 36,5 & 10,09 & 63,95 & $5,93 \pm 0,02$ \\
\hline & RQA9 & 120 & 42,5 & 11,39 & 71,15 & $8,06 \pm 0,02$ \\
\hline & RQA10 & 150 & 47,5 & 13,02 & 82,10 & $13,48 \pm 0,03$ \\
\hline
\end{tabular}

dos [36]. Para cada qualidade RQA, de acordo com a recomendação IEC 61267 [36], deve ser utilizada a mesma filtração auxiliar obtida para sua qualidade correspondente em RQR além de uma filtração adicional que funciona como objeto simulador, cujo valor pode ser visto na Tabela 4.3. Dessa forma, as camadas semirredutoras seriam as mesmas fornecidas pela norma IEC 61267 [36 como de fato ocorreu. Outra mudança foi com relação ao posicionamento da filtração adicional. Para as qualidades RQR a filtração adicional foi posicionada logo na saída do tubo de raios X. Para as qualidades RQA, a filtração adicional que funciona como objeto simulador foi posicionada após a câmara de transmissão e o colimador do campo. Essa diferença no posicionamento das filtrações adicionais entre uma norma e outra pode ser vista na Figura 4.2 . 
TABELA 4.3 - Qualidades de radiodiagnóstico convencional recomendadas pela nova publicação IEC 61267 de 2005 [36].

\begin{tabular}{|c|c|c|c|c|}
\hline \multicolumn{2}{|c|}{$\begin{array}{l}\text { Qualidade } \\
\text { da } \\
\text { Radiação }\end{array}$} & $\begin{array}{c}\text { Tensão } \\
\text { do Tubo } \\
(\mathrm{kV})\end{array}$ & $\begin{array}{c}\text { Filtração } \\
\text { Adicional } \\
(\mathrm{mmAl})\end{array}$ & $\begin{array}{c}\text { Camada } \\
\text { Semirredutora } \\
(\mathrm{mmAl})\end{array}$ \\
\hline \multirow{9}{*}{ 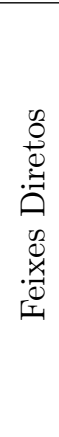 } & RQR2 & 40 & - & 1,42 \\
\hline & RQR3 & 50 & - & 1,78 \\
\hline & RQR4 & 60 & - & 2,19 \\
\hline & RQR5 & 70 & - & 2,58 \\
\hline & RQR6 & 80 & - & 3,01 \\
\hline & RQR7 & 90 & - & 3,48 \\
\hline & RQR8 & 100 & - & 3,97 \\
\hline & RQR9 & 120 & - & 5,00 \\
\hline & RQR10 & 150 & - & 6,57 \\
\hline \multirow{9}{*}{ 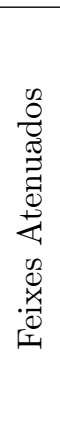 } & RQA2 & 40 & 4 & 2,2 \\
\hline & RQA3 & 50 & 10 & 3,8 \\
\hline & RQA4 & 60 & 16 & 5,4 \\
\hline & RQA5 & 70 & 21 & 6,8 \\
\hline & RQA6 & 80 & 26 & 8,2 \\
\hline & RQA7 & 90 & 30 & 9,2 \\
\hline & RQA8 & 100 & 34 & 10,1 \\
\hline & RQA9 & 120 & 40 & 11,6 \\
\hline & RQA10 & 150 & 45 & 13,3 \\
\hline
\end{tabular}

Ainda neste equipamento foram implantadas algumas qualidades de mamografia. Essas qualidades não são as recomendadas pela norma IEC 61267 [36], pois o alvo do tubo de raios $\mathrm{X}$ deste equipamento é de tungstênio $(\mathrm{W})$ e as qualidades da norma são baseadas em um equipamento com alvo de molibdênio (Mo). Esse problema foi solucionado utilizando as qualidades estabelecidas pelo próprio Laboratório Padrão Primário PTB no qual a câmara padrão secundário foi calibrada. As qualidades implantadas no equipamento de raios X do LCI estão descritas na Tabela 4.5. 
TABela 4.4 - Características dos feixes padronizados de radiação X para radiodiagnóstico convencional implantadas no equipamento Pantak/Seifert, de acordo com a nova publicação IEC 61267 de 2005 [36].

\begin{tabular}{|c|c|c|c|c|c|c|}
\hline \multicolumn{2}{|c|}{$\begin{array}{l}\text { Qualidade } \\
\text { da } \\
\text { Radiação }\end{array}$} & $\begin{array}{c}\text { Tensão } \\
\text { do Tubo } \\
(\mathrm{kV})\end{array}$ & $\begin{array}{c}\text { Camada } \\
\text { Semirredutora } \\
(\mathrm{mmAl})\end{array}$ & $\begin{array}{c}\text { Filtração Auxiliar } \\
+ \text { Adicional } \\
(\mathrm{mmAl})\end{array}$ & $\begin{array}{c}\text { Energia } \\
\text { Efetiva } \\
(\mathrm{keV})\end{array}$ & $\begin{array}{c}\text { Taxa de Kerma } \\
\text { no Ar } \\
(\mathrm{mGy} / \mathrm{min})\end{array}$ \\
\hline \multirow{4}{*}{ 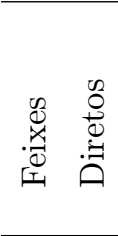 } & RQR3 & 50 & 1,78 & 2,4 & 31,04 & $22,40 \pm 0,18$ \\
\hline & RQR5 & 70 & 2,58 & 2,8 & 33,77 & $38,57 \pm 0,32$ \\
\hline & RQR8 & 100 & 3,97 & 3,2 & 35,82 & $69,28 \pm 0,54$ \\
\hline & RQR10 & 150 & 6,57 & 4,2 & 39,24 & $120,01 \pm 1,02$ \\
\hline \multirow{4}{*}{ 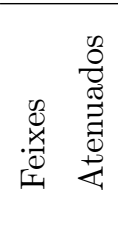 } & RQA3 & 50 & 3,8 & $2,4+10$ & 38,09 & $3,27 \pm 0,03$ \\
\hline & RQA5 & 70 & 6,8 & $2,8+21$ & 49,53 & $3,13 \pm 0,03$ \\
\hline & RQA8 & 100 & 10,1 & $3,2+34$ & 66,21 & $5,11 \pm 0,04$ \\
\hline & RQA10 & 150 & 13,3 & $4,2+45$ & 87,41 & $11,28 \pm 0,09$ \\
\hline
\end{tabular}

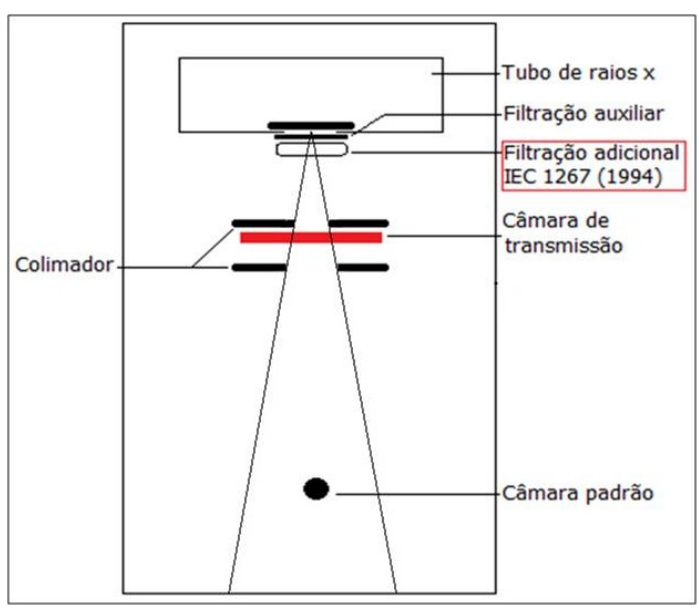

(A) IEC 1267

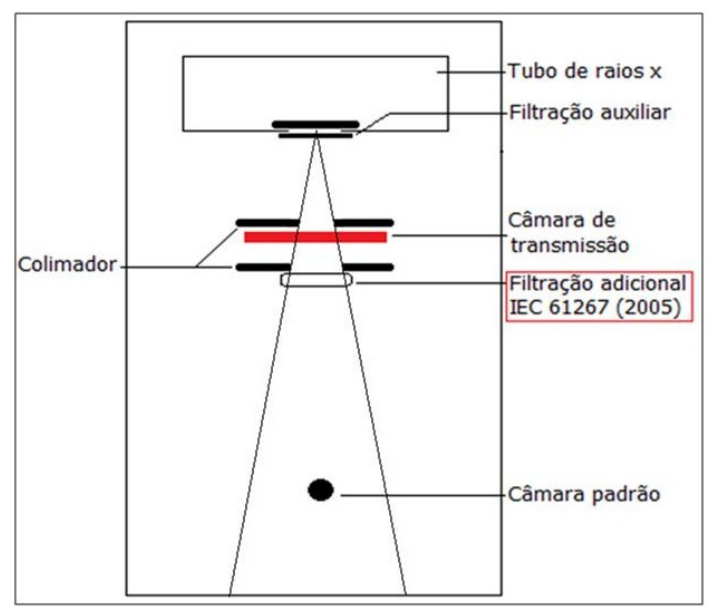

(B) IEC 61267

Figura 4.2 - Esquema do aparato experimental utilizado, para as normas IEC 1267 e IEC 61267. 
TABela 4.5 - Características dos feixes padronizados de radiação X para mamografia implantadas no equipamento de radiação $X$ do LCI, de acordo com certificado emitido pelo PTB [54].

\begin{tabular}{c|c|c|c|c|c}
\hline $\begin{array}{c}\text { Qualidade } \\
\text { da } \\
\text { Radiação }\end{array}$ & $\begin{array}{c}\text { Tensão } \\
\text { do Tubo } \\
(\mathrm{kV})\end{array}$ & $\begin{array}{c}\text { Camada } \\
\text { Semirredutora } \\
(\mathrm{mmAl})\end{array}$ & $\begin{array}{c}\text { Filtração } \\
\text { Adicional } \\
(\mathrm{mmMo})\end{array}$ & $\begin{array}{c}\text { Energia } \\
\text { Efetiva } \\
(\mathrm{keV})\end{array}$ & $\begin{array}{c}\text { Taxa de Kerma } \\
\text { no Ar } \\
(\mathrm{mGy} / \mathrm{min})\end{array}$ \\
\hline WMV 25 & 25 & 0,36 & 0,07 & 15,91 & $9,76 \pm 0,08$ \\
WMV 28 & 28 & 0,37 & 0,07 & 16,13 & $12,19 \pm 0,09$ \\
WMV 30 & 30 & 0,38 & 0,07 & 16,33 & $13,81 \pm 0,11$ \\
WMV 35 & 35 & 0,41 & 0,07 & 16,88 & $17,96 \pm 0,14$ \\
\hline
\end{tabular}

\subsubsection{Irradiador gama}

O irradiador gama do LCI possui quatro fontes de radiação, mas somente duas foram utilizadas neste trabalho. As características das fontes estão descritas na Tabela 4.6 e o irradiador pode ser visto na Figura 4.3. Os valores das taxas de kerma no ar foram obtidos durante a dosimetria do feixe de radiação realizada em 20 de outubro de 2009, utilizando uma câmara de ionização esférica de 1 litro PTW, modelo 32002-035, pelos técnicos do LCI.

TABELA 4.6 - Características das fontes de radiação gama.

\begin{tabular}{c|c|c}
\hline Fonte & $\begin{array}{c}\text { Energia Média } \\
(\mathrm{keV})\end{array}$ & $\begin{array}{c}\text { Taxa de Kerma no Ar a } 100 \mathrm{~cm}^{*} \\
\left(\mathrm{mGy} \cdot \mathrm{h}^{-} 1\right)\end{array}$ \\
\hline${ }^{60} \mathrm{Co}$ & 1.250 & $39,10 \pm 0,56$ \\
${ }^{137} \mathrm{Cs}$ & 662 & $1,62 \pm 0,02$ \\
\hline${ }^{*} \mathrm{Os}$ valo
\end{tabular}

*Os valores da taxa de kerma no ar são referentes à data de 20/10/2009. 


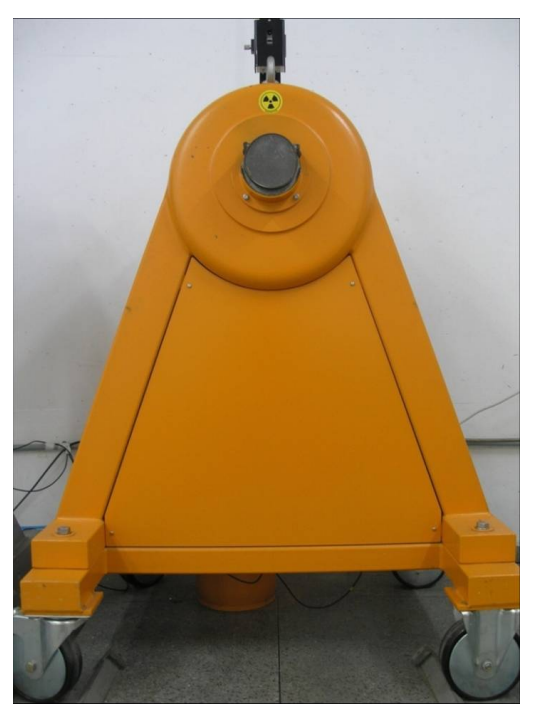

FigurA 4.3 - Irradiador gama Steuerungstechnik Strahlenschutz GmbH, modelo 0B85, Alemanha.

\subsubsection{Sistema padrão secundário de radiação beta}

O sistema de radiação beta (Figura 4.4) possui três fontes cujas características estão descritas na Tabela 4.7. Estas fontes possuem certificados de calibração do laboratório padrão primário Physikalisch-Technische Bundesanstalt (PTB) [55].

TABEla 4.7 - Características das fontes de radiação beta.

\begin{tabular}{c|c|c|c|c}
\hline \multirow{2}{*}{ Fonte } & $\begin{array}{c}\text { Energia } \\
\text { Média } \\
(\mathrm{keV})\end{array}$ & $\begin{array}{c}\text { Distância de } \\
\text { Calibração } \\
(\mathrm{cm})\end{array}$ & $\begin{array}{c}\text { Filtro } \\
\text { Homogeneizador } \\
\text { de Campo }\end{array}$ & $\begin{array}{c}\text { Taxa de Dose } \\
\text { Absorvida no Ar* } \\
\left(\mathrm{mGy.s} \mathrm{s}^{-1}\right)\end{array}$ \\
\hline & & 11,0 & Não & $111,13 \pm 1,84$ \\
& & 20,0 & Não & $34,87 \pm 0,60$ \\
${ }^{90} \mathrm{Sr}+{ }^{90} \mathrm{Y}$ & \multirow{2}{*}{800} & 30,0 & Não & $15,47 \pm 0,26$ \\
& & 30,0 & Sim & $10,14 \pm 0,17$ \\
& & 50,0 & Não & $5,53 \pm 0,10$ \\
\hline${ }^{85} \mathrm{Kr}$ & 251 & 30,0 & Sim & $41,68 \pm 0,66$ \\
\hline${ }^{147} \mathrm{Pm}$ & 60 & 20,0 & Sim & $11,37 \pm 0,27$ \\
\hline
\end{tabular}

*Os valores da taxa de dose absorvida no ar são relativos à data de calibração das fontes em 11/2004, do Certificado de Calibração emitido pelo laboratório padrão primário Physikalisch-Technische Bundesanstalt (PTB) [55]. 


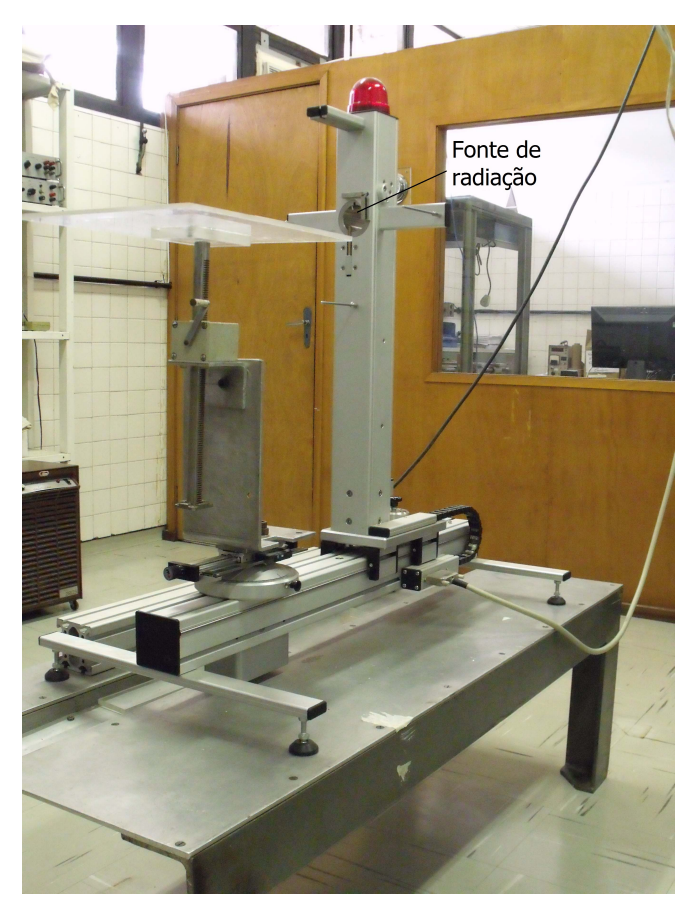

Figura 4.4 - Sistema de radiação beta padrão secundário Beta Sekundär Standard BSS2, AEA Technology QSA, Alemanha.

\subsection{Testes de Caracterização e de Controle de Qua- lidade}

Os testes de caracterização e de controle de qualidade das câmaras de ionização consistem em: curva de saturação, eficiência de coleção de íons, efeito de polaridade, linearidade da resposta, dependência energética e testes de estabilidade (tempo de estabilização, corrente de fuga, repetitividade e reprodutibilidade). Estes testes são determinantes para aceitação ou não da câmara de ionização. Além disso, as câmaras de ionização foram testadas também em feixes de radiação beta e gama. 


\subsubsection{Curva de saturação}

Neste teste, a curva de saturação da resposta da câmara de ionização é determinada. Para tanto, a resposta é medida para diferentes tensões do campo elétrico em passos de $\pm 50 \mathrm{~V}$. A câmara de ionização deve apresentar uma saturação da resposta e a tensão de operação deve estar dentro do patamar da curva, o que garante a coleção de todos os íons produzidos dentro do volume sensível da câmara de ionização [32.

\subsubsection{Efeito de polaridade}

Neste teste, são comparadas as respostas da câmara de ionização obtidas com tensões de mesmo valor, mas de sinais opostos. De acordo com as recomendações internacionais [51], a diferença entre essas respostas não deve ser maior que 1\%. Para este teste são utilizados os resultados obtidos na determinação da curva de saturação.

\subsubsection{Eficiência de coleção de íons}

Este teste tem o objetivo de verificar se está ocorrendo recombinação de pares de íons dentro do volume sensível da câmara ou se todos os íons estão sendo coletados. Para a realização deste teste, foi utilizado o método das duas tensões [7], dado por:

$$
k_{S}=\frac{\left(V_{1} / V_{2}\right)^{2}-1}{\left(V_{1} / V_{2}\right)^{2}-\left(M_{1} / M_{2}\right)}
$$

sendo $M_{i}$ a carga coletada à tensão $V_{i}$, e $V_{1} / V_{2}=2$.

\subsubsection{Linearidade de resposta}

O teste de linearidade mostra se a resposta da câmara de ionização é linear em função da taxa de kerma no ar. Para realizar este teste, a corrente do tubo de raios $\mathrm{X}$ é variada para uma determinada tensão. Neste trabalho a corrente foi variada de 0,5 mA a 45,0 mA, para uma qualidade de radiação, no caso RQR5. O intervalo da 
taxa de kerma no ar varia dependendo da distância entre a câmara de ionização e o ponto focal do tubo de raios $\mathrm{X}$.

\subsubsection{Calibração}

As câmaras de ionização precisam ser calibradas utilizando sistemas padrões para se determinar os coeficientes de calibração para os diferentes intervalos e tipos de radiação para os quais elas serão utilizadas. A partir dos coeficientes de calibração de uma câmara de ionização é possível determinar a taxa de dose absorvida ou taxa de kerma no ar, dependendo da grandeza para a qual a câmara de ionização foi calibrada. Para sistemas padrões é interessante que os coeficientes de calibração não apresentem valores muito distintos uns dos outros, i.e., que a câmara não apresente uma dependência energética alta. Para câmaras de ionização de uso rotineiro esta não é uma exigência, pois este equipamento será periodicamente calibrado contra um sistema padrão. As câmaras monitoras não são utilizadas para medições de taxa de dose absorvida ou de taxa de kerma no ar e, sim, para verificação da constância da intensidade do feixe de radiação. Por este motivo, a dependência energética deste tipo de câmara de ionização não tem a mesma importância que para as câmaras de ionização citadas.

\subsubsection{Testes de estabilidade}

São quatro os testes relacionados com a estabilidade de resposta das câmaras de ionização: tempo de estabilização, teste de corrente de fuga, repetitividade e reprodutibilidade.

O tempo de estabilização de uma câmara de ionização verifica o tempo necessário para que a resposta da câmara se torne eletricamente estável a partir do momento da aplicação da alta tensão. Quando a câmara de ionização é conectada ao cabo e a alta tensão é aplicada, as cargas elétricas são criadas gerando uma corrente de resposta que não se deve a nenhuma fonte de radiação. Para a realização 
deste teste a câmara de ionização é conectada ao eletrômetro sem aplicação da alta tensão. Uma fonte de radiação conhecida é posicionada e então a câmara é polarizada. A resposta da câmara é verificada transcorridos 15, 30, 45 e 60 minutos da aplicação da alta tensão.

O teste de corrente de fuga consiste em se avaliar a resposta da câmara de ionização quando não está submetida a uma fonte de radiação. Este teste é realizado de duas maneiras: antes de qualquer irradiação e sem a presença de nenhuma fonte de radiação, a carga é coletada durante 20 minutos; e após uma irradiação prévia, com uma certa quantidade de carga coletada, p. ex., durante 1 minuto, a fonte de radiação é retirada e a carga é coletada durante 20 minutos.

No teste de repetitividade (ou estabilidade a curto prazo) da resposta da câmara de ionização mede-se o "grau de concordância entre os resultados de medições sucessivas de um mesmo mensurando efetuadas sob as mesmas condições de medição" [56]. Para a realização deste teste foram efetuadas 10 medições consecutivas da carga coletada sob as mesmas condições experimentais.

O teste de reprodutibilidade (ou estabilidade a longo prazo) da resposta da câmara de ionização foi realizado a partir dos dados obtidos nos testes de repetitividade. A reprodutibilidade da resposta de uma câmara de ionização mostra o "grau de concordância entre os resultados das medições de um mesmo mensurando efetuadas sob condições variadas de medição" [56. Para cada série de medições realizadas no teste de repetitividade, foi calculado um valor médio. A variação destes valores médios e de seus desvios padrões da média ao longo do tempo fornece a reprodutibilidade da resposta do equipamento. 


\section{Desenvolvimento de Câmaras de Ionização Monitoras}

O principal objetivo deste trabalho é o desenvolvimento de uma câmara monitora em formato anelar, mas ao final do processo foi desenvolvida também uma câmara monitora de formato convencional. O processo de desenvolvimento da câmara de ionização monitora anelar foi realizado de acordo com as seguintes etapas:

- Determinação do diâmetro de abertura do furo central da câmara. Para isso foi necessário determinar o tamanho do campo de radiação na posição da câmara;

- Determinação do volume sensível da câmara. Este volume deve ser grande para que a resposta da câmara de ionização seja sensível, i.e., apresente valores apropriados, levando em consideração certos limites físicos e experiências do grupo;

- Desenho e confecção das peças; e

- Montagem da câmara de ionização.

Juntamente com a câmara monitora anelar foi construído um sistema de colimação de feixe semelhante ao já utilizado no LCI (Figura 5.1). Assim, a câmara anelar e o sistema de colimação formaram um conjunto, podendo facilmente ser posicionado à frente do tubo de raios X. A câmara anelar sempre foi posicionada neste trabalho a uma distância de $30 \mathrm{~cm}$ do ponto focal do tubo de raios $\mathrm{X}$. 


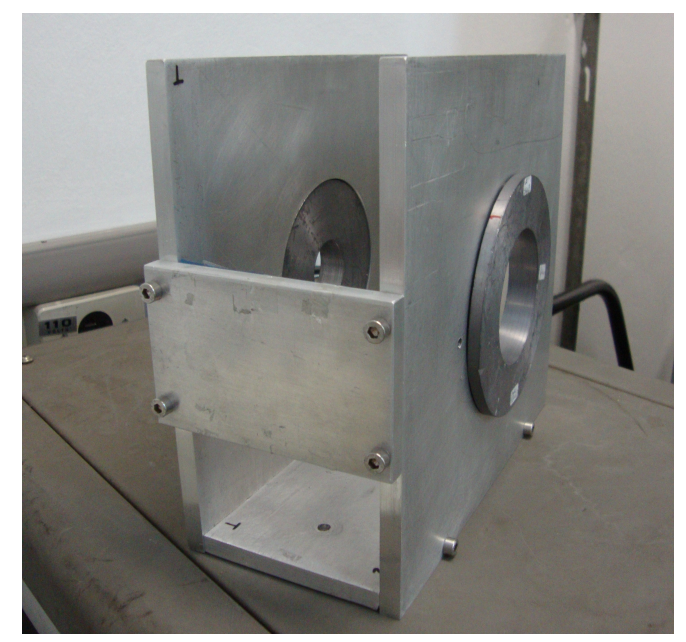

Figura 5.1 - Sistema de colimação de feixes de raios $X$ utilizado no sistema Pantak/Seifert do LCI.

O processo de desenvolvimento da câmara monitora do tipo convencional foi mais simples, pois esta câmara de ionização foi baseada na câmara de transmissão comercial PTW e por não possuir um furo central. Outra diferença com relação às câmaras de ionização anelares desenvolvidas é seu volume sensível duplo que é sua maior semelhança com relação à câmara de transmissão comercial.

\subsection{Câmara Monitora Anelar com Eletrodo Cole- tor de Alumínio (Primeiro Protótipo)}

O primeiro protótipo de uma câmara de ionização anelar foi construído utilizando placas de PMMA de espessuras diferentes para a confecção do corpo da câmara, placas de alumínio para confecção do eletrodo coletor e do anel de guarda, uma folha fina de poliéster aluminizado com densidade superficial igual a 1,87 mg.cm ${ }^{-2}$ para a confecção da janela de entrada e cabos para conexão da câmara de ionização. O volume sensível da câmara de ionização é de aproximadamente $105 \mathrm{~cm}^{3}$. Esta câmara de ionização pode ser vista na Figura 5.2 


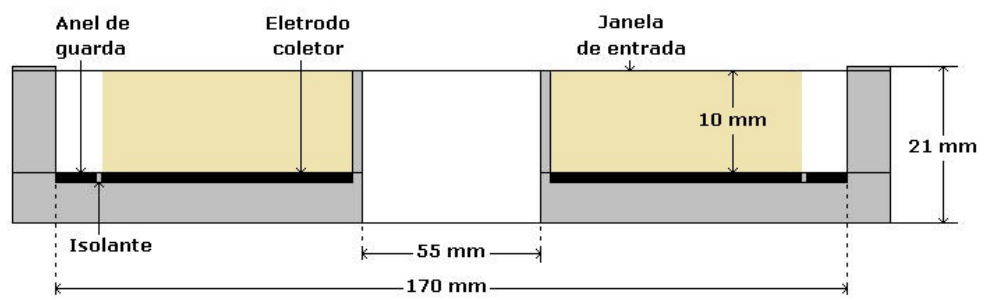

(A)

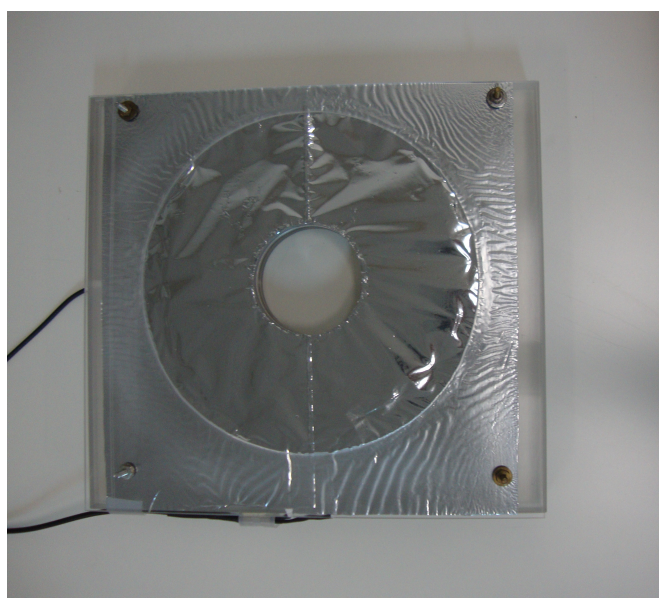

(в)

FIgURA 5.2 - Diagrama e fotografia do primeiro protótipo de câmara de ionização anelar.

O projeto desta câmara falhou no primeiro teste de caracterização: teste de saturação. Utilizando o equipamento de radiação X, foi constatado que a resposta da câmara anelar sempre aumentava com o crescimento da tensão aplicada ao seu volume sensível, não atingindo a saturação. Isso ocorreu, porque o campo elétrico aplicado ao volume sensível da câmara anelar não era constante ao longo do seu diâmetro interno (ao redor do furo central), ocorrendo efeito de borda. Este problema foi solucionado no projeto seguinte, acrescentando-se um anel de guarda nesta região. 


\subsection{Câmara Monitora Anelar com Eletrodo Cole- tor de Alumínio (Segundo Protótipo)}

A segunda câmara anelar desenvolvida, denominada câmara A, sofreu algumas mudanças no projeto original, como pode ser observado comparando-se as Figuras 5.2 e 5.3 .

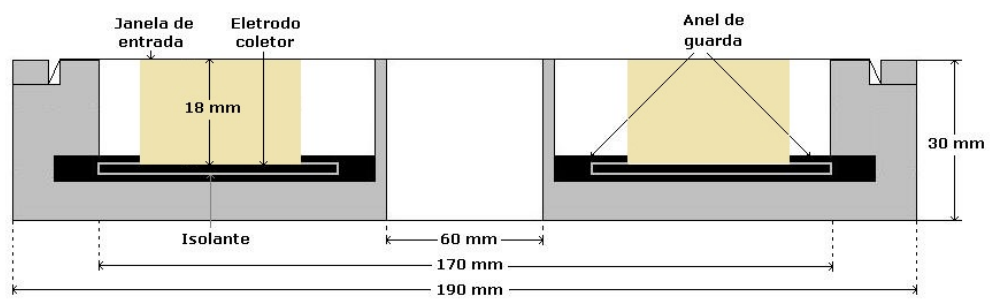

(A)

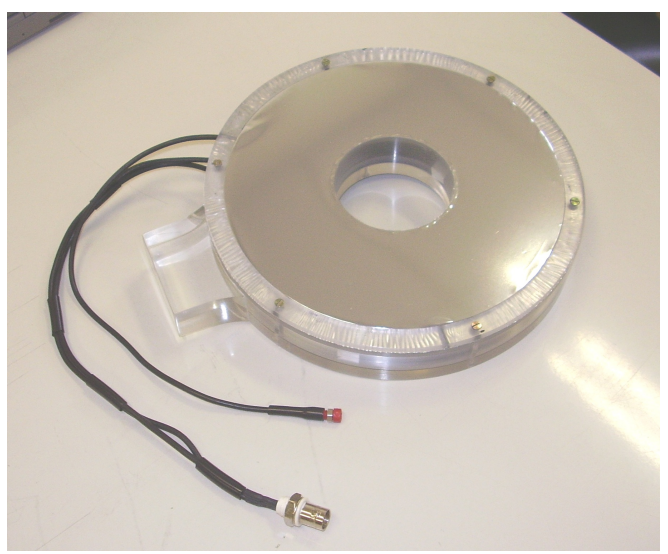

(B)

Figura 5.3 - Diagrama e fotografia da câmara de ionização anelar A desenvolvida.

Esta câmara de ionização possui toda a estrutura do corpo em acrílico, janela de entrada de poliéster aluminizado de densidade superficial igual a 1,87 mg.cm ${ }^{-2}$ e eletrodo coletor de alumínio. O volume sensível desta câmara de ionização é de aproximadamente $200 \mathrm{~cm}^{3}$ e o diâmetro do furo central é de $6,0 \mathrm{~cm}$. Com relação ao primeiro protótipo, esta câmara apresenta uma geometria diferente; suas placas possuem formato circular, mas de seção reta retangular. Este formato foi 
utilizado para acentuar a forma anelar proposta para a câmara de ionização. Pelo fato de a seção reta das paredes da câmara de ionização ainda ser retangular, a câmara permanece facilmente na posição vertical. Todas as câmaras desenvolvidas apresentam dois tipos de conectores: um conector coaxial que é conectado ao eletrodo coletor e ao anel de guarda, e um conector do tipo banana que é conectado à janela de entrada e pelo qual é aplicada a alta tensão. A câmara A foi sempre utilizada juntamente com o eletrômetro PTW UNIDOS 10474 e mostrou bons resultados na maioria dos testes aplicados, como será descrito no capítulo 7.

\subsection{Câmara Monitora Anelar com Eletrodo Cole- tor de Grafite}

Por motivos que serão apresentados no capítulo 7, uma nova câmara anelar, desta vez com eletrodo coletor de grafite, foi desenvolvida. Neste trabalho esta câmara de ionização anelar será denominada câmara G. A câmara monitora anelar com eletrodo coletor de grafite pode ser vista na Figura 5.4. O eletrodo coletor desta câmara de ionização foi feito a partir de uma placa de PMMA recoberta com uma camada de spray de grafite de alta condutividade Aerodag $G^{\circledR}$.

Comparando-se as Figuras 5.3 e 5.4 nota-se algumas diferenças no projeto das câmaras de ionização anelares. A primeira diferença é na profundidade do volume sensível que foi diminuído para melhorar a homogeneidade do campo, não sendo necessário utilizar uma tensão tão alta quanto na câmara A. Outra diferença é no posicionamento do anel de guarda com relação ao eletrodo coletor, que, nesta última câmara, se apresenta no mesmo nível. Essa mudança foi feita para evitar possíveis distorções no campo elétrico aplicado ao volume sensível da câmara de ionização. Além disso, o diâmetro do furo central foi acrescido de $1 \mathrm{~cm}$, passando de $6 \mathrm{~cm}$ para $7 \mathrm{~cm}$, para garantir que a câmara de ionização não interfira no espectro do feixe de radiação que a atravessa. O volume sensível da câmara $\mathrm{G}$ é de aproximadamente $160 \mathrm{~cm}^{3}$. Exceto o eletrodo coletor, que nesta câmara de ionização foi feito de uma 


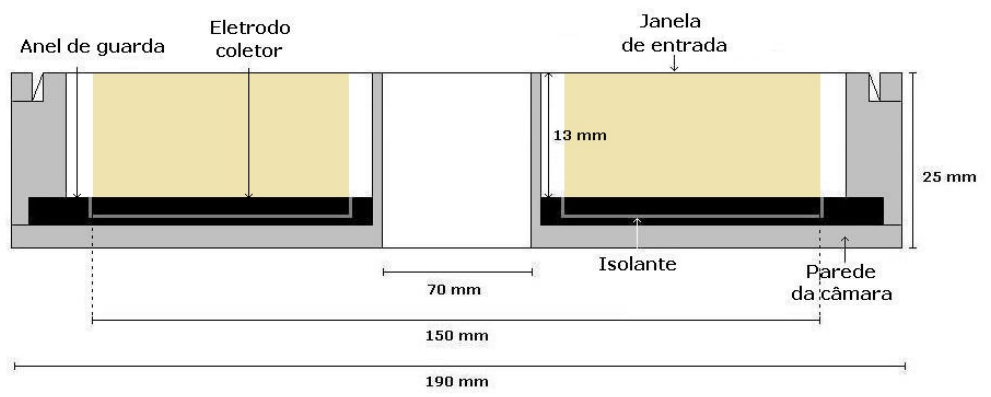

(A) Diagrama da câmara

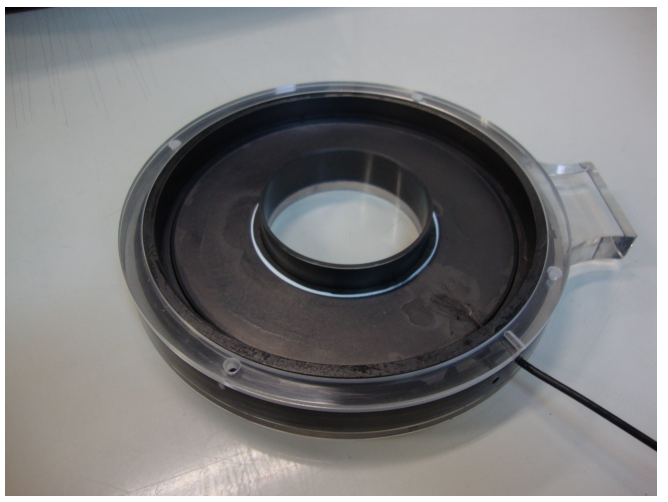

(B) Câmara no momento da montagem

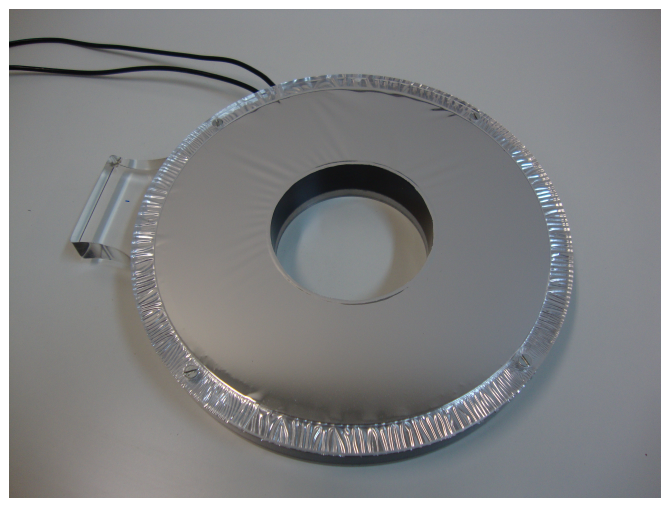

(c) Câmara pronta

FiguRA 5.4 - Câmara de ionização monitora anelar com eletrodo coletor de grafite.

cobertura de grafite, os outros materiais (corpo da câmara, janela de entrada e conectores) foram do mesmo tipo e qualidade que os utilizados na construção da câmara A. A câmara G foi utilizada sempre com o eletrômetro PTW UNIDOS 10474.

\subsection{Câmara Monitora de Transmissão com Volume Duplo}

Neste trabalho foi construída ainda uma câmara de ionização do tipo câmara de transmissão. Esta câmara possui dois volumes sensíveis como a câmara de transmissão comercial, para apresentar uma resposta mais sensível e, também como 
a câmara comercial, ela não possui um furo central. A Figura 5.5 mostra o diagrama e a fotografia da câmara monitora de volume duplo desenvolvida neste trabalho. Ao longo deste trabalho esta câmara será denominada câmara T.

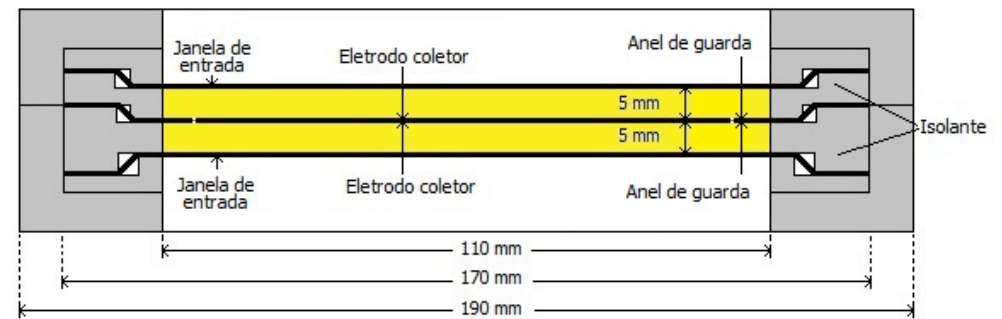

(A)

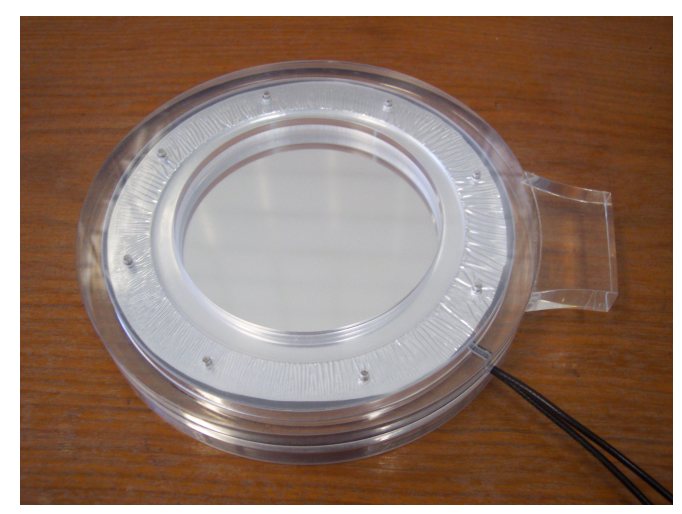

(B)

Figura 5.5 - Diagrama e fotografia da câmara de ionização de transmissão com volume duplo.

Como esta câmara de ionização é do tipo câmara de transmissão, ela deverá ficar posicionada no feixe direto de radiação. Para minimizar a interferência causada no espectro do feixe de radiação pela presença da câmara de ionização, esta câmara deve ser o mais fina possível e utilizar materiais que, ao mesmo tempo, devem fornecer estrutura física para o volume sensível da câmara, realizar leitura da intensidade do feixe de radiação e causar a menor interferência possível no espectro do feixe de radiação. Com esse intuito, os eletrodos da câmara de transmissão foram feitos a partir de uma folha plástica fina, utilizada para retroprojeção, recoberta de ambos os lados por uma camada de spray de grafite. Cada face da folha plástica 
foi recoberta com um fina camada de spray de grafite e utilizando uma máscara feita de papelão no formato de anel com raio interno de $7 \mathrm{~cm}$ e raio externo de $9 \mathrm{~cm}$. Esta máscara de papelão foi utilizada para separar o eletrodo coletor (parte interna do anel) do anel de guarda (parte externa do anel). O volume sensível total desta câmara de ionização é de aproximadamente $63 \mathrm{~cm}^{3}$, enquanto que o volume de uma câmara monitora comercial (PTW) é de $86 \mathrm{~cm}^{3}$. As janelas de entrada, o corpo da câmara de ionização e os conectores foram do mesmo tipo e qualidade utilizados nas outras câmaras de ionização. A diferença entre os volumes sensíveis das câmaras de ionização desenvolvida e comercial se deve à diferença entre os diâmetros das câmaras de ionização, que não puderam ser iguais por causa de limitações físicas no arranjo experimental.

A câmara de ionização de transmissão foi inicialmente testada utilizando o eletrômetro PTW UNIDOS 10474, mas, após alguns testes, notou-se que a resposta da câmara é muito sensível por ficar posicionada no feixe direto de radiação. Foi portanto utilizado o eletrômetro PTW UNIDOS E 00178. 


\section{Desempenho das Câmaras Monitoras Comerciais}

Duas câmaras monitoras comerciais foram estudadas: uma câmara de transmissão PTW, modelo 34014-0031 acoplada ao eletrômetro PTW UNIDOS E 00190, e uma câmara de ionização cilíndrica (dedal) do tipo Baldwin-Farmer Nuclear Enterprises, modelo 1229, acoplada ao eletrômetro PTW UNIDOS 10476. Neste trabalho, a câmara Baldwin-Farmer, modelo 1229, será chamada simplesmente de câmara Farmer. Estas câmaras de ionização podem ser vistas na Figura 6.1.

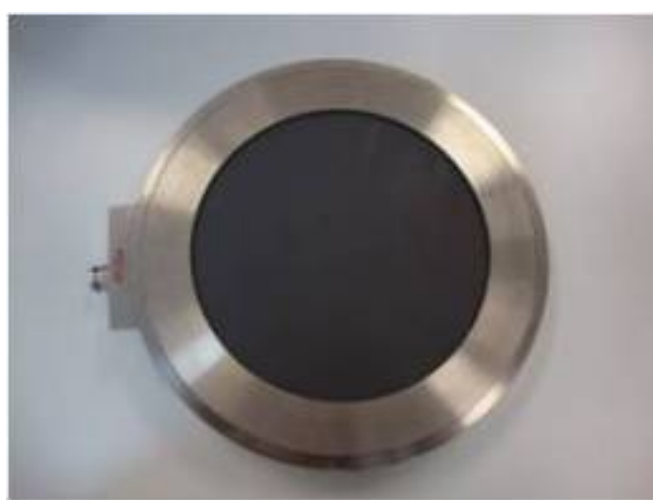

(A) Câmara de transmissão

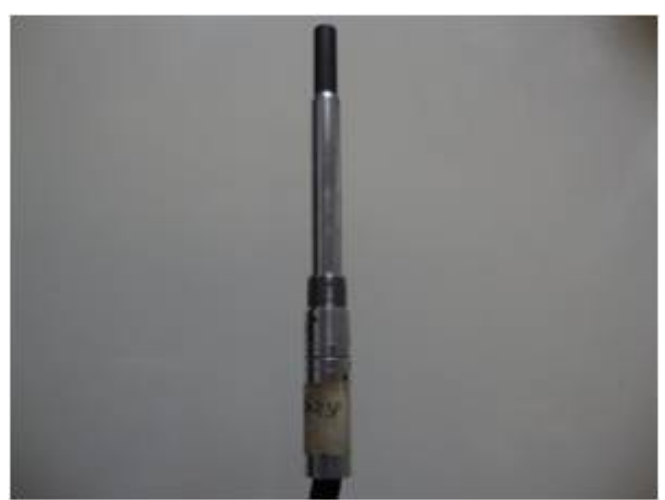

(B) Câmara do tipo Baldwin-Farmer

FigurA 6.1 - Câmaras de ionização comerciais de transmissão e do tipo Baldwin-Farmer.

No sistema de raios X Pantak, do Laboratório de Calibração de Instrumentos, é atualmente utilizada uma câmara de transmissão, PTW, modelo 34014, para o monitoramento da intensidade dos feixes de radiação $\mathrm{X}$. Todas as medições 
realizadas nesses feixes são corrigidas para a leitura desta câmara de transmissão. Neste laboratório há, também, uma câmara de ionização dedal, do tipo Farmer, que pode ser utilizada como câmara monitora se posicionada fora do feixe útil de radiação [32]. As desvantagens dessas câmaras de ionização têm a ver com a dificuldade de reprodutibilidade do posicionamento no caso da câmara Farmer e a alteração do espectro do campo de radiação X pela câmara de transmissão, já que ela fica posicionada diretamente no campo de radiação X. Será apresentado neste capítulo um estudo quanto às características e à estabilidade de resposta destas duas câmaras monitoras, a fim de compará-las com os protótipos das câmaras monitoras desenvolvidas.

\subsection{Testes de Caracterização}

\subsubsection{Curva de saturação, efeito de polaridade e eficiência de coleção de íons}

Para a determinação da curva de saturação, a resposta da câmara de transmissão foi medida no intervalo de $-400 \mathrm{~V}$ a $+400 \mathrm{~V}$, em passos de $\pm 50 \mathrm{~V}$, enquanto que a câmara Farmer foi testada no intervalo de $-300 \mathrm{~V}$ a $+300 \mathrm{~V}$, utilizando a qualidade RQR5, como mostrado na Figura 6.2. Verificou-se que a resposta de ambas as câmaras atinge a saturação já em $\pm 50 \mathrm{~V}$.

Com os resultados obtidos neste teste, foi possível determinar o efeito de polaridade e a eficiência de coleção de íons. Para o efeito de polaridade, a diferença máxima obtida para a câmara de transmissão foi de 0,7\% e para a câmara Farmer foi de $0,5 \%$. Ambos os resultados se mostraram dentro do limite recomendado de $1 \%$ [51.

Utilizando $V_{1}= \pm 300 \mathrm{~V}$ na equação do método das duas tensões, foi obtida uma eficiência de coleção de íons maior que $99 \%$ para ambas as câmaras. 


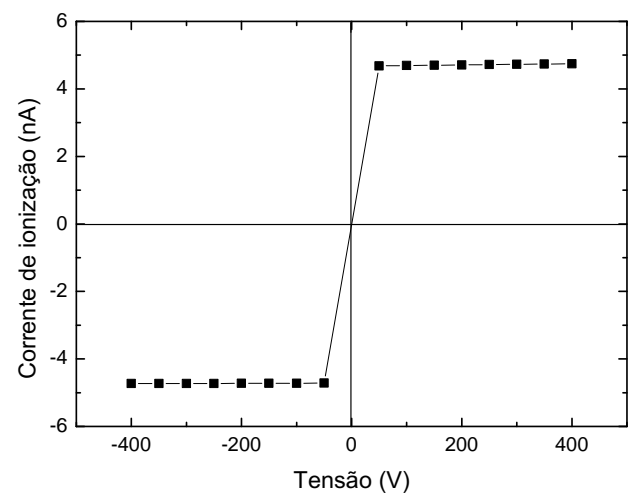

(A) Câmara de transmissão PTW, modelo 34014-0031

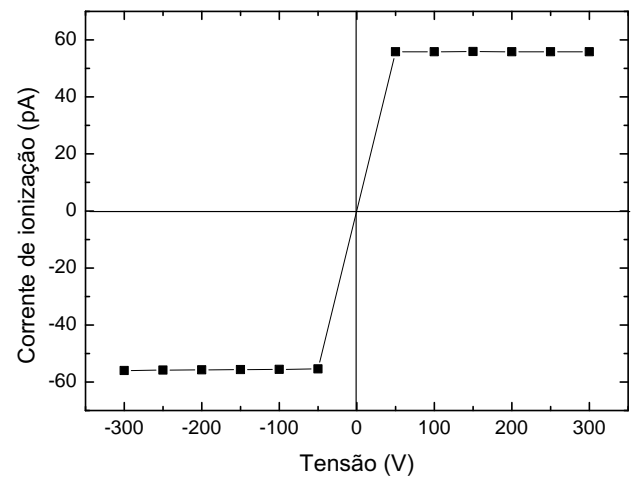

(B) Câmara Farmer NE, modelo 1229

Figura 6.2 - Curvas de saturação das câmaras de ionização. As incertezas das medições são menores que 0,33\%, o que torna impossível de serem visualizados nos gráficos.

\subsubsection{Linearidade de resposta}

Para a determinação da linearidade, a resposta das câmaras de ionização comerciais foi determinada variando-se a corrente do tubo de raios $\mathrm{X}$ e mantendo a tensão do tubo constante; neste caso a tensão utilizada foi de $70 \mathrm{kV}$ e filtração adicional de 2,5 mmAl, correspondendo à qualidade RQR5.

Pela Figura 6.3 é possível verificar que a resposta das câmaras Farmer e de transmissão foi linear no intervalo estudado, apresentando, na regressão linear, valores de $\mathrm{R}$ (coeficiente de correlação entre as variáveis) iguais a 0,999 e 1,000, respectivamente. O intervalo da taxa de kerma no ar foi diferente para cada câmara monitora, pois a câmara Farmer foi posicionada a $50 \mathrm{~cm}$ do ponto focal do tubo enquanto que a câmara de transmissão foi posicionada a $30 \mathrm{~cm}$. O posicionamento das câmaras monitoras não foi escolhido por acaso; a câmara de transmissão deve ser posicionada em torno de $30 \mathrm{~cm}$ de distância do ponto focal de acordo com a recomendação IEC 61267 [36] e a câmara cilíndrica, como não há nenhuma 
recomendação quanto à sua posição, foi posicionada a $50 \mathrm{~cm}$ do ponto focal, à mesma distância de calibração dos equipamentos de terapia. Esta câmara poderia ter sido posicionada também a 100 cm, que corresponde à distância de calibração dos equipamentos de diagnóstico convencional ou, ainda, a $250 \mathrm{~cm}$, que corresponde à distância de calibração dos detectores utilizados em proteção radiológica. $\mathrm{O}$ inconveniente para a utilização dessas outras distâncias é a menor intensidade do feixe de radiação.

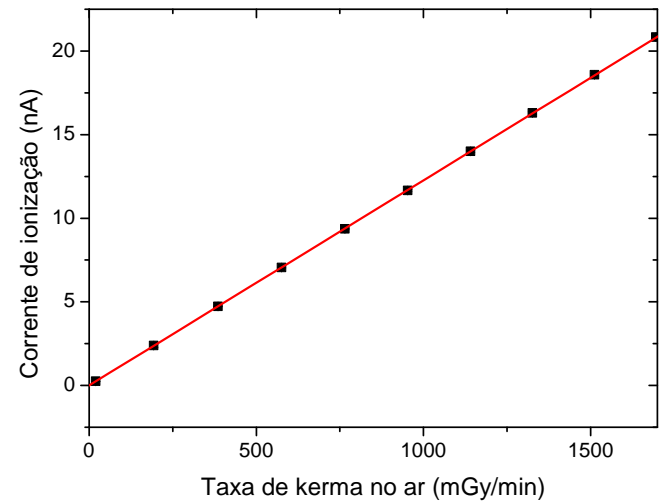

(A) Câmara de transmissão

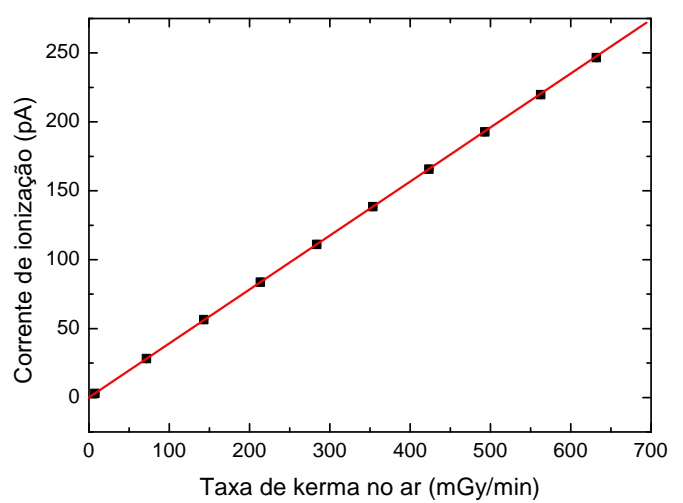

(B) Câmara Farmer

Figura 6.3 - Linearidade das respostas das câmaras de transmissão e Farmer. O desvio padrão máximo das medições foi de 0,32\%, o que torna impossível de serem visualizados nos gráficos.

\subsection{Testes de Estabilidade de Resposta utilizando Fontes de Controle}

Os testes de estabilidade de resposta foram realizados utilizando fontes de controle de ${ }^{90} \mathrm{Sr}+{ }^{90} \mathrm{Y}$ e suportes de acrílico apropriados para cada câmara. A Figura 6.4 mostra as fontes de controle e seus respectivos suportes para os testes de estabilidade das câmaras comerciais. 


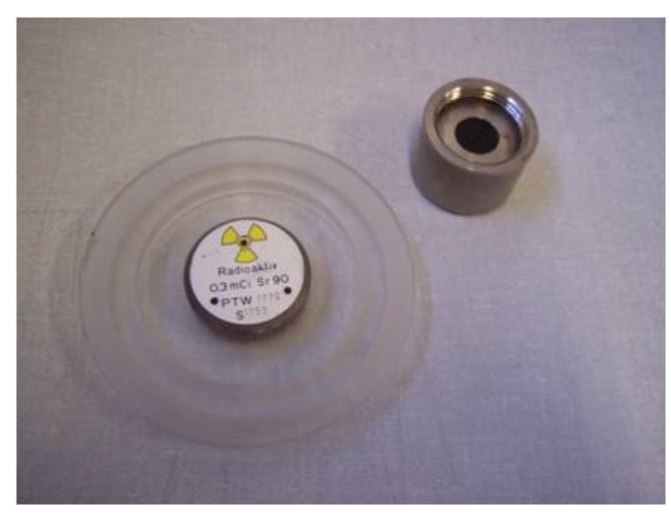

(A) Suporte e fonte de controle para a câmara de transmissão

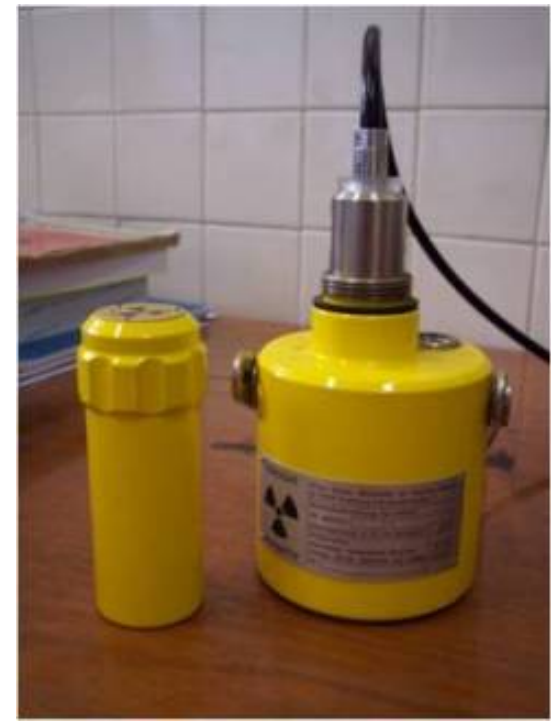

(B) Fonte de controle para a câmara Farmer

Figura 6.4 - Arranjos experimentais para os testes de estabilidade de resposta (utilizando fontes de controle) das câmaras comerciais de transmissão e Farmer.

\subsubsection{Tempo de estabilização}

O teste do tempo de estabilização da resposta é realizado com uma fonte de controle posicionada em frente à câmara de ionização conectada ao eletrômetro. No momento em que a alta tensão é aplicada à câmara de ionização a corrente começa a ser monitorada. Os valores da corrente de ionização aos 15, 30, 45 e 60 minutos após a aplicação da alta tensão são verificados. Este teste foi realizado somente com a câmara Farmer, pois a câmara de transmissão, por ser um equipamento amplamente utilizado no LCI, principalmente no serviço de rotina, é mantida conectada e com alta tensão aplicada em tempo integral.

A Tabela 6.1 mostra a resposta obtida para a câmara de ionização Farmer. Podese observar que a resposta da câmara estabiliza-se rapidamente, pois a diferença entre as respostas a 15 e 60 minutos é de apenas $0,37 \%$. 
TABela 6.1 - Tempo de estabilização da câmara de ionização Farmer.

\begin{tabular}{c|c}
\hline Tempo $(\mathrm{min})$ & Corrente de ionização $(\mathrm{pA})$ \\
\hline 15 & $10,70 \pm 0,06$ \\
30 & $10,71 \pm 0,08$ \\
45 & $10,72 \pm 0,14$ \\
60 & $10,74 \pm 0,06$ \\
\hline
\end{tabular}

\subsubsection{Teste de corrente de fuga}

A corrente de fuga é avaliada durante um intervalo de 20 minutos antes e depois de uma irradiação. Neste teste, a corrente de fuga, pré- e pós-irradiação, não ultrapassou 1,7\% para a câmara de transmissão e 0,1\% para a câmara Farmer, estando ambos os resultados dentro do valor recomendado de $\pm 5 \%$ da corrente de ionização obtida na menor taxa de kerma no ar utilizada [51].

\subsubsection{Testes de repetitividade e reprodutibilidade}

Para o teste de repetitividade de resposta (estabilidade a curto prazo) foram efetuadas 10 medições consecutivas da carga coletada por 1 minuto. Foram realizadas várias séries de medições, sendo que o desvio padrão máximo das medições foi apenas $0,3 \%$ para a câmara de transmissão e 0,1\% para a câmara Farmer, portanto dentro do limite recomendado de $\pm 3 \%$ [51].

Para cada série de medições realizadas no teste de repetitividade, foi calculado um valor médio. Uma análise destes valores médios foi realizada ao longo do tempo constituindo o teste de reprodutibilidade de resposta (estabilidade de médio ou longo prazo), como pode ser visto na Figura 6.5.

A variação máxima obtida para o teste de reprodutibilidade de resposta foi de 1,3\% para a câmara de transmissão e de 0,9\% para a câmara Farmer. Estes resultados estão dentro do limite recomendado de $\pm 2 \%[51$. 


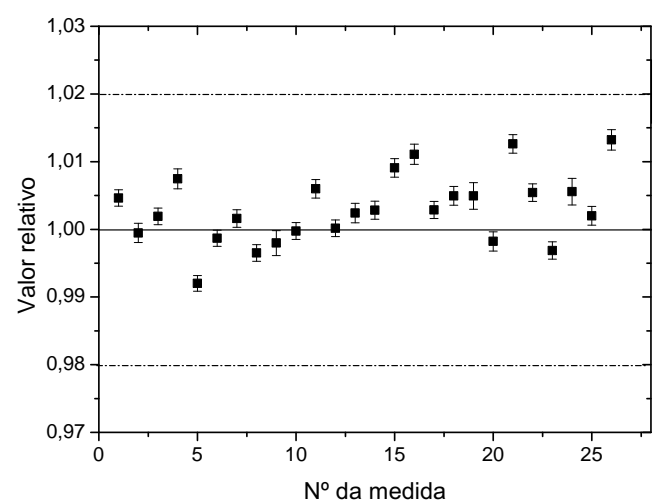

(A) Câmara de transmissão

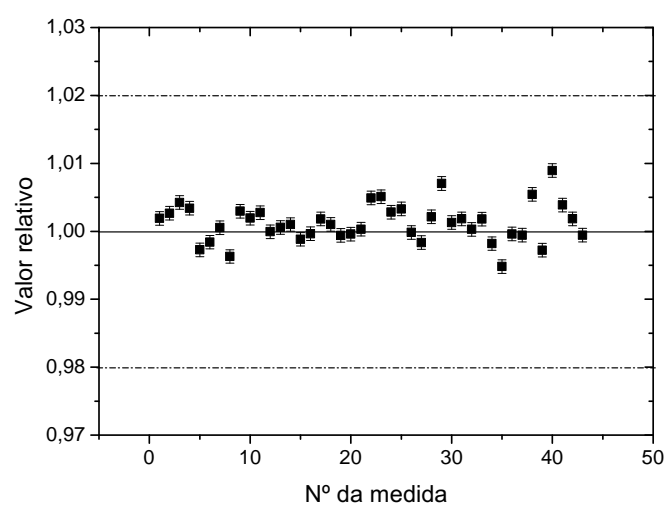

(B) Câmara Farmer

Figura 6.5 - Reprodutibilidade da resposta das câmaras de transmissão e Farmer, utilizando-se fontes de controle.

\subsection{Testes de Estabilidade de Resposta em Feixes de Radiação X}

Os testes de estabilidade (repetitividade e reprodutibilidade) foram repetidos utilizando-se o equipamento de raios X, mostrado na Figura 4.1. Neste teste foram utilizadas quatro qualidades de feixes de radiação: RQR5, RQR7, RQA5 e RQA7. A Figura 6.6 apresenta a reprodutibilidade da resposta das câmaras monitoras nestes feixes de radiação.

No teste de reprodutibilidade utilizando feixes de radiação X, a câmara de transmissão apresentou resultados ótimos, enquanto que a câmara Farmer apresentou resultados fora do limite recomendado de $\pm 2 \%$ [51]. A variação máxima obtida para o teste de repetitividade foi de $0,1 \%$ e 0,4\% para as câmaras de transmissão e Farmer, respectivamente. Os resultados para o teste de reprodutibilidade foram de $0,7 \%$ e $5,5 \%$, respectivamente. 


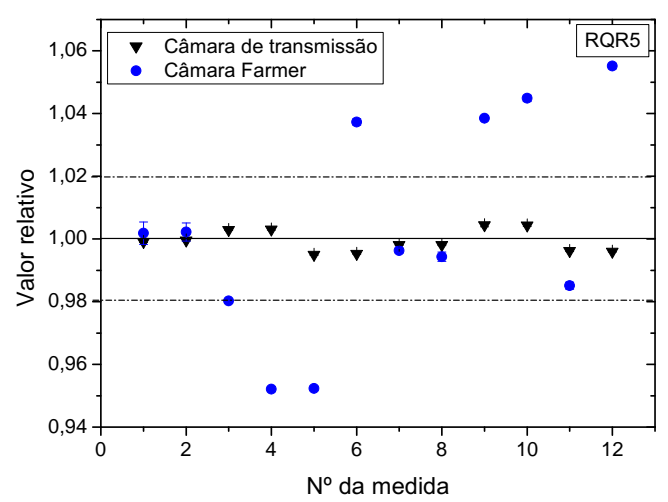

(A) $R Q R 5$

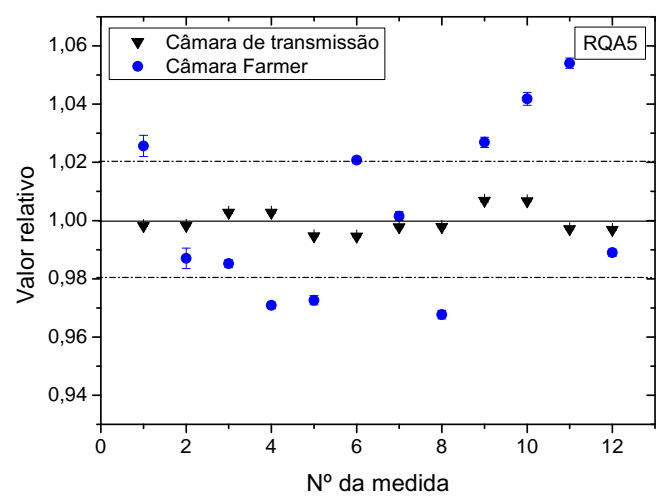

(c) RQA5

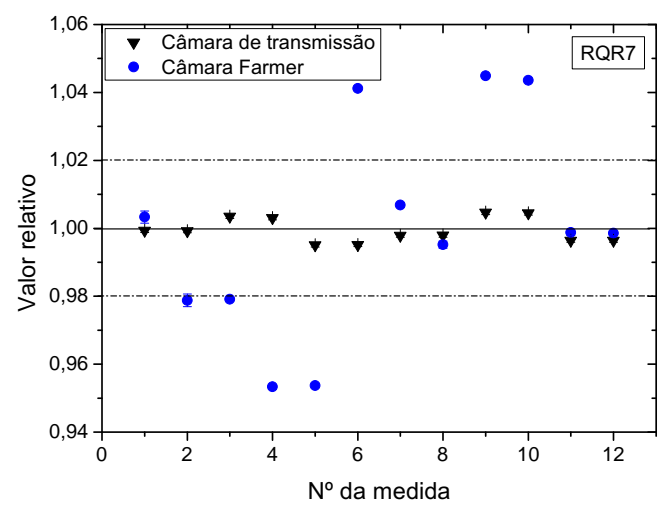

(в) $R Q R 7$

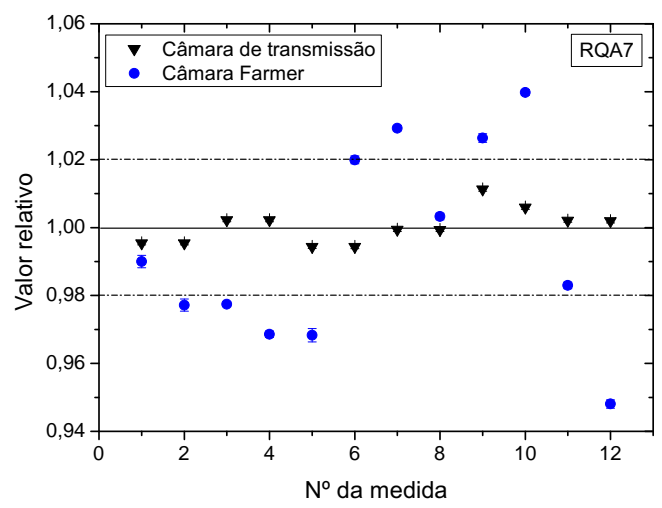

(D) RQA7

FIgURA 6.6 - Reprodutibilidade da resposta das câmaras monitoras comerciais para as qualidades de radiação $R Q R 5, R Q R 7, R Q A 5$ e $R Q A 7$. Os valores das incertezas das medições são menores que 0,35\%, o que torna impossível de serem visualizados nos gráficos.

\subsection{Calibração das Câmaras de Ionização Comer- ciais}

As câmaras de ionização comerciais foram calibradas em diversos feixes de radiação $\mathrm{X}$, além de feixes de radiação beta e gama. Para os feixes de radiação X, foi utilizado 
o método da substituição para a calibração da câmara Farmer. Neste método uma câmara de ionização padrão secundário é posicionada à distância de 100 cm, que é a distãncia de calibração de feixes de radiação para diagnóstico convencional, sendo assim, realizadas medições da taxa de kerma no ar. Posteriormente, a câmara de ionização a ser calibrada é posicionada sob mesmas condições de geometria e assim são feitas as medições de sua resposta. O fator de calibração da câmara de ionização submetida à calibração é determinado a partir da equação apresentada no item 2.8 .

No caso da câmara de transmissão, esse procedimento foi modificado, porque este tipo de câmara de ionização é especial e sua calibração não tem o mesmo objetivo que a calibração de qualquer outra câmara de ionização, que é determinar a taxa de dose absorvida ou taxa de kerma no ar a uma certa distância de uma fonte de radiação. A resposta da câmara de transmissão funciona como uma referência para correção do valor apresentado por um equipamento devido a variações na intensidade do feixe de radiação, em geral por causa de flutuações na rede elétrica. Assim, foi realizado um procedimento similar a uma calibração, que neste caso, pode ser chamado de "transferência do coeficiente de calibração do instrumento padrão". A câmara de ionização padrão secundário foi posicionada à distância de calibração de 100 cm e a câmara de transmissão foi posicionada a $30 \mathrm{~cm}$, que é a sua posição de operação. As duas câmaras de ionização foram expostas ao feixe de radiação ao mesmo tempo e suas respostas foram coletadas simultaneamente. Dessa forma, o coeficiente de calibração obtido é na verdade um coeficiente de equivalência entre as respostas das câmaras de ionização, irradiadas sob mesmas condições, mas, lembrando que cada câmara de ionização está em uma posição diferente em relação ao ponto focal do tubo de radiação X. Este procedimento foi adotado para todas as câmaras de ionização desenvolvidas neste trabalho, pois elas também devem ser utilizadas à distância de $30 \mathrm{~cm}$.

Analisando esta transferência do coeficiente de calibração do instrumento padrão para as câmaras de ionização monitoras, as quais podem então ser chamadas 
de padrões de transferência [56]. No LCI, a câmara de transmissão comercial PTW, modelo 34014-0031, já é utilizada como padrão de transferência no sistema Pantak/Seifert há 3 anos, sendo recalibrada periodicamente.

Para os feixes de radiação beta e gama, foi utilizado o método do campo conhecido, pois, por se tratar de fontes radioativas, os valores da taxa de kerma no ar para diferentes distâncias são conhecidos por medições prévias, utilizando-se sistemas de referência (mapeamento periódico do campo de radiação).

\subsubsection{Calibração em feixes de radiação $\mathrm{X}$}

Para a calibração (ou transferência do coeficiente de calibração) em feixes de radiação X foram utilizadas primeiramente as qualidades de feixe, nível radiodiagnóstico [35], estabelecidas no equipamento de radiação X do LCI. Os coeficientes de calibração (ou coeficientes de equivalência) e os respectivos fatores de correção podem ser vistos nas Tabelas 6.2 e 6.3 e nas Figuras 6.7 e 6.8. Por estas tabelas, é facilmente verificado que os coeficientes de calibração (ou coeficientes de equivalência) foram normalizados para as qualidades RQR5 e RQA5. Este procedimento foi adotado pelo fato da câmara padrão secundário PTW, modelo 77334, apresentar certificado de calibração nessas mesmas condições.

Recentemente foram estabelecidas as novas qualidades de radiação nível radiodiagnóstico [57], dadas pela norma IEC 61267 de 2005 [36], e nível mamografia, utilizadas pelo PTB, no equipamento de radiação X Pantak/Seifert.

A implantação dessas novas qualidades de radiação só foi possível depois da calibração das câmaras de ionização padrões do LCI pelo laboratório padrão primário PTB. Assim, a câmara padrão secundário Radcal Corporation, modelo RC6, foi calibrada nos feixes de radiodiagnóstico convencional e a câmara padrão secundário Radcal Corporation, modelo RC6M, foi calibrada nos feixes de mamografia. Essas câmaras de ionização padrões foram utilizadas para calibrar as câmaras de ionização monitoras comerciais em seus respectivos intervalos de calibração. 
Os resultados para os feixes de radiodiagnóstico podem ser vistos nas Tabelas 6.4 e 6.5 e na Figura 6.9 . 
TABela 6.2 - Coeficientes de equivalência e fatores de correção da câmara de transmissão, para as qualidades de diagnóstico, de acordo com a norma IEC 1267 [35].

\begin{tabular}{c|c|c}
\hline $\begin{array}{c}\text { Qualidade } \\
\text { da } \\
\text { Radiação }\end{array}$ & $\begin{array}{c}\text { Coeficiente } \\
\text { de Equivalência } \\
\left(\text { x10 } G y \cdot C^{-1}\right)\end{array}$ & $\begin{array}{c}\text { Fator } \\
\text { de } \\
\text { Correção }\end{array}$ \\
\hline \multicolumn{3}{|c}{ Feixes Diretos } \\
\hline RQR3 & $11,815 \pm 0,129$ & $1,016 \pm 0,013$ \\
RQR4 & $11,695 \pm 0,056$ & $1,005 \pm 0,011$ \\
RQR5 & $11,633 \pm 0,235$ & $1,000 \pm 0,018$ \\
RQR6 & $11,669 \pm 0,236$ & $1,003 \pm 0,018$ \\
RQR7 & $11,773 \pm 0,095$ & $1,012 \pm 0,012$ \\
RQR8 & $11,838 \pm 0,067$ & $1,018 \pm 0,011$ \\
RQR9 & $11,972 \pm 0,096$ & $1,029 \pm 0,012$ \\
RQR10 & $12,179 \pm 0,057$ & $1,047 \pm 0,012$ \\
\hline \multicolumn{3}{c}{ Feixes Atenuados } \\
\hline RQA3 & $9,340 \pm 0,159$ & $1,104 \pm 0,021$ \\
RQA4 & $8,644 \pm 0,049$ & $1,022 \pm 0,010$ \\
RQA5 & $8,456 \pm 0,068$ & $1,000 \pm 0,011$ \\
RQA6 & $8,387 \pm 0,040$ & $0,992 \pm 0,009$ \\
RQA7 & $8,431 \pm 0,049$ & $0,997 \pm 0,009$ \\
RQA8 & $8,394 \pm 0,039$ & $0,993 \pm 0,009$ \\
RQA9 & $7,954 \pm 0,037$ & $0,940 \pm 0,009$ \\
RQA10 & $7,683 \pm 0,084$ & $0,908 \pm 0,012$ \\
\hline
\end{tabular}

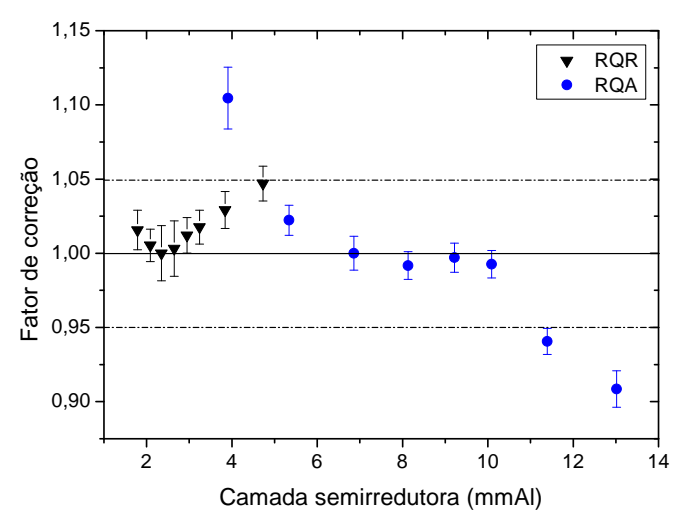

Figura 6.7 - Fatores de correção da resposta da câmara de transmissão para as qualidades de radiodiagnóstico da norma IEC 1267 [35]. 
TABEla 6.3 - Coeficientes de calibração e fatores de correção da câmara Farmer, para as qualidades de diagnóstico, de acordo com a norma IEC 1267 [35].

\begin{tabular}{c|c|c}
\hline $\begin{array}{c}\text { Qualidade } \\
\text { da } \\
\text { Radiação }\end{array}$ & $\begin{array}{c}\text { Coeficiente } \\
\text { de Calibração } \\
\left(\mathrm{x} 10^{7} \text { Gy. } C^{-1}\right)\end{array}$ & $\begin{array}{c}\text { Fator } \\
\text { de } \\
\text { Correção }\end{array}$ \\
\hline \multicolumn{3}{|c}{ Feixes Diretos } \\
\hline RQR3 & $4,462 \pm 0,026$ & $1,015 \pm 0,008$ \\
RQR4 & $4,421 \pm 0,026$ & $1,006 \pm 0,008$ \\
RQR5 & $4,396 \pm 0,026$ & $1,000 \pm 0,008$ \\
RQR6 & $4,388 \pm 0,025$ & $0,998 \pm 0,008$ \\
RQR7 & $4,396 \pm 0,025$ & $0,999 \pm 0,008$ \\
RQR8 & $4,422 \pm 0,025$ & $1,006 \pm 0,008$ \\
RQR9 & $4,364 \pm 0,025$ & $0,993 \pm 0,008$ \\
RQR10 & $4,356 \pm 0,017$ & $0,991 \pm 0,007$ \\
\hline \multicolumn{3}{c}{ Feixes Atenuados } \\
\hline RQA3 & $1,649 \pm 0,009$ & $1,286 \pm 0,011$ \\
RQA4 & $1,384 \pm 0,008$ & $1,079 \pm 0,009$ \\
RQA5 & $1,282 \pm 0,007$ & $1,000 \pm 0,008$ \\
RQA6 & $1,219 \pm 0,007$ & $0,951 \pm 0,008$ \\
RQA7 & $1,175 \pm 0,007$ & $0,917 \pm 0,005$ \\
RQA8 & $1,164 \pm 0,007$ & $0,908 \pm 0,007$ \\
RQA9 & $1,141 \pm 0,007$ & $0,889 \pm 0,007$ \\
RQA10 & $1,131 \pm 0,007$ & $0,882 \pm 0,007$ \\
\hline
\end{tabular}

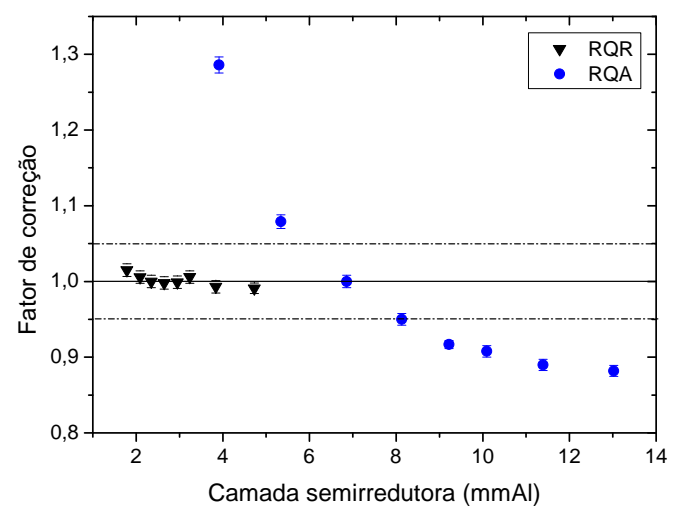

Figura 6.8 - Fatores de correção da resposta da câmaras Farmer para as qualidades de radiodiagnóstico da norma IEC 1267 [35]. 
TABela 6.4 - Coeficientes de equivalência e fatores de correção da câmara de transmissão, para as qualidades de diagnóstico, de acordo com a norma IEC 61267 [36].

\begin{tabular}{c|c|c}
\hline $\begin{array}{c}\text { Qualidade } \\
\text { da } \\
\text { Radiação }\end{array}$ & $\begin{array}{c}\text { Coeficiente } \\
\text { de Equivalência } \\
\left(\mathrm{x}^{4} \text { Gy.C }^{-1}\right)\end{array}$ & $\begin{array}{c}\text { Fator } \\
\text { de } \\
\text { Correção }\end{array}$ \\
\hline \multicolumn{3}{|c}{ Feixes Diretos } \\
\hline RQR3 & $11,552 \pm 0,095$ & $1,041 \pm 0,012$ \\
RQR5 & $11,092 \pm 0,091$ & $1,000 \pm 0,012$ \\
RQR8 & $11,203 \pm 0,088$ & $1,010 \pm 0,011$ \\
RQR10 & $11,358 \pm 0,096$ & $1,024 \pm 0,012$ \\
\hline \multicolumn{3}{c}{ Feixes Atenuados } \\
\hline RQA3 & $0,839 \pm 0,007$ & $1,895 \pm 0,023$ \\
RQA5 & $0,443 \pm 0,004$ & $1,000 \pm 0,011$ \\
RQA8 & $0,406 \pm 0,003$ & $0,9164 \pm 0,011$ \\
RQA10 & $0,523 \pm 0,004$ & $1,181 \pm 0,014$ \\
\hline
\end{tabular}

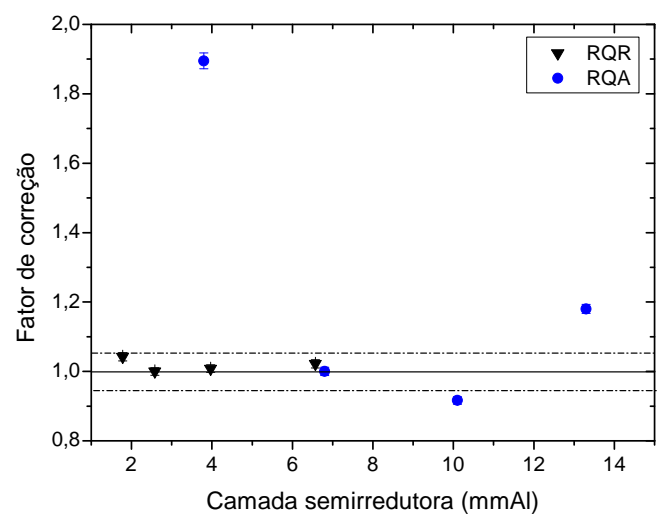

(A) Câmara de transmissão

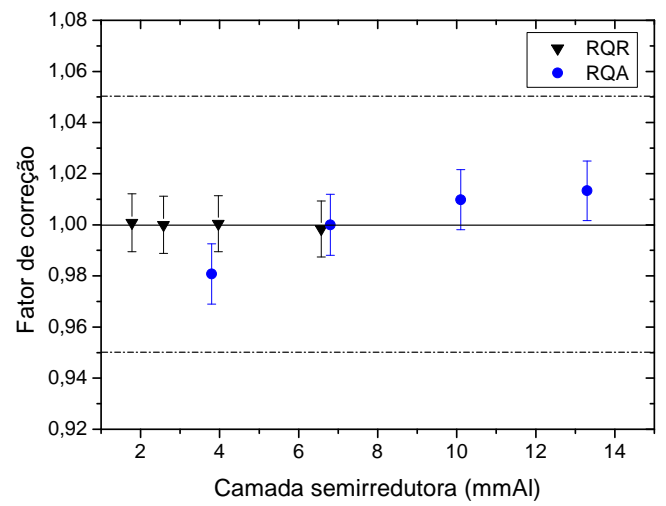

(B) Câmara Farmer

Figura 6.9 - Fatores de correção da resposta das câmaras monitoras para as novas qualidades nível radiodiagnóstico [36].

Para os feixes de mamografia os resultados são mostrados nas Tabelas 6.6 e 6.7 e na Figura6.10.

A partir dos valores dos coeficientes de calibração ou coeficientes de equivalência (dependendo da câmara de ionização) e/ ou dos fatores de correção, é possível 
TABEla 6.5 - Coeficientes de calibração e fatores de correção da câmara de ionização Farmer, para as qualidades de diagnóstico, de acordo com a norma IEC 61267 [36].

\begin{tabular}{|c|c|c|}
\hline $\begin{array}{c}\text { Qualidade } \\
\text { da } \\
\text { Radiação }\end{array}$ & $\begin{array}{c}\text { Coeficiente } \\
\text { de Calibração } \\
\left(\mathrm{x} 10^{7} \mathrm{~Gy}^{-\mathrm{C}^{-1}}\right)\end{array}$ & $\begin{array}{c}\text { Fator } \\
\text { de } \\
\text { Correção }\end{array}$ \\
\hline \multicolumn{3}{|c|}{ Feixes Diretos } \\
\hline RQR3 & $4,111 \pm 0,033$ & $1,001 \pm 0,011$ \\
\hline RQR5 & $4,108 \pm 0,032$ & $1,000 \pm 0,011$ \\
\hline RQR8 & $4,109 \pm 0,032$ & $1,000 \pm 0,011$ \\
\hline RQR10 & $4,101 \pm 0,032$ & $0,998 \pm 0,011$ \\
\hline \multicolumn{3}{|c|}{ Feixes Atenuados } \\
\hline RQA3 & $3,920 \pm 0,033$ & $0,981 \pm 0,011$ \\
\hline RQA5 & $3,997 \pm 0,033$ & $1,000 \pm 0,012$ \\
\hline RQA8 & $4,036 \pm 0,032$ & $1,010 \pm 0,011$ \\
\hline RQA10 & $4,050 \pm 0,032$ & $1,013 \pm 0,011$ \\
\hline
\end{tabular}

TABela 6.6 - Coeficientes de equivalência e fatores de correção da câmara de transmissão para as qualidades de mamografia [54].

\begin{tabular}{c|c|c}
\hline $\begin{array}{c}\text { Qualidade } \\
\text { da } \\
\text { Radiação }\end{array}$ & $\begin{array}{c}\text { Coeficiente } \\
\text { de Equivalência } \\
\left(\mathrm{x} 10^{5} \text { Gy.C } \mathrm{C}^{-1}\right)\end{array}$ & $\begin{array}{c}\text { Fator } \\
\text { de } \\
\text { Correção }\end{array}$ \\
\hline WMV25 & $1,581 \pm 0,002$ & $1,014 \pm 0,014$ \\
WMV28 & $1,558 \pm 0,002$ & $1,000 \pm 0,014$ \\
WMV30 & $1,543 \pm 0,002$ & $0,989 \pm 0,014$ \\
WMV35 & $1,496 \pm 0,001$ & $0,960 \pm 0,014$ \\
\hline
\end{tabular}

TABela 6.7 - Coeficientes de calibração e fatores de correção da câmara de ionização Farmer para as qualidades de mamografia [54].

\begin{tabular}{c|c|c}
\hline $\begin{array}{c}\text { Qualidade } \\
\text { da } \\
\text { Radiação }\end{array}$ & $\begin{array}{c}\text { Coeficiente } \\
\text { de Calibração } \\
(\text { x107 Gy.C }\end{array}$ & $\begin{array}{c}\text { Fator }) \\
\text { de } \\
\text { Correção }\end{array}$ \\
\hline WMV25 & $4,675 \pm 0,046$ & $1,002 \pm 0,014$ \\
WMV28 & $4,665 \pm 0,046$ & $1,000 \pm 0,014$ \\
WMV30 & $4,662 \pm 0,046$ & $0,999 \pm 0,014$ \\
WMV35 & $4,638 \pm 0,046$ & $0,994 \pm 0,014$ \\
\hline
\end{tabular}




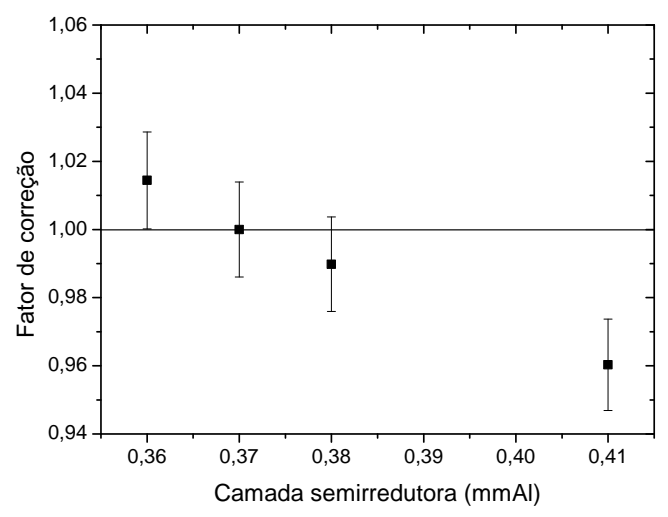

(A) Câmara de transmissão

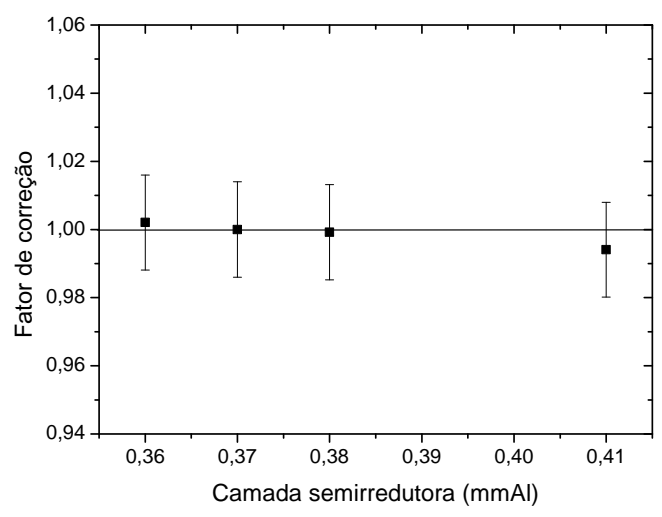

(B) Câmara Farmer

Figura 6.10 - Fatores de correção da resposta das câmaras monitoras para as novas qualidades nível mamografia [54].

verificar a dependência energética das câmaras de ionização monitoras para os feixes estudados. Pela Figura 6.7 é possível verificar que, para os feixes de radiodiagnóstico recomendados pela norma IEC 1267 [35], a resposta da câmara Farmer apresenta uma dependência energética muito pequena para as qualidades de feixes diretos (máximo de 2,4\%), mas para as qualidades de feixes atenuados a dependência energética é bem alta, com máximo de 45,8\%. A câmara de transmissão apresenta resposta fora dos limites recomendados, de $\pm 5 \%$ [51], somente para as qualidades RQA3, 9 e 10. Para os feixes de radiodiagnóstico recomendados pela norma IEC 61267 [36], cujos resultados são mostrados na Figura 6.9. é possível notar que a dependência energética da câmara de ionização Farmer é muito menor para as novas qualidades do que para qualidades da norma de 1994 [35]. O contrário ocorre para a câmara de transmissão, com relação às qualidades de feixe atenuado, mas este fato é facilmente explicado pelo posicionamento da filtração adicional descrito na Figura 4.2. As qualidades da norma IEC 1267 [35] foram implantadas no equipamento de raios X do LCI posicionando-se a filtração adicional antes da câmara de transmissão e, consequentemente, antes da câmara de ionização de referência. Por outro lado, as qualidades da norma IEC 61267 [36] foram estabelecidas com 
essas filtrações depois da câmara de ionização de transmissão e antes da câmara de ionização de referência. Essa diferença no posicionamento da filtração adicional acarreta essas diferenças grandes nos coeficientes calibração ou de equivalência. Considerando os feixes de mamografia recomendados pelo PTB [54], as câmaras comerciais apresentaram pouca dependência energética, sendo no máximo 5,6\% e 0,8\%, para as câmaras de transmissão e Farmer, respectivamente, como mostrado na Figura 6.10.

Deve-se lembrar que a calibração de um equipamento permite a determinação de um coeficiente de calibração, que é um valor que, multiplicado pela resposta deste equipamento quando exposto a um certo feixe de radiação, fornece o valor da dose absorvida (ou kerma no ar) ou da taxa de dose absorvida (ou da taxa de kerma no ar). Portanto, para um equipamento que não constitui um sistema padrão primário, uma calibração permite que este equipamento seja utilizado para medidas de dose nos feixes para os quais ele foi calibrado, desde que ele apresente uma resposta estável, o que garante a estabilidade do coeficiente de calibração.

\subsubsection{Calibração em feixes de radiação beta e gama}

A câmara de ionização do tipo Farmer foi testada também em feixes de radiação beta e gama. A câmara de transmissão não foi testada nestes feixes de radiação, pois esta câmara faz parte de um sistema fixo no banco óptico do equipamento de radiação X não podendo, assim, ser retirada para utilização em outro laboratório.

Utilizando o sistema de radiação beta da Figura 4.4 foi possível determinar os coeficientes de calibração da câmara Farmer para as fontes de ${ }^{90} \mathrm{Sr}+{ }^{90} \mathrm{Y}$ e ${ }^{85} \mathrm{Kr}$, como mostrado na Tabela 6.8. A fonte de ${ }^{147} \mathrm{Pm}$ está com uma atividade muito baixa, o que impossibilitou a sua utilização neste trabalho.

TABela 6.8 - Coeficientes de calibração da câmara Farmer para feixes de radiação beta.

\begin{tabular}{l|c|c}
\hline & ${ }^{90} \mathrm{Sr}+{ }^{90} \mathrm{Y}$ & ${ }^{85} \mathrm{Kr}$ \\
\hline Coeficiente de calibração $\left(\mu G y \cdot p C^{-1}\right)$ & $46,7 \pm 0,3$ & $196,7 \pm 1,6$ \\
\hline
\end{tabular}


Para a calibração da câmara Farmer em feixes de radiação gama, foram utilizadas as fontes de ${ }^{60} \mathrm{Co}$ e ${ }^{137} \mathrm{Cs}$ do irradiador gama do LCI. Os coeficientes de calibração obtidos podem ser vistos na Tabela 6.9.

TABela 6.9 - Coeficientes de calibração da câmara Farmer para feixes de radiação gama.

\begin{tabular}{|c|c|c|}
\hline & ${ }^{60} \mathrm{Co}$ & ${ }^{137} \mathrm{Cs}$ \\
\hline Coeficiente de calibração ( $\mu$ Gy.pC $\left.{ }^{-1}\right)$ & $42,26 \pm 0,03$ & $68,76 \pm 0,05$ \\
\hline
\end{tabular}

Pode-se notar que a câmara de ionização Farmer possui uma dependência energética muito alta para feixes de radiação beta, sendo o valor do coeficiente de calibração para a fonte de ${ }^{85} \mathrm{Kr}$ 4,2 vezes maior que o valor obtido para a fonte de ${ }^{90} \mathrm{Sr}+{ }^{90} \mathrm{Y}$. Esta câmara possui parede de espessura inadequada para detecção de radiação beta. Para feixes de radiação gama, a dependência energética da resposta da câmara Farmer é de $63 \%$ no intervalo de energia estudado.

Além da calibração da câmara de ionização Farmer em feixes de radiação beta, foi feito também um estudo da resposta desta câmara de ionização em função da distância da fonte. Isso foi possível, porque a fonte de ${ }^{90} \mathrm{Sr}+{ }^{90} \mathrm{Y}$ deste sistema possui certificado de calibração para várias distâncias fonte-detector. O resultado pode ser visto na Figura 6.11.

Pode-se perceber que a resposta da câmara varia de forma hiperbólica com a distância da fonte, como esperado, seguindo a lei do inverso do quadrado da distância. 


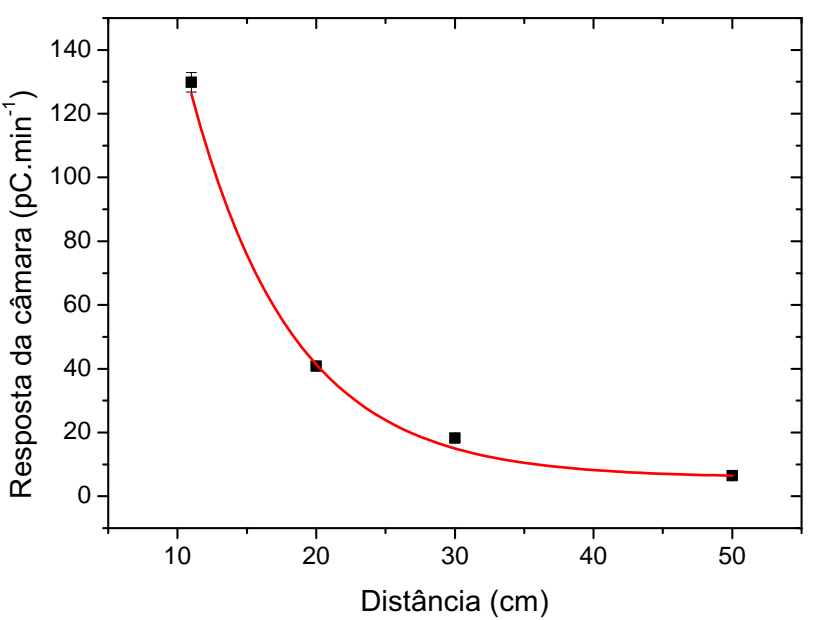

Figura 6.11 - Dependência com a distância fonte-detector da câmara de ionização Farmer. 


\section{Desempenho das Câmaras de Ionização Desenvolvidas}

Os resultados obtidos com as câmaras A, G e T serão expostos juntos para facilitar a comparação entre eles e evitar que a apresentação dos resultados do trabalho fique repetitiva. Mas vale ressaltar que cada câmara de ionização foi construída separadamente e os testes foram realizados após a construção de cada uma das câmaras de ionização.

\subsection{Testes de Caracterização}

\subsubsection{Curva de saturação, efeito de polaridade e eficiência de coleção de íons}

Para a determinação da curva de saturação, a resposta das câmaras foi estudada no intervalo de $-400 \mathrm{~V}$ a $+400 \mathrm{~V}$, em passos de $\pm 50 \mathrm{~V}$, como mostrado na Figura 7.1. Verifica-se que a resposta de todas as câmaras atinge a saturação já em $\pm 50 \mathrm{~V}$; mesmo assim, foi escolhida a tensão de $-400 \mathrm{~V}$ para operação da câmara A e -300 V para as câmaras G e T. A escolha das tensões de operação foi arbitrária, pois como pode ser visto na Figura 7.1, a tensão de operação poderia ser qualquer outra dentro do intervalo estudado; no entanto, deve-se evitar as tensões menores para evitar os efeitos de recombinação iônica e as tensões maiores por causa da 
isolação elétrica do sistema. A câmara de ionização de transmissão PTW do LCI é utilizada com uma tensão de $+400 \mathrm{~V}$.

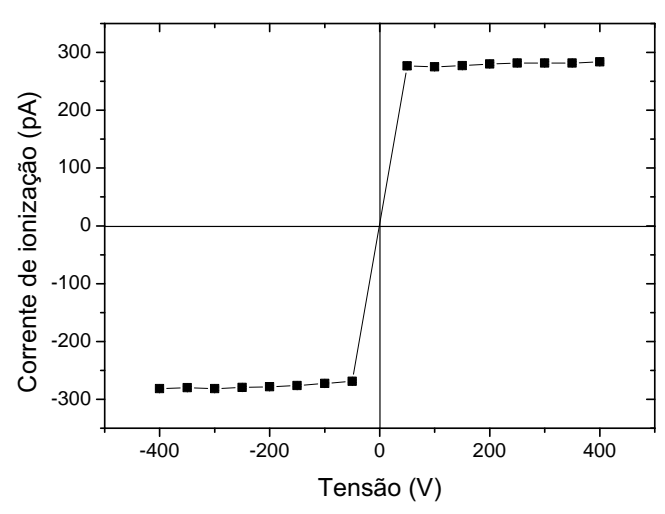

(A) Câmara A

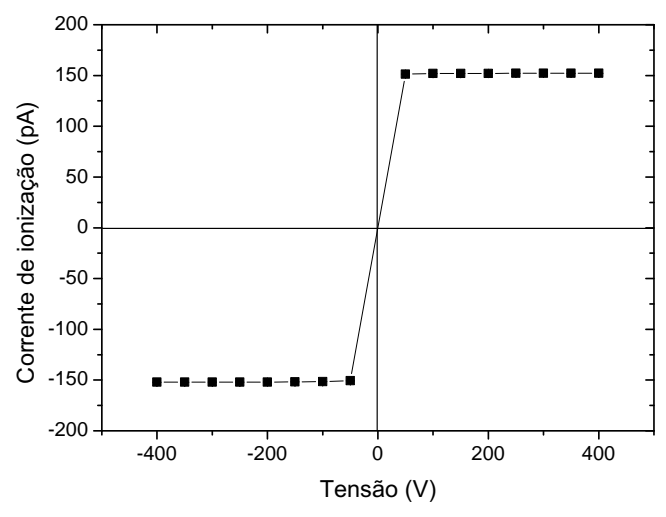

(в) Câmara $G$

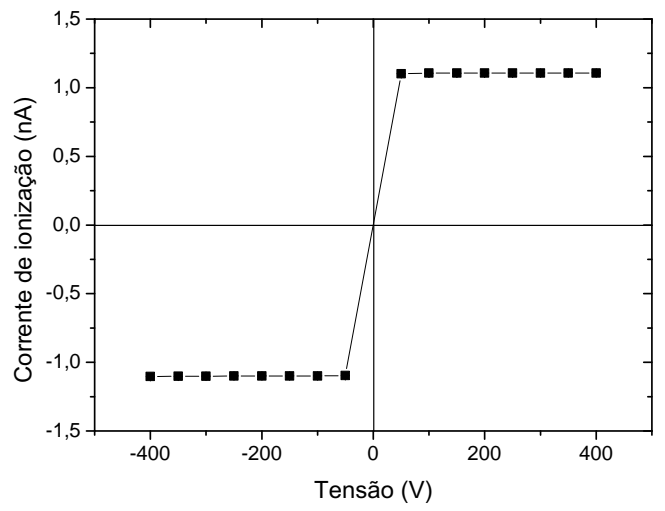

(c) Câmara T

Figura 7.1 - Curva de saturação das câmaras A, G e T. Os valores das incertezas das medições são menores que $2 \%$, o que torna impossível de serem visualizados nos gráficos.

Os resultados obtidos no teste de polaridade e no teste de eficiência de coleção de íons estão mostrados na Tabela 7.1. Para todo o intervalo de tensão estudado, o efeito de polaridade de todas as câmaras apresentou resultados dentro do limite recomendado de $1 \%$ [51], exceto para a tensão de $50 \mathrm{~V}$ para a câmara A. Este 
resultado fora do limite recomendado não tem importância prática, pois a câmara A não será operada nesta tensão. A eficiência de coleção de íons para $V_{1}= \pm 300 \mathrm{~V}$, foi maior que $99 \%$ para todas as câmaras.

TABela 7.1 - Teste de polaridade e eficiência de coleção de íons das câmaras de ionização desenvolvidas.

\begin{tabular}{c|c|c}
\hline Câmara & Teste de polaridade & Eficiência de coleção de íons \\
\hline $\mathrm{A}$ & $\begin{array}{c}\text { Máximo de } 3 \% \text { para } 50 \mathrm{~V} \text { e menor } \\
\text { que } 1 \% \text { para demais tensões }\end{array}$ & $>99 \%$ \\
\hline $\mathrm{G}$ & Máximo de $0,4 \%$ & $>99 \%$ \\
\hline $\mathrm{T}$ & Máximo de $0,01 \%$ & $>99 \%$ \\
\hline
\end{tabular}

\subsubsection{Linearidade de resposta}

A linearidade de resposta das câmaras de ionização desenvolvidas foi testada utilizando o equipamento de raios X do LCI, variando-se a corrente do tubo desde 0,5 mA até 40,0 mA. Para as câmaras A e G foi utilizada tensão do tubo igual a $70 \mathrm{kV}$, com filtração adicional de $2,5 \mathrm{mmAl}$ (o que corresponde à qualidade de radiação RQR5 [35]) e para a câmara T a tensão do tubo utilizada foi $50 \mathrm{kV}$ com filtração adicional de 12,5 mmAl (o que corresponde à qualidade de radiação RQA3 [35]). Esse procedimento foi feito por limitações dos eletrômetros utilizados neste teste. Como a câmara $\mathrm{T}$ possui um volume sensível muito grande, sua resposta apresenta valores altos, o que fez a escala do eletrômetro PTW, modelo UNIDOS saturar. Assim, foi utilizada a qualidade de radiação RQA3 que apresenta valores de taxa de kerma no ar menores que a qualidade de radiação RQR5. Após este teste, a câmara $\mathrm{T}$ foi acoplada a um eletrômetro do tipo UNIDOS E, que possui uma escala de leitura maior que o UNIDOS.

A Figura 7.2 mostra a linearidade da resposta das câmaras de ionização. A regressão linear das curvas foi feita e foram obtidos valores de $\mathrm{R}$ maiores que 0,999 para as câmaras A e T e igual a 1,000 para a câmara G. 


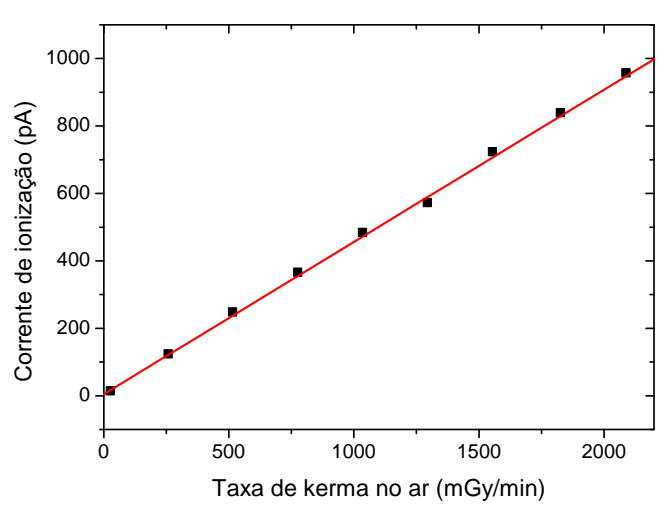

(A) Câmara $A$

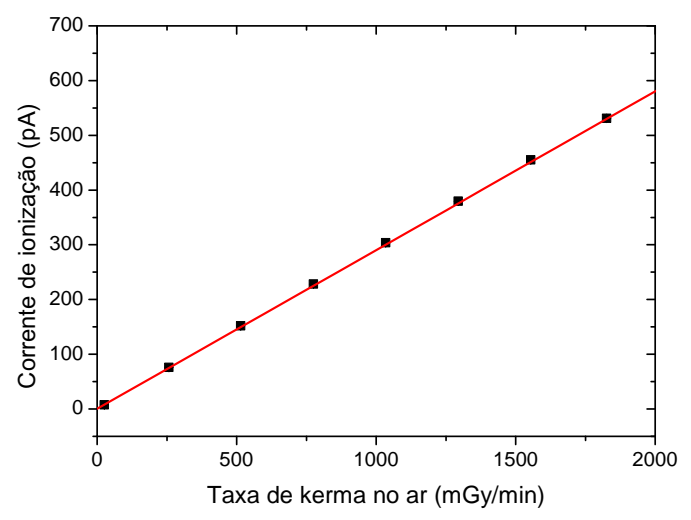

(в) Câmara $G$

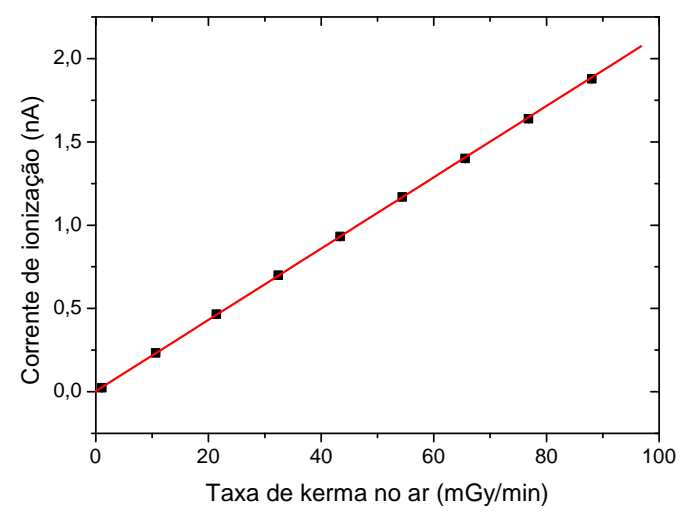

(c) Câmara $T$

Figura 7.2 - Linearidade da resposta das câmaras A, G e T. Os valores das incertezas das medições são menores que 1,5\%, o que torna impossível de serem visualizados nos gráficos.

\subsection{Testes de Estabilidade de Resposta utilizando uma Fonte de Controle}

Após a caracterização de cada câmara de ionização, o próximo passo foi determinar a estabilidade de suas respostas. Para isso foi utilizada uma fonte de controle de 
${ }^{90} \mathrm{Sr}+{ }^{90} \mathrm{Y}$ posicionada em um suporte de acrílico fabricado na Oficina Mecânica do IPEN que possui 5 posições diferentes para a fonte. A Figura 7.3 mostra o suporte de acrílico utilizado e suas respectivas posições. Para as câmaras A e G foram utilizadas as posições 1, 2, 3 e 4 do suporte para a fonte de controle por causa do formato anelar de seus volumes sensíveis. A câmara $\mathrm{T}$ foi testada somente com a fonte na posição 5 do suporte.

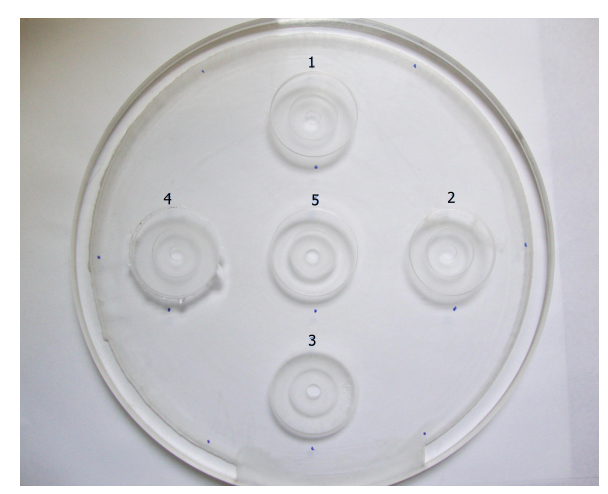

Figura 7.3 - Suporte de acrílico confeccionado para posicionamento da fonte de controle nos testes de estabilidade das câmaras desenvolvidas.

A Figura 7.4 mostra a câmara A com a fonte de controle disposta na posição 1 do suporte.

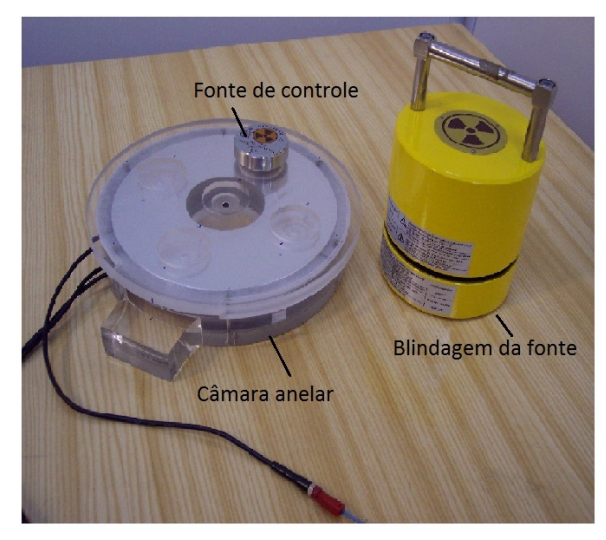

Figura 7.4 - Câmara de ionização A com a fonte de controle disposta na posição 1 do suporte. 


\subsubsection{Tempo de estabilização}

O primeiro teste de estabilidade realizado foi o de tempo de estabilização. Pela norma internacional é recomendado que 15 minutos depois de ligado, os limites de variação de resposta do instrumento devem estar dentro de $2 \%$ do valor da resposta do instrumento estável [51]. As câmaras de ionização desenvolvidas apresentaram variações nos tempos de estabilização de no máximo 1,82\%, 0,14\% e 0,98\%, para as câmaras A, G e T, respectivamente, e portanto dentro do limite recomendado, como mostrado nas Tabelas 7.2 e 7.3 .

TABela 7.2 - Tempo de estabilização da resposta das câmaras de ionização desenvolvidas $A$ e $G$.

\begin{tabular}{|c|c|c|c|c|c|}
\hline & $\begin{array}{c}\text { Tempo } \\
(\min )\end{array}$ & & Corrent & $\begin{array}{l}\text { Ionização } \\
\text { ) }\end{array}$ & \\
\hline \multirow{5}{*}{ 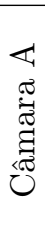 } & & Posição 1 & Posição 2 & Posição 3 & Posição 4 \\
\hline & 15 & $328,49 \pm 1,84$ & $298,30 \pm 3,14$ & $299,92 \pm 2,34$ & $304,10 \pm 1,68$ \\
\hline & 30 & $324,18 \pm 3,40$ & $296,02 \pm 1,66$ & $303,10 \pm 1,36$ & $306,36 \pm 4,10$ \\
\hline & 45 & $327,12 \pm 4,42$ & $297,55 \pm 1,34$ & $299,49 \pm 1,65$ & $307,07 \pm 1,38$ \\
\hline & 60 & $328,53 \pm 1,84$ & $294,74 \pm 1,62$ & $304,95 \pm 1,68$ & $304,80 \pm 3,21$ \\
\hline \multirow{4}{*}{ 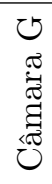 } & 15 & $120,00 \pm 1,70$ & $120,37 \pm 0,60$ & $122,29 \pm 1,37$ & $121,26 \pm 1,72$ \\
\hline & 30 & $120,12 \pm 0,99$ & $120,31 \pm 1,70$ & $122,32 \pm 0,71$ & $121,19 \pm 0,71$ \\
\hline & 45 & $120,05 \pm 0,69$ & $120,31 \pm 0,99$ & $122,38 \pm 1,00$ & $121,19 \pm 0,58$ \\
\hline & 60 & $120,04 \pm 1,70$ & $120,41 \pm 0,58$ & $122,21 \pm 2,13$ & $121,26 \pm 0,99$ \\
\hline
\end{tabular}

TABela 7.3 - Tempo de estabilização da câmara T.

\begin{tabular}{c|c}
\hline $\begin{array}{c}\text { Tempo } \\
(\min )\end{array}$ & $\begin{array}{c}\text { Corrente de Ionização } \\
(\mathrm{pA})\end{array}$ \\
\hline 15 & $100,93 \pm 0,81$ \\
30 & $101,20 \pm 3,30$ \\
45 & $101,92 \pm 2,35$ \\
60 & $101,22 \pm 0,81$ \\
\hline
\end{tabular}




\subsubsection{Teste de corrente de fuga}

Para ambos os testes, pré- e pós-irradiação, a corrente de fuga de todas as câmaras foi coletada durante um intervalo de tempo igual a 20 minutos. Os valores obtidos das correntes de fuga foram desprezíveis para todas as câmaras de ionização, não ultrapassando o valor recomendado de no máximo $5 \%$ do valor da corrente de ionização produzida pela menor taxa de kerma no ar utilizada [51]. Os valores máximos obtidos são mostrados na Tabela 7.4 .

TABELA 7.4 - Teste de corrente de fuga das câmaras de ionização desenvolvidas.

\begin{tabular}{c|c|c}
\hline Câmara & Fuga pré-irradiação & Fuga pós-irradiação \\
\hline $\mathrm{A}$ & $<0,52 \%$ & $<0,59 \%$ \\
\hline $\mathrm{G}$ & $<0,14 \%$ & $<0,21 \%$ \\
\hline $\mathrm{T}$ & $<0,10 \%$ & $<0,10 \%$ \\
\hline
\end{tabular}

\subsubsection{Testes de repetitividade e reprodutibilidade}

Para cada câmara de ionização foram realizadas séries de 10 medições. Estas séries de medições foram coletadas em diferentes dias cobrindo um período de 3 meses para as câmaras A e T, e de 7 meses para a câmara G.

De acordo com a publicação IEC 61674 de 1997 [51], o desvio padrão das 10 medições não deve ser maior que $\pm 3 \%$. Todas as câmaras desenvolvidas apresentaram resposta repetitiva dentro do período para o qual foram estudadas, com variações máximas de 0,37\%, 0,42\% e 0,84\% para as câmaras A, G e T, respectivamente.

Para o teste de reprodutibilidade, os valores médios de cada série de 10 medições do teste de repetitividade foram analisados e os resultados podem ser vistos nas Figuras 7.5, 7.6 e 7.7. A variação máxima obtida para as quatro posições diferentes da fonte de controle foi de 1,0\% e 0,6\% para as câmaras A e G, respectivamente e 1,1\% para a câmara T. Essas variações estão dentro do limite recomendado de $\pm 2 \%$ [51] que é mostrado nos gráficos com linhas tracejadas. 


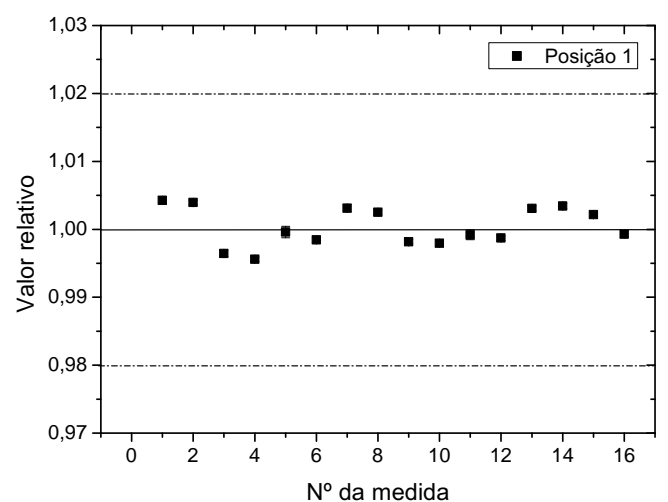

(A) Posição 1

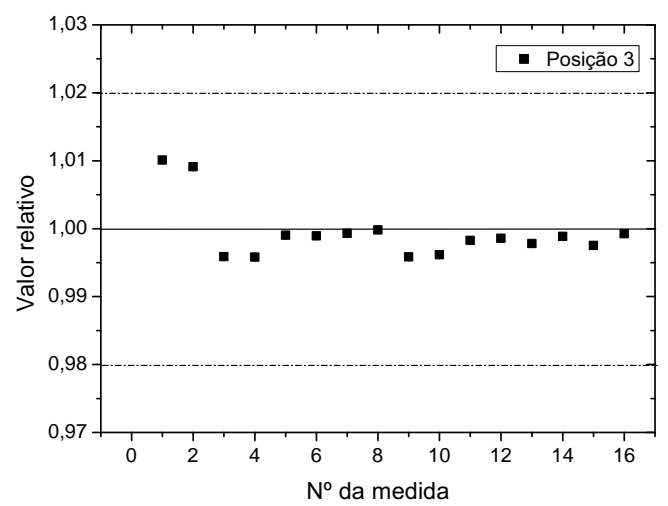

(C) Posição 3

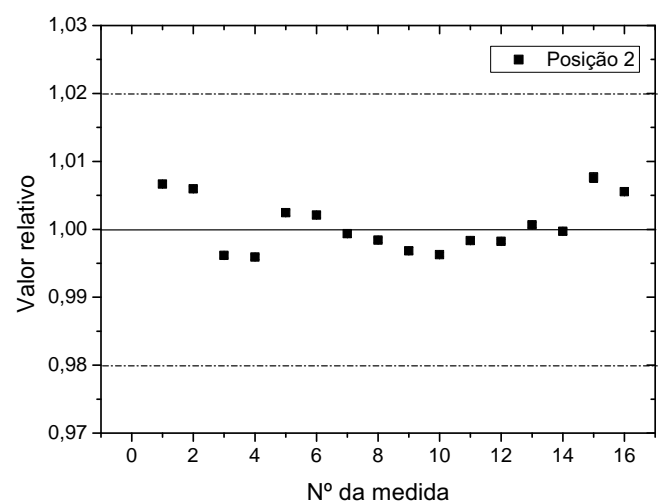

(B) Posição 2

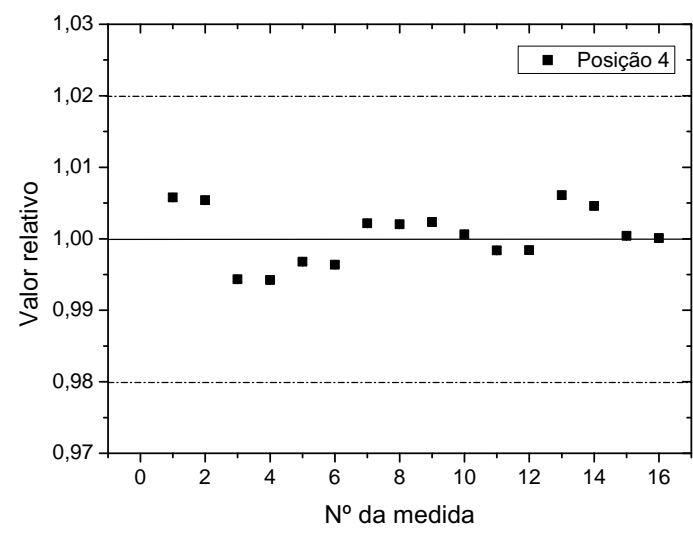

(D) Posição 4

Figura 7.5 - Reprodutibilidade da resposta da câmara A para as posições 1, 2, 3 e 4 do suporte, com fonte de controle de ${ }^{90} \mathrm{Sr}+{ }^{90} \mathrm{Y}$. As incertezas das medições são menores que 0,1\%, o que torna impossível de serem visualizadas nos gráficos.

\subsection{Testes de Estabilidade de Resposta em Feixes de Radiação X}

Os testes de estabilidade (repetitividade e reprodutibilidade) foram repetidos utilizando-se o equipamento de raios X, mostrado na Figura 4.1. Neste teste foram 


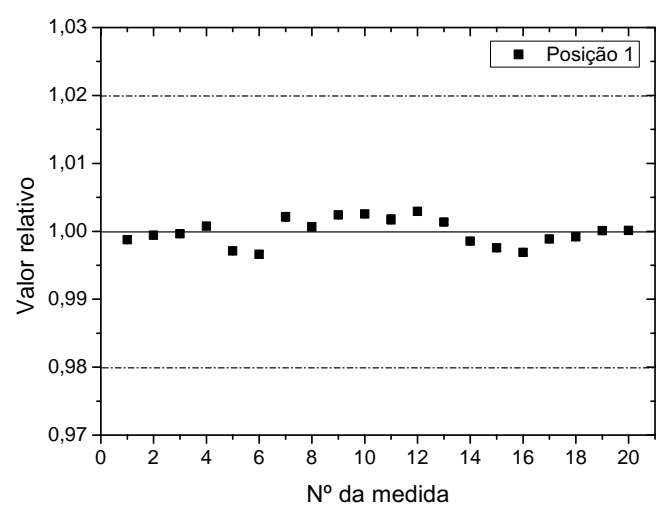

(A) Posição 1

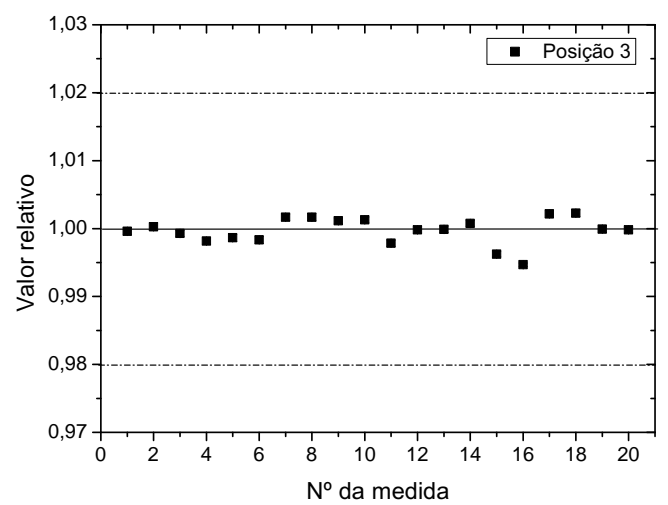

(C) Posição 3

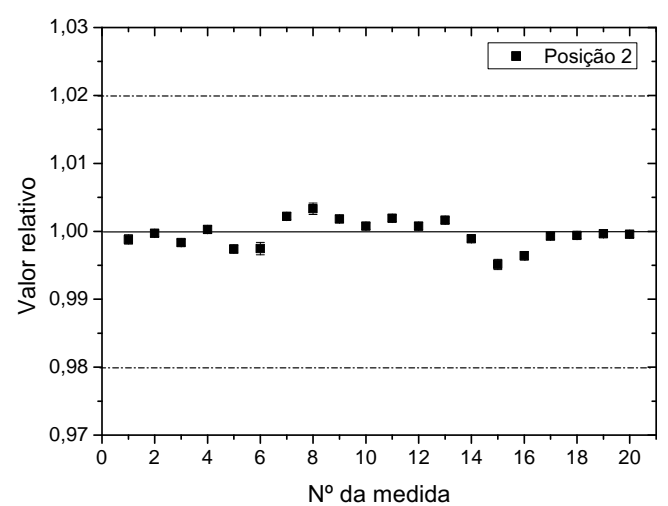

(B) Posição 2

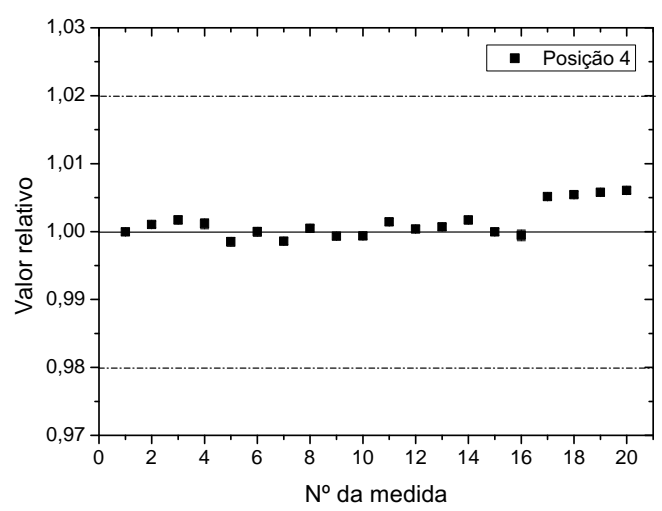

(D) Posição 4

Figura 7.6 - Reprodutibilidade da resposta da câmara G para as posições 1, 2, 3 e 4 do suporte para fonte de controle. As incertezas das medições são no máximo iguais a $0,3 \%$, o que torna impossível de serem visualizadas nos gráficos.

utilizadas quatro qualidades de feixe: RQR5, RQR7, RQA5 e RQA7, para os testes com as câmaras A e G. Como as novas qualidades de diagnóstico convencional já haviam sido implantadas quando a câmara T foi construída, os testes de estabilidade desta câmara foram realizados utilizando as novas qualidades: RQR3, RQR5, RQA3 e RQA5. 


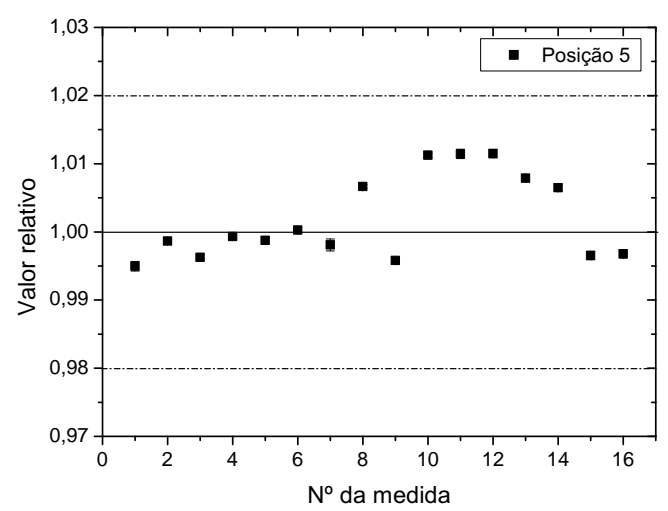

Figura 7.7 - Reprodutibilidade da resposta da câmara $T$ para a posição 5 do suporte para fonte de controle. As incertezas das medições são menores que 0,2\%, não sendo possível visualizá-las na figura.

A variação máxima obtida no teste de repetitividade foi de 1,14\%, 0,57\% e 0,54\% para as câmaras A, G e T, respectivamente. Todos os resultados estão dentro do limite recomendado de $\pm 3 \%$ [51]. Como pode ser visto nas Figuras 7.8, 7.9 e 7.10, no teste de reprodutibilidade as variações máximas foram de 4,2\%, 1,3\% e 0,8\%, respectivamente, para as câmaras A, G e T.

Como dito anteriormente, o limite de variação para o teste de reprodutibilidade é de $\pm 2 \%$ |51]. As câmaras G e T, que possuem eletrodos coletores de grafite, apresentaram resultados dentro deste limite. A câmara A, com eletrodo coletor de alumínio, não apresentou uma resposta reprodutível para feixes de radiação X. Exatamente por este motivo é que a câmara $G$ foi construída, pois esperava-se que o grafite apresentasse resposta mais estável que o alumínio, de acordo com experiências anteriores do grupo. 


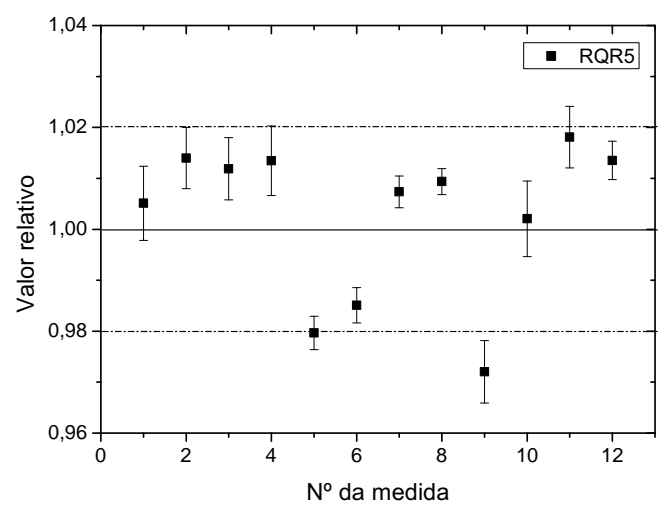

(A) $R Q R 5$

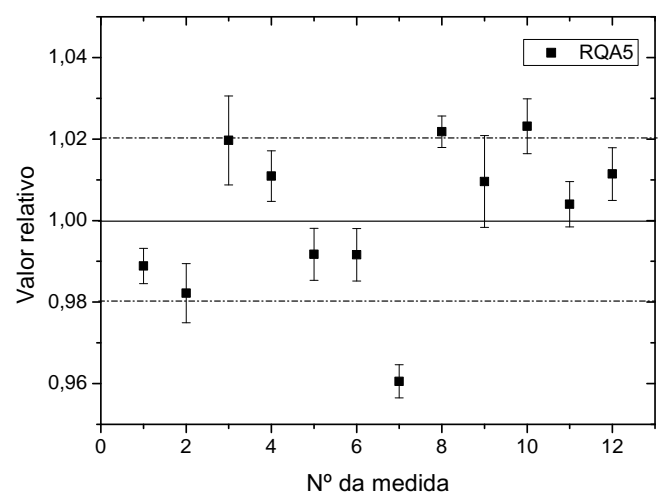

(C) $R Q A 5$

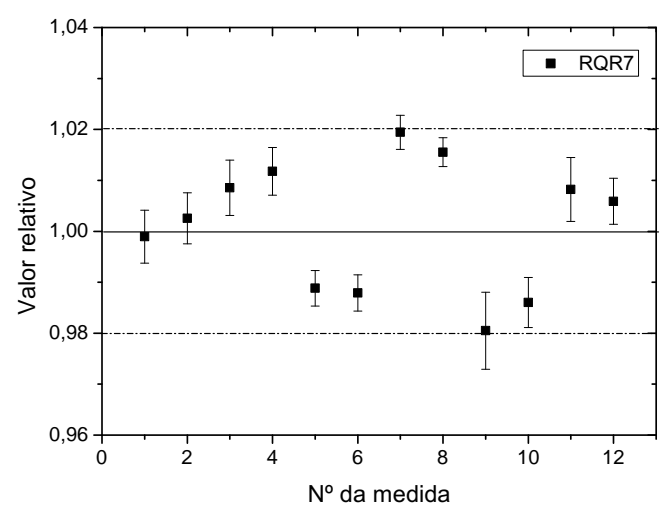

(B) $R Q R 7$

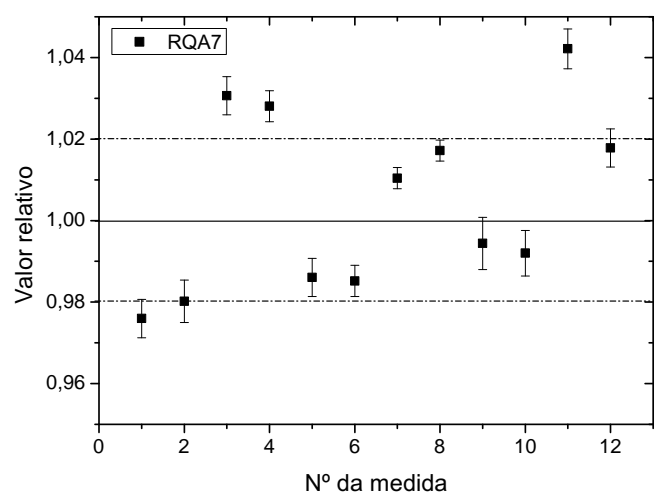

(D) $R Q A 7$

Figura 7.8 - Reprodutibilidade da resposta da câmara A para as qualidades $R Q R 5$, RQR7, RQA5 e RQA7 da norma IEC 1267 de 1994 [35].

\subsection{Calibração e Transferência do Coeficiente de Calibração do Instrumento Padrão para as Câ- maras de Ionização Desenvolvidas}

Para a transferência do coeficiente de calibração do instrumento padrão para as câmaras de ionização monitoras desenvolvidas em feixes de radiação X, foi utilizado 
o mesmo método descrito no item 6.4 para a câmara de transmissão. Assim, a câmara de ionização padrão secundário foi posicionada a 100 cm, que é a distância de calibração e a leitura de sua resposta foi realizada concomitantemente com a leitura da resposta de cada câmara de ionização desenvolvida, posicionada a $30 \mathrm{~cm}$. Para os feixes de radiação beta foi utilizado o sistema padrão secundário constituído

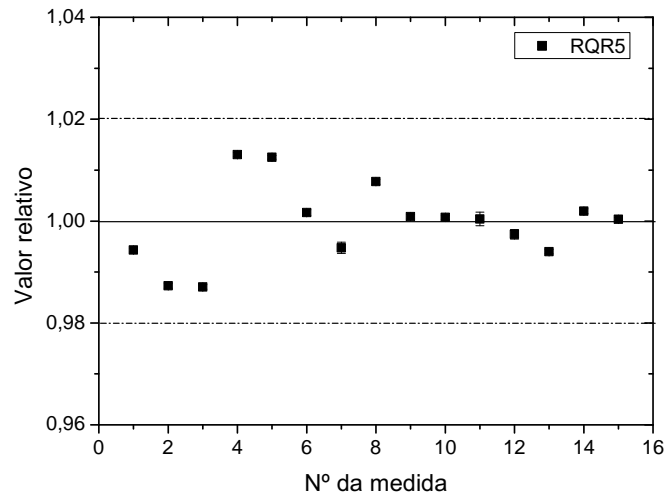

(A) $R Q R 5$

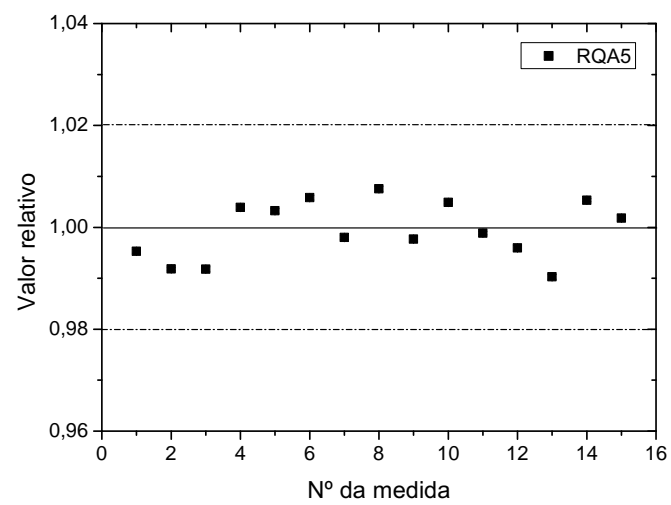

(C) $R Q A 5$

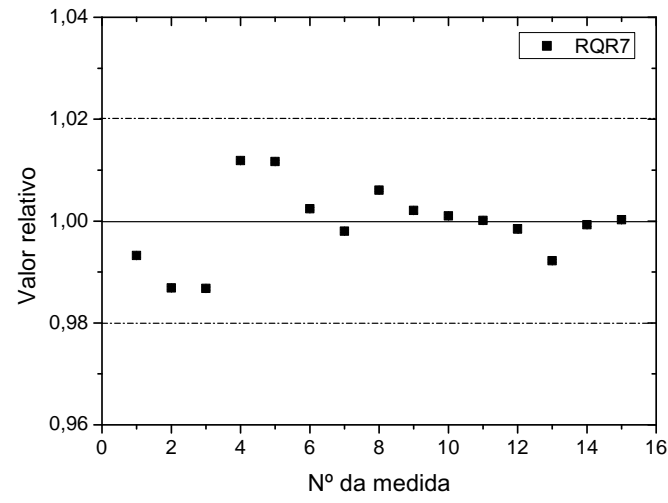

(B) $R Q R 7$

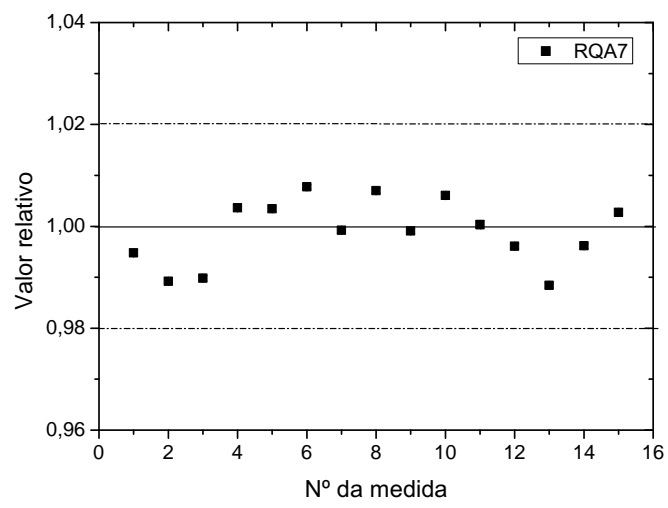

(D) $R Q A 7$

Figura 7.9 - Reprodutibilidade da resposta da câmara G para as qualidades RQR5, RQR7, RQA5 e RQA7 da norma IEC 1267 de 1994 [35]. As incertezas das medições são menores que 0,1\%, o que torna impossível de serem visualizados nos gráficos. 


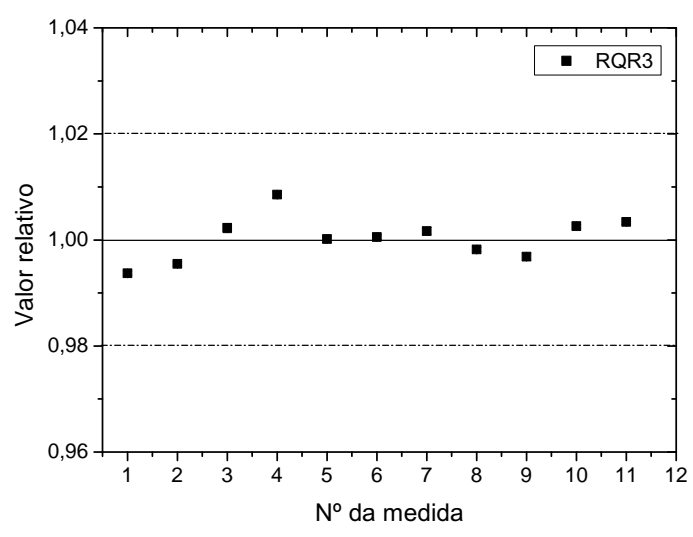

(A) $R Q R 3$

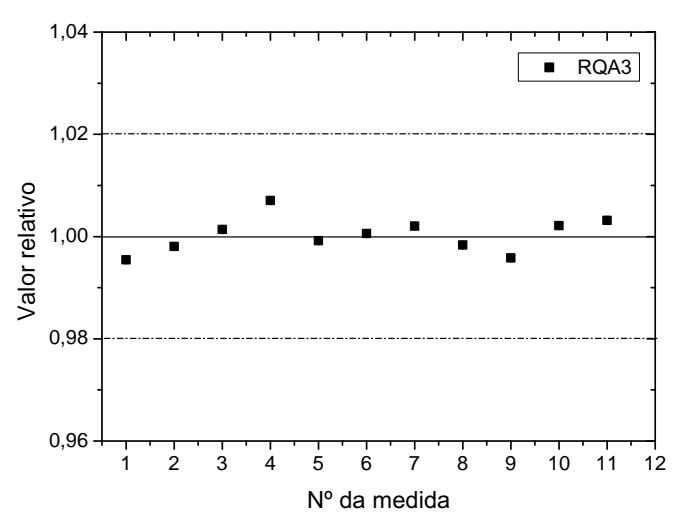

(C) RQA3

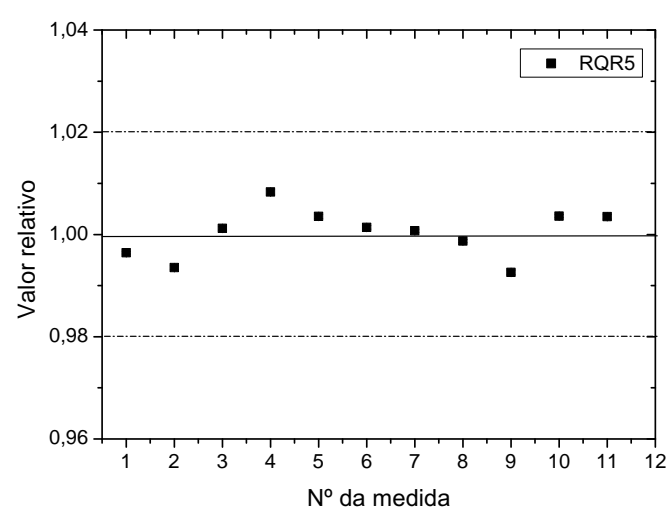

(B) $R Q R 5$

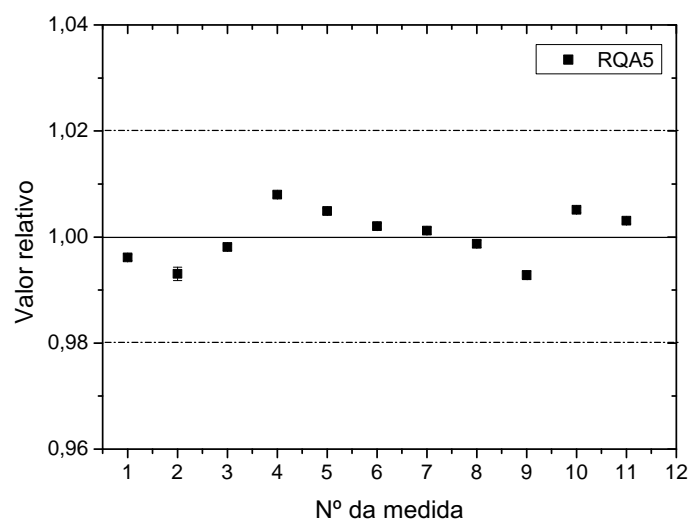

(D) $R Q A 5$

Figura 7.10 - Reprodutibilidade da resposta da câmara $T$ para as qualidades RQR3, RQR5, RQA3 e RQA5 da norma IEC 61267 de 2005 [36]. As incertezas das medições são menores que 0,1\%, o que torna impossível de serem visualizados nos gráficos.

pelas próprias fontes de ${ }^{90} \mathrm{Sr}+{ }^{90} \mathrm{Y}$ e ${ }^{85} \mathrm{Kr}$, calibradas no PTB. No caso da radiação gama, o mapeamento do campo foi realizado previamente com uma câmara de ionização de 1 litro, que é o sistema padrão secundário do LCI, para avaliações em nível de radioproteção. Desta forma, são conhecidos os valores de taxa de kerma no ar para várias distâncias fonte-detector. 


\subsubsection{Transferência do coeficiente de calibração do instru- mento padrão utilizando feixes de radiação $\mathrm{X}$}

Utilizando as qualidades da publicação IEC 1267 de 1994 [35], as câmaras de ionização desenvolvidas foram submetidas ao procedimento de transferência do coeficiente de calibração do instrumento padrão; os coeficientes de equivalência e os fatores de correção obtidos podem ser vistos nas Tabelas 7.5, 7.6 e 7.7

TABela 7.5 - Coeficientes de equivalência e fatores de correção da câmara A para as qualidades de diagnóstico, de acordo com a norma IEC 1267 [35].

\begin{tabular}{c|c|c}
\hline $\begin{array}{c}\text { Qualidade } \\
\text { da } \\
\text { Radiação }\end{array}$ & $\begin{array}{c}\text { Coeficiente } \\
\text { de Equivalência } \\
\left(\text { x10 } \text { Gy.C }^{-1}\right)\end{array}$ & $\begin{array}{c}\text { Fator } \\
\text { de } \\
\text { Correção }\end{array}$ \\
\hline \multicolumn{3}{|c}{ Feixes Diretos } \\
\hline RQR3 & $2,749 \pm 0,022$ & $1,068 \pm 0,012$ \\
RQR4 & $2,639 \pm 0,022$ & $1,025 \pm 0,011$ \\
RQR5 & $2,574 \pm 0,022$ & $1,000 \pm 0,012$ \\
RQR6 & $2,498 \pm 0,021$ & $0,970 \pm 0,011$ \\
RQR7 & $2,417 \pm 0,019$ & $0,939 \pm 0,011$ \\
RQR8 & $2,195 \pm 0,017$ & $0,853 \pm 0,009$ \\
RQR9 & $1,567 \pm 0,012$ & $0,609 \pm 0,012$ \\
RQR10 & $0,945 \pm 0,007$ & $0,367 \pm 0,004$ \\
\hline \multicolumn{3}{|c}{ Feixes Atenuados } \\
\hline RQA3 & $1,113 \pm 0,009$ & $2,738 \pm 0,033$ \\
RQA4 & $0,597 \pm 0,005$ & $1,469 \pm 0,019$ \\
RQA5 & $0,406 \pm 0,003$ & $1,000 \pm 0,012$ \\
RQA6 & $0,304 \pm 0,002$ & $0,748 \pm 0,009$ \\
RQA7 & $0,242 \pm 0,002$ & $0,595 \pm 0,005$ \\
RQA8 & $0,196 \pm 0,001$ & $0,484 \pm 0,006$ \\
RQA9 & $0,136 \pm 0,001$ & $0,335 \pm 0,004$ \\
RQA10 & $0,100 \pm 0,001$ & $0,247 \pm 0,003$ \\
\hline
\end{tabular}

A Figura 7.11 mostra os fatores de correção das câmaras A, G e T.

Utilizando as qualidades de radiodiagnóstico estabelecidas pela norma IEC 61267 de 2005 [36], foram obtidos os coeficientes de equivalência mostrados nas Tabelas 7.8, 7.9 e 7.10 

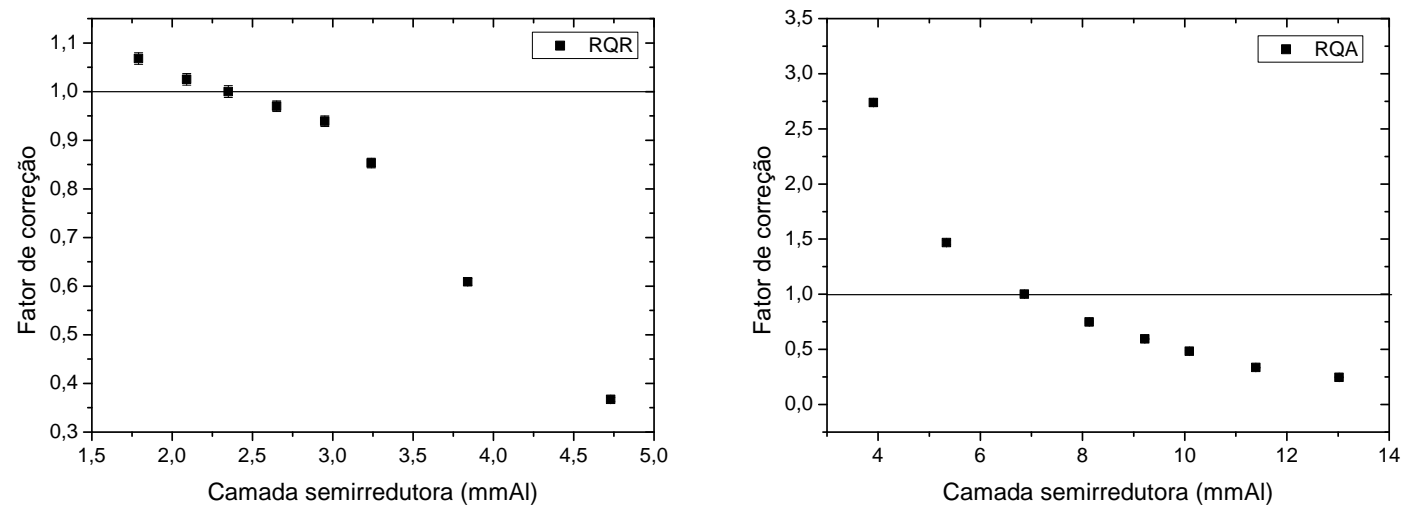

(A) Câmara $A$
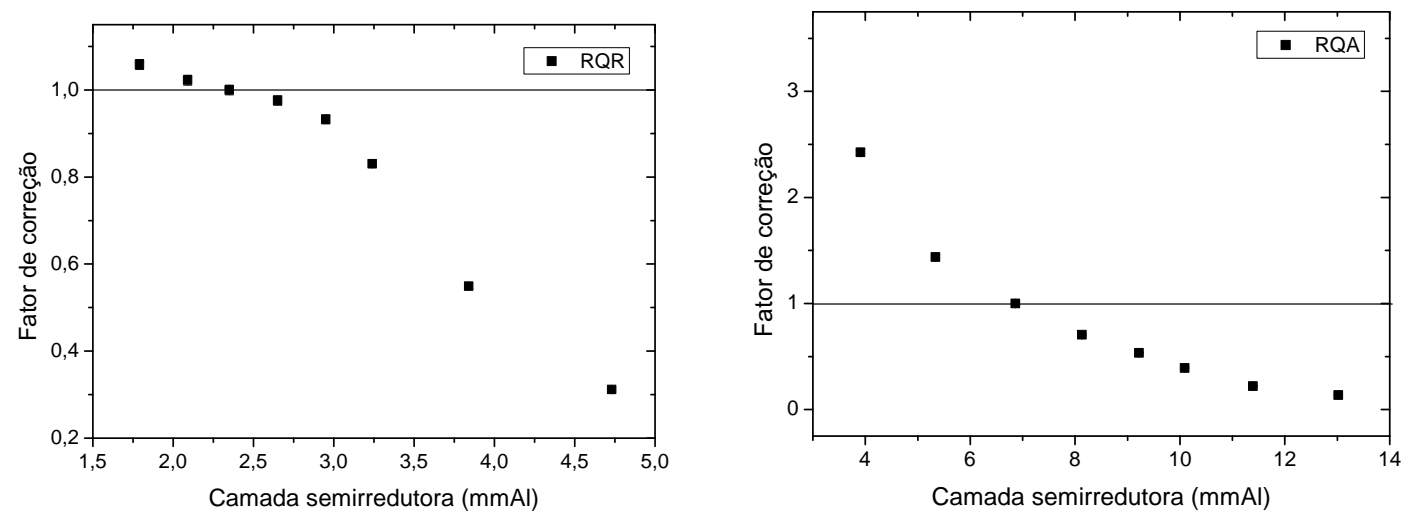

(B) Câmara G
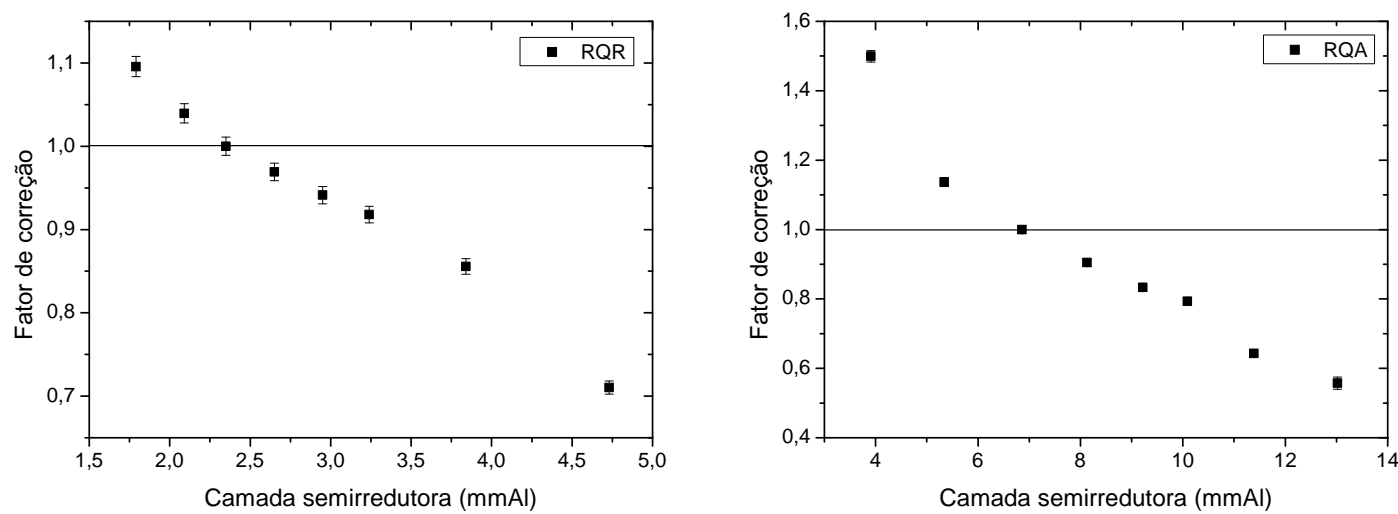

(C) Câmara T

FigurA 7.11 - Fatores de correção das câmaras A, G e T, utilizando as qualidades definidas na norma IEC 1267 de 1994 [35]. 
TABEla 7.6 - Coeficientes de equivalência e fatores de correção da câmara G para as qualidades de diagnóstico, de acordo com a norma IEC 1267 [35].

\begin{tabular}{c|c|c}
\hline $\begin{array}{c}\text { Qualidade } \\
\text { da } \\
\text { Radiação }\end{array}$ & $\begin{array}{c}\text { Coeficiente } \\
\text { de Equivalência } \\
\left(\mathrm{x} 10^{6} \text { Gy.C }{ }^{-1}\right)\end{array}$ & $\begin{array}{c}\text { Fator } \\
\text { de } \\
\text { Correção }\end{array}$ \\
\hline \multicolumn{3}{|c}{ Feixes Diretos } \\
\hline RQR3 & $5,384 \pm 0,042$ & $1,059 \pm 0,012$ \\
RQR4 & $5,200 \pm 0,041$ & $1,022 \pm 0,011$ \\
RQR5 & $5,085 \pm 0,039$ & $1,000 \pm 0,011$ \\
RQR6 & $4,962 \pm 0,038$ & $0,976 \pm 0,011$ \\
RQR7 & $4,742 \pm 0,036$ & $0,932 \pm 0,010$ \\
RQR8 & $4,222 \pm 0,032$ & $0,830 \pm 0,009$ \\
RQR9 & $2,792 \pm 0,022$ & $0,549 \pm 0,006$ \\
RQR10 & $1,584 \pm 0,012$ & $0,312 \pm 0,003$ \\
\hline \multicolumn{3}{|c}{ Feixes Atenuados } \\
\hline RQA3 & $4,287 \pm 0,033$ & $2,425 \pm 0,026$ \\
RQA4 & $2,543 \pm 0,021$ & $1,438 \pm 0,016$ \\
RQA5 & $1,768 \pm 0,014$ & $1,000 \pm 0,011$ \\
RQA6 & $1,246 \pm 0,009$ & $0,705 \pm 0,008$ \\
RQA7 & $0,942 \pm 0,007$ & $0,533 \pm 0,004$ \\
RQA8 & $0,693 \pm 0,005$ & $0,392 \pm 0,004$ \\
RQA9 & $0,388 \pm 0,003$ & $0,219 \pm 0,002$ \\
RQA10 & $0,239 \pm 0,007$ & $0,136 \pm 0,004$ \\
\hline
\end{tabular}

A Figura 7.12 mostra os fatores de correção das câmaras de ionização desenvolvidas utilizando as novas qualidades, nível radiodiagnóstico, obtidas para as câmaras A, G e T. 
TABEla 7.7 - Coeficientes de equivalência e fatores de correção da câmara T para as qualidades de diagnóstico, de acordo com a norma IEC 1267 [35].

\begin{tabular}{c|c|c}
\hline $\begin{array}{c}\text { Qualidade } \\
\text { da } \\
\text { Radiação }\end{array}$ & $\begin{array}{c}\text { Coeficiente } \\
\text { de Equivalência } \\
\left(\mathrm{x} 10^{5} \text { Gy.C }{ }^{-1}\right)\end{array}$ & $\begin{array}{c}\text { Fator } \\
\text { de } \\
\text { Correção }\end{array}$ \\
\hline \multicolumn{3}{|c}{ Feixes Diretos } \\
\hline RQR3 & $20,006 \pm 0,156$ & $1,096 \pm 0,012$ \\
RQR4 & $18,979 \pm 0,149$ & $1,039 \pm 0,011$ \\
RQR5 & $18,257 \pm 0,142$ & $1,000 \pm 0,011$ \\
RQR6 & $17,695 \pm 0,137$ & $0,969 \pm 0,011$ \\
RQR7 & $17,186 \pm 0,132$ & $0,941 \pm 0,010$ \\
RQR8 & $16,758 \pm 0,128$ & $0,918 \pm 0,010$ \\
RQR9 & $15,621 \pm 0,121$ & $0,856 \pm 0,009$ \\
RQR10 & $12,968 \pm 0,100$ & $0,710 \pm 0,008$ \\
\hline \multicolumn{3}{|c}{ Feixes Atenuados } \\
\hline RQA3 & $1,539 \pm 0,012$ & $1,500 \pm 0,016$ \\
RQA4 & $1,167 \pm 0,009$ & $1,137 \pm 0,013$ \\
RQA5 & $1,027 \pm 0,008$ & $1,000 \pm 0,011$ \\
RQA6 & $0,929 \pm 0,007$ & $0,905 \pm 0,010$ \\
RQA7 & $0,855 \pm 0,006$ & $0,833 \pm 0,006$ \\
RQA8 & $0,814 \pm 0,006$ & $0,794 \pm 0,009$ \\
RQA9 & $0,659 \pm 0,005$ & $0,643 \pm 0,007$ \\
RQA10 & $0,572 \pm 0,018$ & $0,557 \pm 0,018$ \\
\hline
\end{tabular}

Com relação às qualidades de mamografia os resultados da transferência do coeficiente de calibração do instrumento padrão para as câmaras de ionização monitoras desenvolvidas podem ser vistos nas Tabelas $7.11,7.12$ e 7.13 e na Figura 7.13 . 
TABela 7.8 - Coeficientes de equivalência e fatores de correção da câmara $A$ para as qualidades de diagnóstico, de acordo com a norma IEC 61267 [36].

\begin{tabular}{|c|c|c|}
\hline $\begin{array}{l}\text { Qualidade } \\
\text { da } \\
\text { Radiação }\end{array}$ & $\begin{array}{c}\text { Coeficiente } \\
\text { de Equivalência } \\
\left(\mathrm{x} 10^{4} \mathrm{~Gy}^{\left.-\mathrm{C}^{-1}\right)}\right.\end{array}$ & $\begin{array}{l}\text { Fator } \\
\text { de } \\
\text { Correção }\end{array}$ \\
\hline \multicolumn{3}{|c|}{ Feixes Diretos } \\
\hline RQR3 & $58,775 \pm 1,441$ & $0,957 \pm 0,035$ \\
\hline RQR5 & $61,426 \pm 1,653$ & $1,000 \pm 0,038$ \\
\hline RQR8 & $57,578 \pm 0,812$ & $0,937 \pm 0,019$ \\
\hline RQR10 & $36,307 \pm 0,391$ & $0,591 \pm 0,011$ \\
\hline \multicolumn{3}{|c|}{ Feixes Atenuados } \\
\hline RQA3 & $5,189 \pm 0,147$ & $1,864 \pm 0,058$ \\
\hline RQA5 & $2,784 \pm 0,037$ & $1,000 \pm 0,019$ \\
\hline RQA8 & $2,264 \pm 0,036$ & $0,813 \pm 0,017$ \\
\hline RQA10 & $0,0018 \pm 0,000$ & $0,001 \pm 0,000$ \\
\hline
\end{tabular}

TABela 7.9 - Coeficientes de equivalência e fatores de correção da câmara G para as qualidades de diagnóstico, de acordo com a norma IEC 61267 [36].

\begin{tabular}{c|c|c}
\hline $\begin{array}{c}\text { Qualidade } \\
\text { da } \\
\text { Radiação }\end{array}$ & $\begin{array}{c}\text { Coeficiente } \\
\text { de Equivalência } \\
\left(\text { x10 }^{5} \text { Gy.C }^{-1}\right)\end{array}$ & $\begin{array}{c}\text { Fator } \\
\text { de } \\
\text { Correção }\end{array}$ \\
\hline \multicolumn{3}{|c}{ Feixes Diretos } \\
\hline RQR3 & $52,239 \pm 0,414$ & $1,116 \pm 0,012$ \\
RQR5 & $46,786 \pm 0,379$ & $1,000 \pm 0,011$ \\
RQR8 & $35,765 \pm 0,282$ & $0,764 \pm 0,011$ \\
RQR10 & $11,819 \pm 0,092$ & $0,253 \pm 0,003$ \\
\hline \multicolumn{3}{c}{ Feixes Atenuados } \\
\hline RQA3 & $3,362 \pm 0,029$ & $2,104 \pm 0,026$ \\
RQA5 & $1,598 \pm 0,014$ & $1,000 \pm 0,012$ \\
RQA8 & $1,077 \pm 0,009$ & $0,674 \pm 0,008$ \\
RQA10 & - & - \\
\hline
\end{tabular}


TABEla 7.10 - Coeficientes de equivalência e fatores de correção da câmara $T$ para as qualidades de diagnóstico, de acordo com a norma IEC 61267 [36].

\begin{tabular}{c|c|c}
\hline $\begin{array}{c}\text { Qualidade } \\
\text { da } \\
\text { Radiação }\end{array}$ & $\begin{array}{c}\text { Coeficiente } \\
\text { de Equivalência } \\
\left(\mathrm{x} 10^{3} \text { Gy.C }{ }^{-1}\right)\end{array}$ & $\begin{array}{c}\text { Fator } \\
\text { de } \\
\text { Correção }\end{array}$ \\
\hline \multicolumn{3}{c}{ Feixes Diretos } \\
\hline RQR3 & $76,237 \pm 0,599$ & $1,069 \pm 0,012$ \\
RQR5 & $71,272 \pm 0,596$ & $1,000 \pm 0,012$ \\
RQR8 & $66,497 \pm 0,517$ & $0,933 \pm 0,011$ \\
RQR10 & $57,520 \pm 0,443$ & $0,807 \pm 0,009$ \\
\hline \multicolumn{3}{c}{ Feixes Atenuados } \\
\hline RQA3 & $5,492 \pm 0,051$ & $1,929 \pm 0,024$ \\
RQA5 & $2,847 \pm 0,023$ & $1,000 \pm 0,012$ \\
RQA8 & $2,416 \pm 0,019$ & $0,848 \pm 0,010$ \\
RQA10 & $2,692 \pm 0,021$ & $0,946 \pm 0,011$ \\
\hline
\end{tabular}




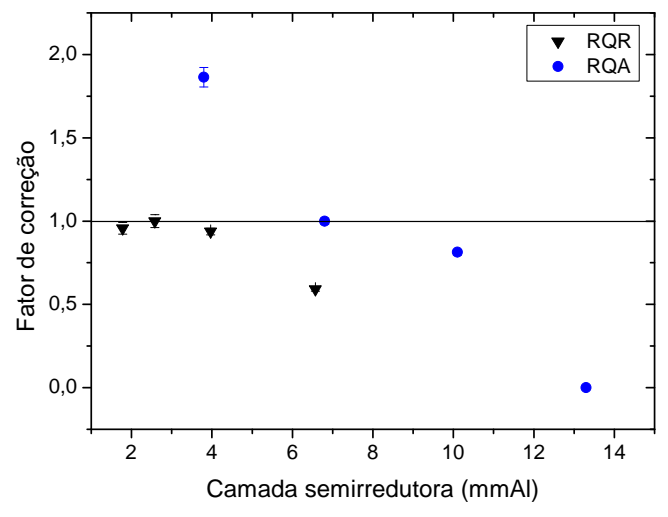

(A) Câmara $A$

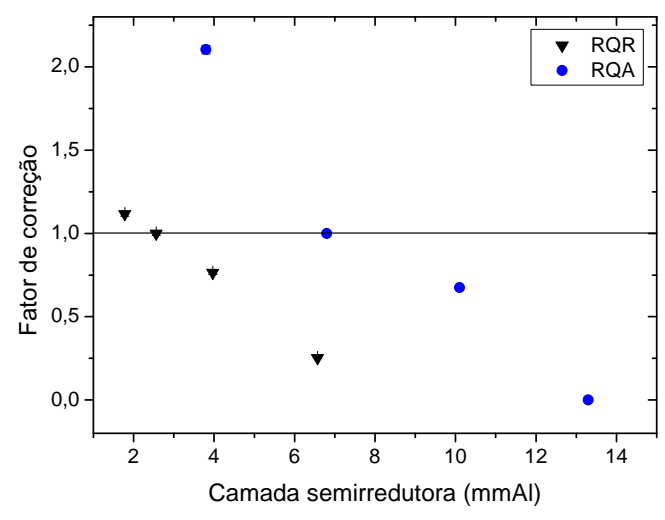

(B) Câmara G

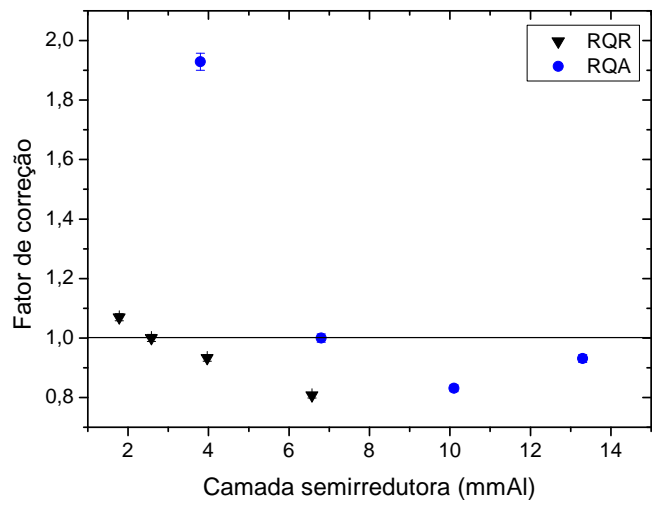

(C) Câmara T

Figura 7.12 - Fatores de correção das câmaras A, G e T, utilizando as novas qualidades definidas na norma IEC 61267 de 2005 [36]. 
TABela 7.11 - Coeficientes de equivalência e fatores de correção da câmara A para as qualidades de mamografia, de acordo com as qualidades de radiação definidas pelo PTB [54].

\begin{tabular}{c|c|c}
\hline $\begin{array}{c}\text { Qualidade } \\
\text { da } \\
\text { Radiação }\end{array}$ & $\begin{array}{c}\text { Coeficiente } \\
\text { de Equivalência } \\
\left(\mathrm{x} 10^{5} \text { Gy.C }{ }^{-1}\right)\end{array}$ & $\begin{array}{c}\text { Fator } \\
\text { de } \\
\text { Correção }\end{array}$ \\
\hline WMV25 & $4,777 \pm 0,464$ & $0,946 \pm 0,108$ \\
WMV28 & $5,046 \pm 0,304$ & $1,000 \pm 0,085$ \\
WMV30 & $4,896 \pm 0,292$ & $0,970 \pm 0,084$ \\
WMV35 & $4,777 \pm 0,215$ & $0,946 \pm 0,073$ \\
\hline
\end{tabular}

TABela 7.12 - Coeficientes de equivalência e fatores de correção da câmara G para as qualidades de mamografia, de acordo com qualidade de radiação definidas pelo PTB [54].

\begin{tabular}{c|c|c}
\hline $\begin{array}{c}\text { Qualidade } \\
\text { da } \\
\text { Radiação }\end{array}$ & $\begin{array}{c}\text { Coeficiente } \\
\text { de Equivalência } \\
\left(\text { x10 } \text { Gy.C }^{-1}\right)\end{array}$ & $\begin{array}{c}\text { Fator } \\
\text { de } \\
\text { Correção }\end{array}$ \\
\hline WMV25 & $10,741 \pm 0,105$ & $1,109 \pm 0,015$ \\
WMV28 & $9,682 \pm 0,095$ & $1,000 \pm 0,014$ \\
WMV30 & $9,098 \pm 0,088$ & $0,939 \pm 0,014$ \\
WMV35 & $7,990 \pm 0,077$ & $0,825 \pm 0,012$ \\
\hline
\end{tabular}

TABELA 7.13 - Coeficientes de equivalência e fatores de correção da câmara $T$ para as qualidades de mamografia, de acordo com as qualidades de radiação definidas pelo PTB [54].

\begin{tabular}{c|c|c}
\hline $\begin{array}{c}\text { Qualidade } \\
\text { da } \\
\text { Radiação }\end{array}$ & $\begin{array}{c}\text { Coeficiente } \\
\text { de Equivalência } \\
\left(\text { x10 } \text { Gy.C }^{-1}\right)\end{array}$ & $\begin{array}{c}\text { Fator } \\
\text { de } \\
\text { Correção }\end{array}$ \\
\hline WMV25 & $8,274 \pm 0,083$ & $1,009 \pm 0,014$ \\
WMV28 & $8,196 \pm 0,078$ & $1,000 \pm 0,014$ \\
WMV30 & $8,151 \pm 0,079$ & $0,994 \pm 0,014$ \\
WMV35 & $8,029 \pm 0,077$ & $0,979 \pm 0,014$ \\
\hline
\end{tabular}




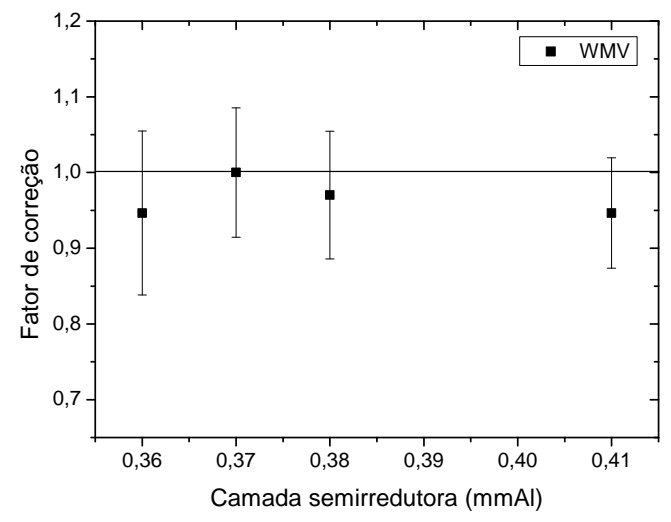

(A) Câmara $A$

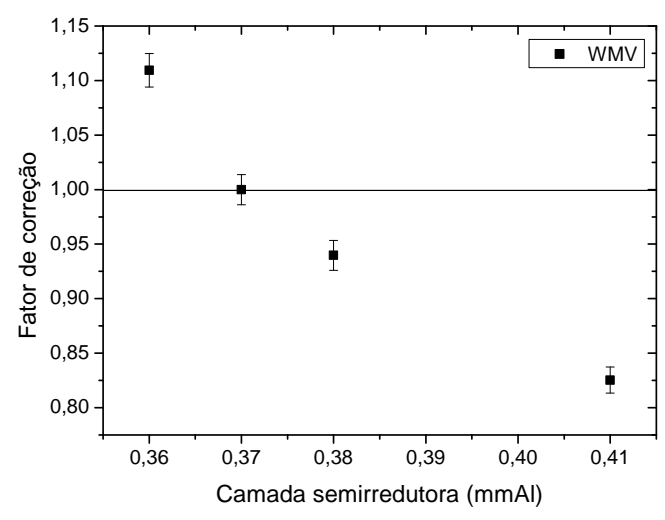

(B) Câmara G

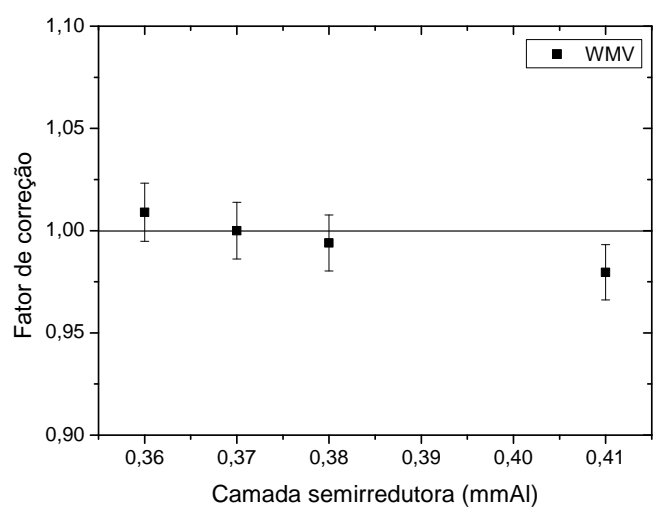

(C) Câmara T

Figura 7.13 - Fatores de correção das câmaras A, G e T, utilizando as qualidades de mamografia recomendadas pelo PTB [54].

Pela Figura 7.11 pode-se observar que as câmaras monitoras apresentam uma dependência energética muito alta, podendo os resultados serem expressos por fatores multiplicativos em alguns casos. Para as qualidades RQR, estes fatores multiplicativos indicadores da dependência energética foram de 2,9 para a câmara A, 3,4 para a câmara G e 1,5 para a câmara T; para as qualidades RQA, foram de 11 para a câmara A, 18 para a câmara G e 2,7 para a câmara T. Provavelmente, este fato ocorreu pela falta de homogeneidade na construção das câmaras de 
ionização 31], lembrando que o intuito deste trabalho era o de desenvolver câmaras de ionização simples e de baixo custo, mas com um bom desempenho. Essa falta de homogeneidade diz respeito tanto a impurezas nos materiais utilizados, pois as câmaras de ionização foram feitas com materiais comuns disponíveis no mercado, quanto à própria construção das câmaras, que foram feitas artesanalmente e, apesar de todos os cuidados tomados, podem ter ocorrido possíveis rugosidades na janela de entrada e imperfeições no encaixe de algumas peças.

Por outro lado, a dependência energética deste tipo de câmara de ionização apresenta uma importância relativa, pois a câmara monitora tem a função de "monitorar" a intensidade do feixe para cada qualidade de radiação e não de medir a dose de um campo desconhecido. A característica de maior importância neste tipo de câmara de ionização é a estabilidade da resposta, que se mostrou excelente nas câmaras G e T, tanto utilizando uma fonte de controle quanto um feixe de raios $\mathrm{X}$.

Com as novas qualidades, nível radiodiagnóstico, os fatores multiplicativos indicadores da dependência energética foram de: 1,7, 4,4 e 1,3 para as câmaras A, G e T, respectivamente, para as qualidades RQR. Para as qualidades RQA, a dependência energética não foi mensurada para as câmaras A e G, sendo seu valor muito alto para essas câmaras de ionização, pois o fator de correção para a qualidade de feixe RQA10 foi próximo de zero. A câmara T apresentou um fator multiplicativo indicador da dependência energética de 2,3. Pelos resultados obtidos é possível notar uma diminuição da dependência energética da câmara T com relação às câmaras anelares, em todos os feixes de radiodiagnóstico estudados. Possivelmente isso ocorreu devido ao fato da câmara T ser posicionada diretamente no feixe de radiação enquanto que as câmaras anelares medem a intensidade da radiação somente na região de penumbra do feixe.

Pela Figura 7.13 observa-se que a dependência energética das câmaras de ionização A, G e T para os feixes de mamografia é de 5\%, 18\% e 2\%, respectivamente. Comparando esses resultados com os obtidos nos feixes de diagnóstico, a dependência 
energética das câmaras de ionização desenvolvidas para os feixes de mamografia foi menor.

\subsubsection{Calibração em feixes de radiação beta e gama}

Apesar de as câmaras de ionização monitoras terem sido desenvolvidas para utilização específica em feixes de radiação X, foi realizada a calibração dessas câmaras de ionização também em feixes de radiação beta e gama, utilizando os irradiadores descritos nas Tabelas 4.6 e 4.7. O intuito destas calibrações foi somente para um melhor conhecimento das características das câmaras, pois as fontes radioativas, uma vez calibradas, não necessitam de monitoramento como os feixes de radiação X. Apesar disso, estas câmaras podem ter uma utilidade na verificação do espalhamento dos feixes de radiação gama, nos procedimentos de dosimetria de feixes, que é realizada periodicamente no LCI.

Utilizando o sistema de radiação beta foi possível determinar os coeficientes de calibração das câmaras de ionização desenvolvidas para o intervalo de energia de $60 \mathrm{keV}$ a $800 \mathrm{keV}$, como mostrado na Tabela 7.14 e na Figura 7.14.

TABela 7.14 - Coeficientes de calibração das câmaras desenvolvidas para feixes de radiação beta.

\begin{tabular}{c|c|c|c}
\hline \multicolumn{4}{c}{ Coeficientes de calibração } \\
$\left(\mu\right.$ Gy.nC $\left.C^{-1}\right)$ \\
\hline Câmara & ${ }^{90} \mathrm{Sr}+{ }^{90} \mathrm{Y}$ & ${ }^{85} \mathrm{Kr}$ & ${ }^{147} \mathrm{Pm}$ \\
\hline $\mathrm{A}$ & $87,64 \pm 3,22$ & $105,64 \pm 1,45$ & $173,71 \pm 2,34$ \\
$\mathrm{G}$ & $197,98 \pm 3,38$ & $223,66 \pm 3,22$ & $373,79 \pm 2,35$ \\
$\mathrm{~T}$ & $380,29 \pm 2,40$ & $455,65 \pm 2,73$ & $1239,35 \pm 16,25$ \\
\hline
\end{tabular}

Utilizando o irradiador gama foi verificada a resposta das câmaras para as fontes de ${ }^{60} \mathrm{Co}$ e ${ }^{137} \mathrm{Cs}$. As câmaras de ionização foram posicionadas a $100 \mathrm{~cm}$ das fontes de radiação. Os coeficientes de calibração obtidos podem ser vistos na Tabela 7.15

Pelas Tabelas 7.14 e 7.15 é possível verificar que a resposta das câmaras de ionização desenvolvidas apresenta uma dependência energética alta tanto para 


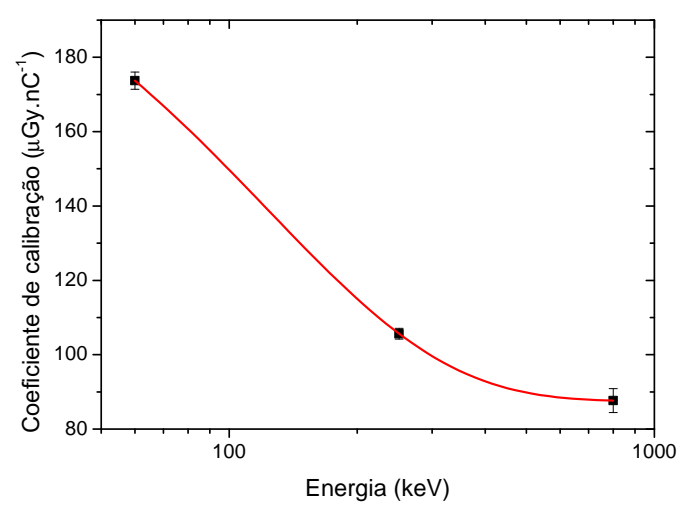

(A) Câmara $A$

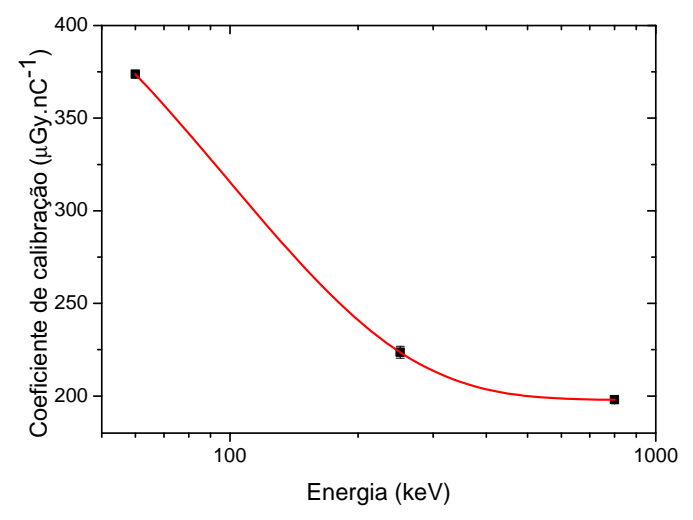

(B) Câmara $G$

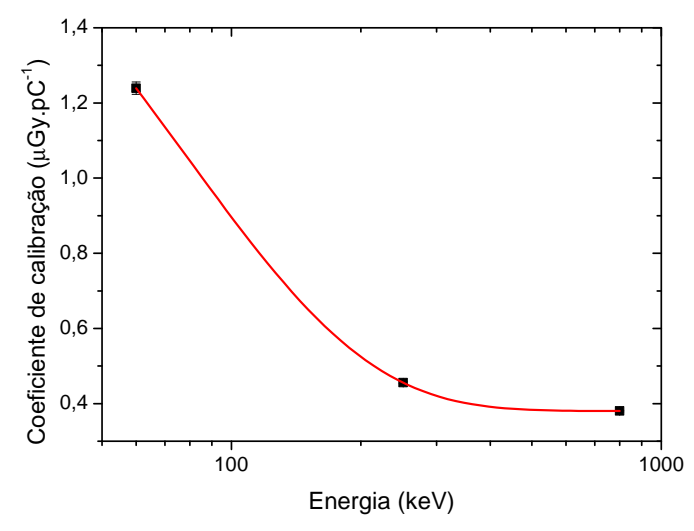

(C) Câmara T

FIgURA 7.14 - Dependência energética das câmaras A, G e T utilizando feixes de radiação beta.

TABEla 7.15 - Coeficientes de calibração para as fontes de radiação gama.

\begin{tabular}{c|c|c}
\hline \multicolumn{3}{c}{$\begin{array}{c}\text { Coeficientes de calibração } \\
\left(\mu G y \cdot p C^{-1}\right)\end{array}$} \\
\hline Câmara & ${ }^{60} \mathrm{Co}$ & ${ }^{137} \mathrm{Cs}$ \\
\hline A & $0,0695 \pm 0,0001$ & $0,0364 \pm 0,0012$ \\
G & $0,4556 \pm 0,0007$ & $0,3013 \pm 0,0014$ \\
T & $0,6847 \pm 0,0006$ & $0,5116 \pm 0,0011$ \\
\hline
\end{tabular}


radiação beta, com fatores multiplicativos indicadores de 2, 1,9 e 3,2, para as câmaras A, G e T, respectivamente, quanto para radiação gama: 1,9, 1,5 e 1,3, respectivamente).

Como a fonte de ${ }^{90} \mathrm{Sr}+{ }^{90} \mathrm{Y}$ do sistema padrão possui certificado de calibração para várias distâncias fonte-detector, foi feito um estudo da resposta das câmaras para estas diferentes distâncias. O resultado pode ser visto na Figura 7.15.

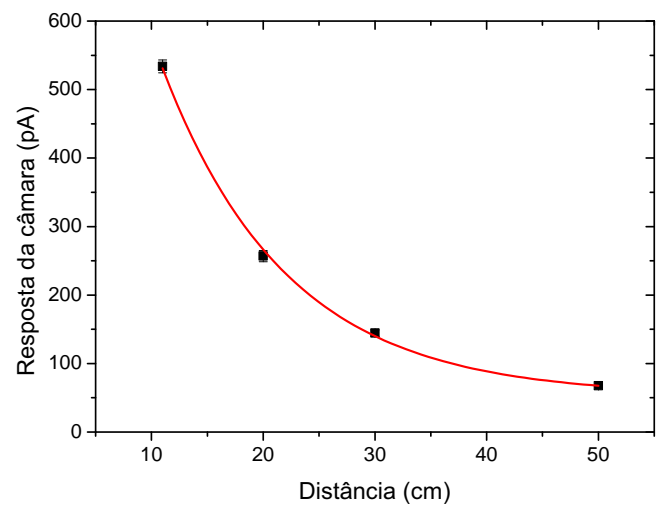

(A) Câmara $A$

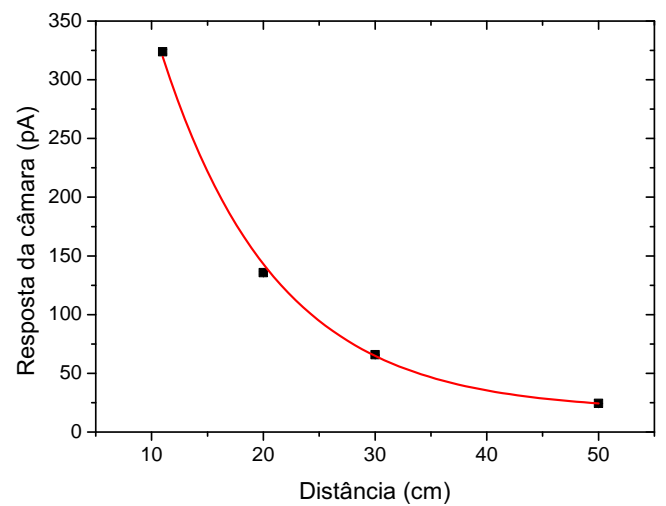

(B) Câmara $G$

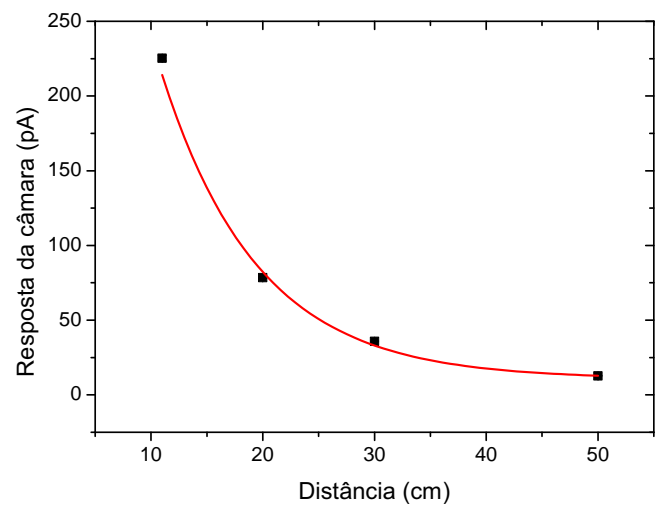

(C) Câmara $T$

Figura 7.15 - Dependência com a distância da fonte da resposta das câmaras A, G e T utilizando feixes de radiação beta $\left({ }^{90} \mathrm{Sr}+{ }^{90} \mathrm{Y}\right)$. As incertezas das medições são menores que 3,3\%, não sendo possível visualizá-las nos gráficos. 
Pela Figura 7.15 observa-se que, neste caso, a lei do inverso do quadrado da distância não foi seguida, pois o volume sensível das câmaras de ionização desenvolvidas não são irradiadas completamente. Dessa forma, com o aumento da distância fonte-detector a área irradiada do volume sensível aumenta também.

\subsection{Comparação entre as Câmaras de Ionização Desenvolvidas e as Câmaras Comerciais}

As câmaras de ionização anelares A e G foram desenvolvidas para substituir por ex. a câmara de ionização Farmer utilizada como câmara monitora. Todas essas câmaras de ionização fazem medições somente na região de penumbra do feixe de radiação; as câmaras de ionização desenvolvidas apresentam a vantagem de poderem ser posicionadas no banco óptico do sistema de radiação X e serem mantidas fixas naquela posição. O desempenho deste tipo de câmara de ionização não pode ser comparado com o desempenho de uma câmara de transmissão, pois esta intercepta toda a seção reta do feixe de radiação. Para a comparação com este tipo de câmara de ionização foi desenvolvida a câmara T, que apresenta características geométricas semelhantes.

O objetivo deste trabalho era desenvolver câmaras de ionização monitoras de baixo custo, utilizando materiais disponíveis no mercado, mas cujo desempenho fosse igual ou superior às câmaras de ionização monitoras comerciais. Assim, para verificar se este objetivo foi alcançado, os resultados obtidos com as câmaras de ionização comerciais e desenvolvidas foram comparados e podem ser vistos nas Tabelas 7.16 e 7.17

Pelos valores apresentados na Tabela 7.16, pode-se perceber que o desempenho de todas as câmaras de ionização apresentadas são equiparáveis, exceto para a reprodutibilidade utilizando o sistema de radiação X. Este resultado é de grande relevância, pois esta é a característica mais importante nestas câmaras de ionização monitoras. Como estas câmaras de ionização são utilizadas para monitorar a 
TABela 7.16 - Comparação do desempenho entre as câmaras de ionização Farmer, A e G. Os valores em vermelho indicam resultados fora dos limites recomendados pela norma IEC 61674 [51].

\begin{tabular}{|c|c|c|c|c|c|}
\hline \multicolumn{2}{|c|}{$\begin{array}{c}\text { Testes de } \\
\text { Caracterização }\end{array}$} & $\begin{array}{l}\text { Recomendação } \\
\text { IEC } 61674 \text { 51 }\end{array}$ & $\begin{array}{l}\text { Câmara } \\
\text { Farmer }\end{array}$ & $\begin{array}{c}\text { Câmara } \\
\text { A }\end{array}$ & $\begin{array}{c}\text { Câmara } \\
\text { G }\end{array}$ \\
\hline \multirow{2}{*}{\multicolumn{2}{|c|}{$\begin{array}{l}\text { Saturação } \\
\text { Polaridade }\end{array}$}} & Saturação & Sim & Sim & Sim \\
\hline & & - & $<0,5 \%$ & $<1 \%$ para tensões & $<0,4 \%$ \\
\hline \multicolumn{2}{|c|}{ Coleção de íons } & $>95 \%$ & $>99 \%$ & $>99 \%$ & $>99 \%$ \\
\hline \multicolumn{2}{|c|}{ Linearidade } & Linear & $\mathrm{R}>0,999$ & $\mathrm{R}>0,999$ & $\mathrm{R}=1,000$ \\
\hline \multirow{2}{*}{\multicolumn{2}{|c|}{$\begin{array}{c}\text { Testes de } \\
\text { Estabilidade }\end{array}$}} & Recomendação & Câmara & Câmara & Câmara \\
\hline & & IEC 61674 51 & Farmer & A & G \\
\hline & & \multicolumn{4}{|c|}{ Variações máximas } \\
\hline \multirow{4}{*}{ 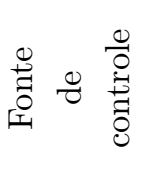 } & Estabilização & $2 \%$ & $0,37 \%$ & $1,82 \%$ & $0,14 \%$ \\
\hline & Corrente de fuga & $5 \%$ & $0,10 \%$ & $0,59 \%$ & $0,21 \%$ \\
\hline & Repetitividade & $3 \%$ & $0,1 \%$ & $0,4 \%$ & $0,5 \%$ \\
\hline & Reprodutibilidade & $2 \%$ & $0,9 \%$ & $1,0 \%$ & $0,6 \%$ \\
\hline \multirow{2}{*}{.} & Repetitividade & $3 \%$ & $0,4 \%$ & $1,1 \%$ & $0,6 \%$ \\
\hline & Reprodutibilidade & $2 \%$ & $5,5 \%$ & $4,2 \%$ & $1,3 \%$ \\
\hline
\end{tabular}

intensidade do feixe de radiação X, é muito importante que suas respostas sejam reprodutíveis nestes feixes de radiação. Assim, somente a câmara G apresentou variações aceitáveis dentro dos limites recomendados internacionalmente pela norma IEC 61674 [51].

Pode-se verificar que as câmaras de ionização de transmissão e T apresentaram desempenhos muito parecidos. Para todos os testes realizados, os resultados de ambas as câmaras de ionização foram dentro dos limites recomendados pela norma IEC 61674 [51].

Comparando o desempenho entre as câmaras de ionização desenvolvidas e as comerciais verifica-se que a câmara G pode substituir a câmara Farmer com vantagens, e que a câmara $\mathrm{T}$ pode substituir a câmara de transmissão sem perda de qualidade. Além disso, pode-se concluir que mesmo a câmara G pode substituir 
TABEla 7.17 - Comparação do desempenho entre as câmaras de ionização de transmissão e $T$.

\begin{tabular}{|c|c|c|c|c|}
\hline \multicolumn{2}{|c|}{$\begin{array}{c}\text { Testes de } \\
\text { Caracterização }\end{array}$} & $\begin{array}{l}\text { Recomendação } \\
\text { IEC } 61674 \mid 51\end{array}$ & $\begin{array}{l}\text { Câmara de } \\
\text { Transmissão }\end{array}$ & $\begin{array}{c}\text { Câmara } \\
\mathrm{T}\end{array}$ \\
\hline \multicolumn{2}{|c|}{ Saturação } & Saturação & Sim & Sim \\
\hline \multicolumn{2}{|r|}{ Polaridade } & - & $<0,7 \%$ & $<0,01 \%$ \\
\hline \multicolumn{2}{|c|}{ Coleção de íons } & $>95 \%$ & $>99 \%$ & $>99 \%$ \\
\hline \multicolumn{2}{|c|}{ Linearidade } & Linear & $\mathrm{R}=1,000$ & $\mathrm{R}>0,999$ \\
\hline \multirow{2}{*}{\multicolumn{2}{|c|}{$\begin{array}{c}\text { Testes de } \\
\text { Estabilidade }\end{array}$}} & Recomendação & Câmara de & Câmara \\
\hline & & IEC 6167451 & Transmissão & $\mathrm{T}$ \\
\hline & & \multicolumn{3}{|c|}{ Variações máximas } \\
\hline \multirow{4}{*}{ 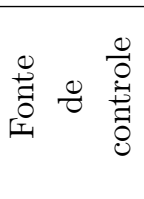 } & Estabilização & $2 \%$ & - & $0,98 \%$ \\
\hline & Corrente de fuga & $5 \%$ & $1,7 \%$ & $0,10 \%$ \\
\hline & Repetitividade & $3 \%$ & $0,3 \%$ & $0,9 \%$ \\
\hline & Reprodutibilidade & $2 \%$ & $1,3 \%$ & $1,1 \%$ \\
\hline \multirow{2}{*}{. } & Repetitividade & $3 \%$ & $0,1 \%$ & $0,5 \%$ \\
\hline & Reprodutibilidade & $2 \%$ & $0,7 \%$ & $0,8 \%$ \\
\hline
\end{tabular}

a câmara de transmissão apresentando a vantagem de não interferir no espectro do feixe de radiação.

\subsection{Estabelecimento de um Sistema Tandem para Avaliação das Camadas Semirredutoras}

O sistema tandem tem sido utilizado há muito tempo e é composto por dois dosímetros distintos, principalmente dosímetros termoluminescentes [58, 59]. Por serem distintos, estes dosímetros apresentam diferentes dependências energéticas. Esta característica pode ser utilizada para se determinar a energia efetiva de um feixe de radiação, ou no caso de feixes de radiação $\mathrm{X}$, a camada semirredutora. Outros tipos de dosímetros podem ser utilizados em sistema tandem [12, 19], desde que a relação entre suas respostas para diferentes energias de radiação seja determinada e unívoca. 
A determinação da camada semirredutora pelo método convencional é um procedimento trabalhoso e demorado. Para isso são realizadas diversas medições da taxa de kerma no ar com filtros de diferentes espessuras entre o tubo de radiação X e o detector. Por método gráfico, obtém-se a espessura de material que reduz a intensidade do feixe de radiação pela metade do valor inicial. A verificação da constância da energia efetiva do feixe de radiação, por meio da camada semirredutora, é um dos testes que pode ser feito para o controle da garantia da qualidade em um serviço clínico onde se utiliza este tipo de radiação. Uma forma muito mais prática de se fazer essa verificação é pelo uso de um sistema tandem.

As câmaras G e T apresentam diferentes dependências energéticas e, para verificar se elas podem constituir um sistema tandem, foi calculada a razão entre suas respostas para as qualidades de radiação RQR, RQA e WMV, como mostrado na Tabela 7.18. A partir dos valores das razões entre as respostas das câmaras G e T obtidos, foram feitos os gráficos apresentados na Figura 7.16 .

Quanto maior a inclinação da curva tandem, é mais fácil diferenciar valores próximos de CSR. Pode-se observar que alguns valores de camada semirredutora das qualidades RQR e RQA se sobrepõem, mas a razão entre as respostas das câmaras G e T não são iguais. Deve-se lembrar, porém, que as condições de irradiação são muito distintas entre essas qualidades, como mostrado na Figura 4.2. Portanto, os feixes de radiação, mesmo com valores iguais de camada semirredutora, não podem, neste caso, serem considerados com mesma energia efetiva na posição das câmaras monitoras.

Utilizando os feixes de radiação, nível mamografia, a curva tandem obtida para as câmaras G e T apresenta uma inclinação ótima, podendo então, constituir um sistema tandem.

Esse sistema tandem foi proposto aqui neste trabalho porque representa uma maneira muito mais prática de verificar a constância da qualidade da radiação por meio da camada semirredutora. Deve-se lembrar porém, que este sistema não deverá 
TABELA 7.18 - Respostas e razão entre as respostas das câmaras G e T para qualidades de radiação $R Q R$ e $R Q A$, nível radiodiagnóstico [36], e WMV, nível mamografia [54].

\begin{tabular}{|c|c|c|c|}
\hline $\begin{array}{c}\text { Qualidade } \\
\text { da } \\
\text { Radiação }\end{array}$ & $\begin{array}{c}\text { Resposta da } \\
\text { Câmara G } \\
\left(\times 10^{-9} \mathrm{C}\right)\end{array}$ & $\begin{array}{c}\text { Resposta da } \\
\text { Câmara T } \\
\left(\times 10^{-9} \mathrm{C}\right)\end{array}$ & $\begin{array}{c}\text { Razão entre } \\
\text { as Respostas } \\
(\mathrm{G} / \mathrm{T})\end{array}$ \\
\hline RQR3 & $2,1748 \pm 0,0038$ & $147,604 \pm 0,098$ & $0,01473 \pm 0,00003$ \\
\hline RQR5 & $4,1778 \pm 0,0012$ & $271,981 \pm 0,131$ & $0,01536 \pm 0,00001$ \\
\hline RQR8 & $9,7076 \pm 0,0143$ & $523,854 \pm 0,217$ & $0,01853 \pm 0,00003$ \\
\hline RQR10 & $51,1540 \pm 0,0124$ & $1047,558 \pm 0,217$ & $0,04920 \pm 0,00002$ \\
\hline RQA3 & $5,0081 \pm 0,0013$ & $296,182 \pm 0,149$ & $0,01691 \pm 0,00001$ \\
\hline RQA5 & $10,1281 \pm 0,0021$ & $546,541 \pm 0,104$ & $0,01853 \pm 0,00001$ \\
\hline RQA8 & $24,1648 \pm 0,0981$ & $1051,821 \pm 0,261$ & $0,02297 \pm 0,00001$ \\
\hline RQA10 & $115,1014 \pm 0,0983$ & $2109,732 \pm 1,276$ & $0,05456 \pm 0,00005$ \\
\hline WMV25 & $0,4704 \pm 0,0002$ & $60,658 \pm 0,015$ & $0,00775 \pm 0,00001$ \\
\hline WMV28 & $0,8491 \pm 0,0001$ & $76,114 \pm 0,025$ & $0,00853 \pm 0,00001$ \\
\hline WMV30 & $0,7806 \pm 0,0002$ & $86,578 \pm 0,013$ & $0,00902 \pm 0,00001$ \\
\hline WMV35 & $1,1566 \pm 0,0011$ & $114,133 \pm 0,107$ & $0,01013 \pm 0,00001$ \\
\hline
\end{tabular}

ser utilizado para determinar a camada semirredutora de um feixe de radiação desconhecido. 


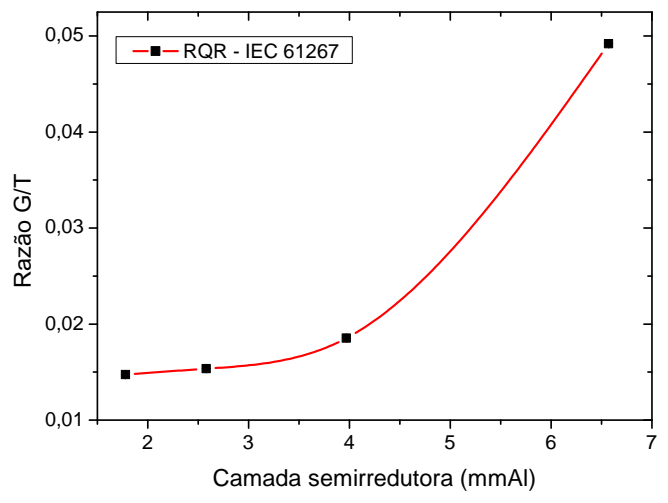

(A) $R Q R$

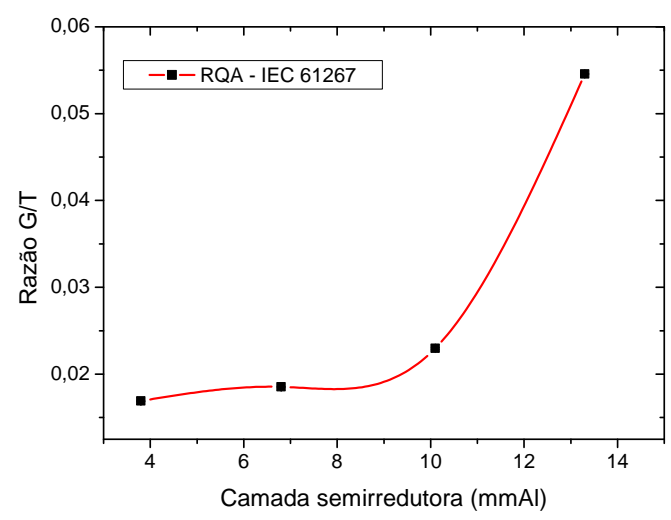

(B) $R Q A$

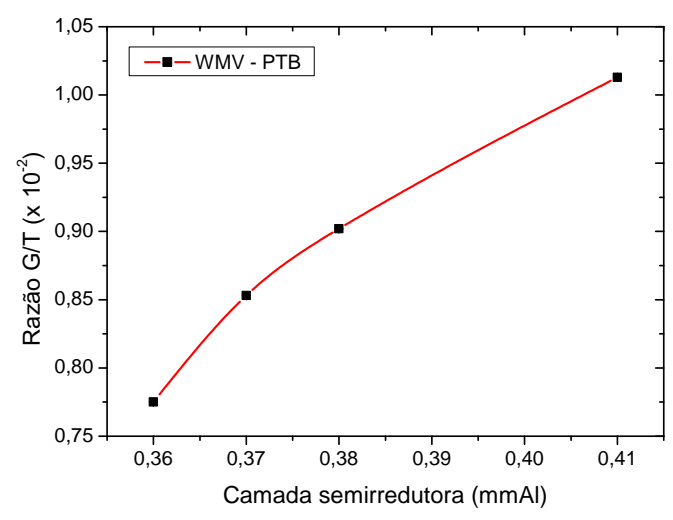

(c) $W M V$

Figura 7.16 - Curvas tandem obtidas da razão entre as respostas das câmaras G e T, utilizando as qualidades de radiação $R Q R, R Q A$ e mamografia (WMV). As incertezas das medições são menores que 0,4\%, imperceptíveis nos gráficos. 


\section{Discussão}

O principal objetivo deste trabalho era desenvolver uma câmara de ionização para monitorar feixes de radiação X. Essa câmara monitora deveria ter algumas características particulares para que fosse diferenciada das câmaras monitoras já existentes no mercado. A principal diferença consistia em seu formato inovador, com um volume sensível em forma de anel, para não causar interferência no feixe de radiação direto e, ainda assim, apresentar uma resposta sensível. Outra característica importante seria sua confecção simples com materiais disponíveis no mercado. Por último, mas não menos importante, ser de baixo custo.

Foram desenvolvidos e construídos três protótipos de câmaras de ionização anelares para alcançar os resultados esperados. O primeiro protótipo apresentou duas falhas graves de concepção. A primeira delas foi a falta de anel de guarda na borda interna do volume sensível causando efeito de borda do campo elétrico. A outra falha foi na fixação da janela de entrada com cola, o que dificultou muito o trabalho de construção da câmara de ionização e, consequentemente, não apresentou bons resultados.

Os erros cometidos no primeiro protótipo serviram de experiência para a construção do segundo protótipo, câmara A. Desta vez foi utilizado um anel de guarda tanto no diâmetro interno quanto no diâmetro externo do volume sensível, que evitou a ocorrência de efeito de borda do campo elétrico. A janela de entrada foi fixada por pressão permitindo assim, que o material da janela de entrada ficasse bem esticado. O problema apresentado por esta câmara foi sua instabilidade de resposta para feixes de radiação X. Como o intuito dessa câmara anelar é monitorar 
a intensidade do feixe de radiação, a resposta instável da câmara inviabilizou sua utilização.

O terceiro e último protótipo de câmara de ionização anelar, câmara G, foi construído com base nos erros e acertos dos outros protótipos. Para corrigir a falta de estabilidade de resposta verificado no protótipo anterior, o eletrodo coletor foi feito, desta vez, de grafite, o que embora tenha diminuído a intensidade de resposta da câmara, possibilitou um aumento substancial na sua estabilidade. A câmara G apresentou ótimos resultados em todos os testes realizados. Sua resposta apresentou uma saturação, significando com isto, que todas as cargas produzidas em seu volume sensível são coletadas, linearidade e estabilidade, tanto utilizando uma fonte de controle de ${ }^{90} \mathrm{Sr}^{+90} \mathrm{Y}$ quanto um sistema de radiação X. A estabilidade de resposta em feixes de radiação X garante que a câmara de ionização pode ser utilizada como câmara monitora, pois, sua resposta sendo estável, ela pode ser utilizada como padrão de referência para outras medições no feixe de radiação.

Outra câmara monitora foi ainda construída, mas no formato tradicional das câmaras monitoras de transmissão comerciais, a qual foi denominada câmara T. O intuito de se construir esta câmara foi o de compará-la com a câmara comercial utilizada atualmente no sistema de radiação X do LCI, além do laboratório poder contar com uma câmara de transmissão de apoio. Ambas as câmaras (a T e a comercial) apresentaram saturação da resposta, estabilidade e linearidade de resposta, tanto para radiação beta da fonte de controle quanto para feixes de radiação X. A maior diferença entre os resultados obtidos com essas câmaras foi a alta dependência energética da câmara monitora desenvolvida com relação à câmara comercial, principalmente para feixes de radiação X, na faixa de energia para radiodiagnóstico.

As câmaras comerciais e as desenvolvidas foram calibradas (ou determinados os coeficientes de equivalência) em feixes de radiação X (radiodiagnóstico convencional e mamografia), gama e beta, em relação aos sistemas padrões secundários de cada intervalo de energia e tipo de radiação. Os dados obtidos mostram a viabilidade da 
utilização das câmaras de ionização G, T e câmara de transmissão PTW, não só no monitoramento dos feixes de radiação X como para a determinação das taxas de dose absorvidas ou taxas de kerma no ar, dos feixes de radiação do equipamento do LCI. Apesar das câmaras desenvolvidas apresentarem uma dependência energética muito alta com relação às câmaras de ionização comerciais, essas câmaras monitoras não foram projetadas para serem instrumentos padrões. Assim, conhecendo-se seus fatores de equivalência e suas estabilidades de resposta, pode-se garantir tanto a monitoração da intensidade do feixe de radiação quanto a determinação da taxa de kerma no ar dos feixes de radiação do equipamento de radiação X do LCI.

Ainda, foi verificada a possibilidade de se formar um sistema tandem utilizando as câmaras G e T. Este sistema tandem pode também ser utilizado para uma verificação rápida da camada semirredutora de um feixe de radiação X conhecido. Essa verificação pode fazer parte de um sistema de controle de qualidade em serviços que utilizam feixes de radiação.

Assim, o objetivo de se construir uma câmara de ionização anelar com desempenho comparável ou melhor que o de uma câmara Farmer e uma câmara de ionização com volume duplo com desempenho comparável ao de uma câmara de transmissão comercial, foi alcançado. No caso da câmara de ionização anelar, seu desempenho foi melhor que o da câmara Farmer, pois sua resposta apresentou maior estabilidade em feixes de radiação X, e no caso da câmara com volume duplo, o desempenho verificado foi comparável com o da câmara de transmissão utilizada atualmente no sistema de radiação X do LCI. 


\section{Conclusões}

Dentre os objetivos propostos neste trabalho todos foram alcançados. Assim, foram construídos três protótipos de câmaras monitoras anelares e um protótipo de câmara de transmissão. Para todas as câmaras de ionização desenvolvidas foram realizados diversos testes de caracterização e de estabilidade de resposta. Esses testes tinham o objetivo de determinar algumas características das câmaras de ionização, como, saturação da resposta, eficiência de coleção de íons, efeito de polaridade, linearidade de resposta, tempo de estabilização, corrente de fuga, e repetitividade e reprodutibilidade utilizando fonte de controle e feixes de radiação $\mathrm{X}$.

A câmara A apresentou bons resultados para todos os testes realizados exceto para o teste de reprodutibilidade de resposta em feixes de radiação X. As câmaras $\mathrm{G}$ e $\mathrm{T}$ apresentaram bons resultados, dentro dos limites recomendados, para todos os testes realizados. Essas câmaras monitoras (a G e a T) apresentaram então, saturação em suas respostas, boa eficiência de coleção de íons, pequeno efeito de polaridade, resposta linear, repetitível e reprodutível tanto para fontes de controle como para feixes de radiação X.

Outra conclusão é que a câmara T pode substituir a câmara de transmissão PTW sem perda de qualidade. Além disso, a câmara G pode substituir a câmara Farmer com a vantagem de apresentar resposta reprodutível para feixes de radiação X e, ainda, substituir a câmara de transmissão PTW com a vantagem de não interferir no feixe direto de radiação. 
Todas as câmaras de ionização monitoras foram construídas artesanalmentee utilizando-se materiais de baixo custo encontrados no mercado nacional. 


\section{Bibliografia}

[1] NATIONAL COUNCIL ON RADIATION PROTECTION AND MEASUREMENTS. Evaluation of the linear non-threshold dose-response model for ionizing radiation. NCRP Report 136. Bethesda, Maryland: NCRP, 2001.

[2] AGÊNCIA NACIONAL DE VIGILÂNCIA SANITÁRIA. Regulamento técnico que estabelece as diretrizes básicas de proteção radiológica em radiodiagnóstico médico e odontológico, dispõe sobre o uso dos raios $X$ diagnósticos em todo território nacional e dá outras providências. Portaria federal $\mathrm{n}^{\mathrm{O}}$ 453, de 1 de junho de 1998.

[3] INTERNATIONAL COMMISSION ON RADIATION UNITS AND MEASUREMENTS. Determination of absorbed dose in a patient irradiated by beams of $X$ and gamma rays in radiotherapy procedures. ICRU Report 24. Bethesda, Maryland: ICRU, 1976.

[4] INTERNATIONAL COMMISSION ON RADIATION UNITS AND MEASUREMENTS. Radiation dosimetry: electron beams with energies between 1 and $50 \mathrm{MeV}$. ICRU Report 35. Washington, DC: ICRU, 1984.

[5] AMERICAN ASSOCIATION OF PHYSICS IN MEDICINE, TASK GROUP 21. RADIATION THERAPY COMMITTEE. "A protocol for the determination of absorbed dose from high energy photon and electron beams." Med. Phys. 10 (1983), pp. 741-771. 
[6] AMERICAN ASSOCIATION OF PHYSICS IN MEDICINE, TASK GROUP 25. RADIATION THERAPY COMMITTEE. "Clinical electron-beam dosimetry." Med. Phys. 18 (1991), pp. 73-109.

[7] InTERnATIONAL ATOMIC ENERGY AGENCY. Absorbed dose determination in external beam radiotherapy. A international code of practice for dosimetry based on standards of absorbed dose to water. Technical Reports Series 398. Vienna: IAEA, 2000.

[8] INTERNATIONAL ATOMIC ENERGY AGENCY. Calibration of radiation protection monitoring instruments. Safety Reports Series 16. Vienna: IAEA, 2000.

[9] INTERNATIONAL ATOMIC ENERGY AGENCY. Calibration of reference dosimeters for external beam radiotherapy. Technical Reports Series 469. Vienna: IAEA, 2009.

[10] INTERNATIONAL ORGANIZATION FOR STANDARDIZATION. $\boldsymbol{X}$ and gamma reference radiations for calibrating dosemeters and doserate meters and for determining their response as function of photon energy. Part 1: Radiation characteristics and production methods. ISO 4037-1:1997. Genève 1997.

[11] ALBUQUERQUE, M.P.P.; CALDAS, L.V.E. "New ionization chambers for beta and X radiation." Nucl. Instrum. Meth. Phys. Res. A280 (1989), pp. $310-313$.

[12] CALDAS, L.V.E. "A sequential tandem system of ionisation chambers for effective energy determination of radiation fields." Radiat. Prot. Dosim. 36(1) (1991), pp. 47-50.

[13] CALDAS, L.V.E.; ALBUQUERQUE, M.P.P. "Angular dependence of parallel plate ionization chambers." Radiat. Prot. Dosim. 37(1) (1991), pp. 55-57. 
[14] SOUZA, C.N.; CALDAS, L.V.E.; SIBATA, C.H.; HO, A.K.; SKIN, K.H. "Two new parallel-plate ionization chambers for electron beam dosimetry." Radiat. Measurem. 26(1) (1996), pp. 65-74.

[15] DIAS, S.K.; CALDAS, L.V.E. "Development of an extrapolation chamber for the calibration for beta ray applicators." IEEE Trans. Nucl. Scie. 45(3) (1998), pp. 1666-1669.

[16] DIAS, S.K.; CALDAS, L.V.E. "Characteristics of an extrapolation chamber for X-ray protection level measurements." J. Appl. Phys. 86(1) (1999), pp. 671-673.

[17] DIAS, S.K.; CALDAS, L.V.E. "Extrapolation chamber response in low-energy beta radiation standard beams." J. A ppl. Phys. 89(1) (2001), pp. 669-671.

[18] COSTA, A.M.; CALDAS, L.V.E. "A special ionization chamber for quality control of diagnostic and mammography X ray equipment." Radiat. Prot. Dosim. 104(1) (2003), pp. 41-45.

[19] COSTA, A.M. CALDAS, L.V.E. "Response characteristics of a Tandem ionization chamber in standard X-ray beams." Appl. Radiat. Isot. 58(4) (2003), pp. 495-500.

[20] OLIVEIRA, M.L.; CALDAS, L.V.E. "A special mini-extrapolation chamber for calibration of ${ }^{90} \mathrm{Sr}+{ }^{90} \mathrm{Y}$ sources." Phys. Med. Biol. 50(4) (2005), pp. 2929-2936.

[21] OLIVEIRA, M.L.; CALDAS, L.V.E. "Performance of a prototype of an extrapolation minichamber in various radiation beams." Appl. Radiat. Isot. 65 (2007), pp. 975-979.

[22] MAIA, A.F.; CALDAS, L.V.E. "A new extended-length parallel-plate ionization chamber." Phys. Med. Biol. 50 (2005), pp. 3837-3847.

[23] AUSTERlitZ, C.; SIBATA, C.H.; ALMEIDA, C.E. "A graphite transmission ionization chamber." Med. Phys. 14(6) (1987), pp. 1056-1059. 
[24] INTERNATIONAL COMMISSION ON RADIATION UNITS AND MEASUREMENTS. "Recommendations of the International Commission on Radiological Units." Brit. J. Rad. 27 (1954), pp. 243-247.

[25] INTERNATIONAL COMMISSION ON RADIATION UNITS AND MEASUREMENTS. Radiation quantities and units. ICRU Report 33. Bethesda, Maryland: ICRU, 1980.

[26] INTERNATIONAL COMMISSION ON RADIATION UNITS AND MEASUREMENTS. Fundamental quantities and units for ionizing radiation. ICRU Report 60. Bethesda, Maryland: ICRU, 1998.

[27] INTERNATIONAL COMMISSION ON RADIATION UNITS AND MEASUREMENTS. Patient dosimetry for $X$ rays used in medical imaging. ICRU Report 74. Bethesda, Maryland: ICRU, 2005.

[28] INTERNATIONAL COMMISSION ON RADIOLOGICAL PROTECTION. "The 2007 Recommendations of the International Commission on Radiological Protection." Annals of the ICRP 37 (2007), pp. 1-332.

[29] TAUHATA, L.; SAlati, I. P. A.; DI PRINZIO, R.; DI PRINZIO, A. R. Radioproteção e dosimetria: Fundamentos. $5^{\text {a }}$ Revisão. Rio de Janeiro: IRD/CNEN, 2003. URL: http://ird.gov.br/index .php?option=com_ docman\&task=cat_view\&gid=45\&Itemid=64 (acesso em 24/11/2006).

[30] INTERNATIONAL COMMISSION ON RADIATION UNITS AND MEASUREMENTS. Radiation quantities and units. ICRU Report 11. Bethesda, Maryland: ICRU, 1968.

[31] INTERNATIONAL ATOMIC ENERGY AGENCY. Radiation Oncology Physics. A handbook for teachers and students. Vienna: IAEA, 2005. URL: http: //www-pub.iaea .org/MTCD/publications/PDF/Pub1196_web. pdf (acesso em 24/11/2006). 
[32] ATTIX, F.H. Introduction on radiological physics and radiological dosimetry. 2nd ed. New York: John Wiley \& Sons, 1986.

[33] INTERNATIONAL ATOMIC ENERGY AGENCY. Dosimetry in diagnostic radiology. An international code of practice. Technical Reports Series 457. Vienna: IAEA, 2007.

[34] SHRIMPTON, P.C.; WALL, B.F. "The measurement of energy imparted to patients during diagnostic X-ray examinations using the Diamentor exposurearea product meter." Phys. Med. Biol. 29(6) (1984), pp. 1199-1208.

[35] INTERNATIONAL ELECTROTECHNICAL COMMISSION. Medical $\boldsymbol{d i}$ agnostic $X$-ray equipment. Radiation conditions for use in the determination of characteristics. 1st ed. IEC 1267. Genève: IEC, 1994.

[36] INTERNATIONAL ELECTROTECHNICAL COMMISSION. Medical diagnostic $X$-ray equipment. Radiation conditions for use in the determination of characteristics. 2nd ed. IEC 61267. Genève: IEC, 2005.

[37] INSTITUTO NACIONAL DE METROLOGIA, NORMALIZAÇÃO E QUALIDADE INDUSTRIAL. Vocabulário internacional de termos fundamentais e gerais de metrologia. 3rd ed. Rio de Janeiro: INMETRO, 2003.

[38] BUREAU INTERNATIONAL DES POIDS ET MESURES. $\boldsymbol{B} \boldsymbol{I P} \boldsymbol{M}-\boldsymbol{X}$ ray dosimetry. URL: http://wwW.bipm.fr/en/scientific/ionizing/ dosimetry/x-ray/ (acesso em 28/11/2006).

[39] PERNICKA, F.; ANDREO, P.; MEGHZIFENE, A.; CZAP, L.; GIRZIKOWSKY, R. "Standards for radiation protection and diagnostic radiology at the IAEA dosimetry laboratory." SSDL Newsletter 41 (1999), pp. 13-25.

[40] COMISSÃO NACIONAL DE ENERGIA NUCLEAR. Diretrizes básicas de proteção radiológica. CNEN-NN-3.01. Rio de Janeiro: CNEN, 2005. 
[41] NATIONAL COUNCIL ON RADIATION PROTECTION AND MEASUREMENTS. Ionizing radiation exposure of the population of the United States. NCRP Report 93. Bethesda: NCRP, 1997.

[42] NATIONAL COUNCIL ON RADIATION PROTECTION AND MEASUREMENTS. Ionizing radiation exposure of the population of the United States. NCRP Report 160. Bethesda, Maryland: NCRP, 2009.

[43] SHRIMPTON, P.C.; WALL, B.F. "An evaluation of the Diamentor transmission ionisation chamber in indicating exposure-area product $\left(\mathrm{r} \mathrm{cm}^{2}\right)$ during diagnostic radiological examinations." Phys. Med. Biol. 27(6) (1982), pp. $871-878$.

[44] GFIRTNER, H.; STIEVE, F.-H.; WILD, J. "A new Diamentor for measuring kerma-area product and air-kerma simultaneously." Med. Phys. 24(12) (1997), pp. 1954-1959.

[45] MCPARLAND, B.J. "Entrance skin dose estimates derived from dose-area product measurements in interventional radiological procedures." Brit. J. Rad. 71(852) (1988), pp. 1288-1295.

[46] SANKARAN, A. "A novel X-ray transmission ionization chamber dosemeter for patient dose measurements in diagnostic radiology." Brit. J. Rad. 61 (1988), pp. 613-618.

[47] WAGNER, L.K.; FONTENLA, D.P.; KIMME-SMITH, C.; ROTHENBERG, L.N.; SHEPARD, J.; BOONE, J.M. "Recommendations on performance characteristics of diagnostic exposure meters." Med. Phys. 19(1) (1992), pp. 231-241.

[48] PALLWAL, B.R.; ZAINI, M.; MCNUTT, T.; FAIRBANKS, E.J.; KITCHEN, R. "A consistency monitor for radiation therapy treatments." Med. Phys. 23(10) (1996), pp. 1805-1807. 
[49] POPPE, B.; THIEKE, C.; BEYER, D.; KOLLHOFF, R.; DJOUGUELA, A.; RÜHMANN, A.; WILLBORN, K.C.; HARDER, D. DAVID. "A translucent multi-wire transmission ionization chamber for in vivo verification of IMRT and conformal irradiation techniques." Phys. Med. Biol. 51 (2006), pp. $1237-1248$.

[50] MIRANDA, J.A.; POTIENS, M.P.A. "Controle de qualidade de câmaras de ionização planas utilizadas como câmaras monitoras em feixes de Radiodiagnóstico." Revista Brasileira de Física Médica 1.1 (2005).

[51] INTERNATIONAL ELECTROTECHNICAL COMMISSION. Medical diagnostic X-ray equipment. Medical electrical equipment - Dosimeters with ionization chambers and/or semi-conductor detectors as used in X-ray diagnostic imaging. IEC 61674. Genève: IEC, 1997.

[52] INTERNATIONAL ORGANIZATION FOR STANDARDIZATION. Guide to the expression of uncertainty in measurement. Genève: ISO, 1995.

[53] ASSOCIAÇÃO BRASILEIRA DE NORMAS TÉCNICAS; INSTITUTO NACIONAL DE METROLOGIA NORMALIZAÇÃO E QUALIDADE INDUSTRIAL. Guia para a Expressão da Incerteza de Medição. $3^{\mathrm{a}}$ Edição Brasileira. Rio de Janeiro: ABNT, 2003.

[54] PHYSIKALISCH-TECHNISCHE BUNDESANSTALT. Calibration certificate of ionisation chamber RC6M Nuclear Enterprises. Braunschweig: 6.25-30/09K, 2009.

[55] PHYSIKALISCH-TECHNISCHE BUNDESANSTALT. Calibration certificate of ${ }^{90} \mathrm{Sr}+{ }^{90} \mathrm{Y},{ }^{85} \mathrm{Kr}$ and ${ }^{147} \mathrm{Pm}$ sources. Braunschweig: PTB6.34-BSS2_04, 2005.

[56] INSTITUTO NACIONAL DE METROLOGIA, NORMALIZAÇÃO E QUALIDADE INDUSTRIAL. Vocabulário internacional de termos fundamentais e gerais de metrologia. $3^{\text {a }}$ Edição. Rio de Janeiro: INMETRO, 2003. 
[57] FRANCISCATTO, P.C. Caracterização das qualidades de radiação $X$ seguindo as recomendações da norma IEC 61267 no laboratório de calibração do IPEN. Dissertação (Mestrado)-Instituto de Pesquisas Energéticas e Nucleares. Universidade de São Paulo: São Paulo, 2009.

[58] GORBICS, S.G.; ATTIX, F.H. "LiF and $\mathrm{CaF}_{2}$ :Mn thermoluminescent dosimeters in Tandem." Int. J. Appl. Radiat. Isot. 19 (1968), pp. 81-89.

[59] DA ROSA, L.A.R.; NETTE, H.P. "Thermoluminescent dosemeters for exposure assessment in gamma or $\mathrm{X}$ radiation fields with unknown spectral distribution." Appl. Radiat. Isot. 39(3) (1988), pp. 191-197. 


\section{A. Artigos Publicados}

Durante a execução deste projeto vários trabalhos foram submetidos e apresentados em congressos nacionais e internacionais. Além disso, foram publicados três artigos completos em periódicos internacionais. São eles:

- Yoshizumi, M.T., Yoriyaz, H., Caldas, L.V.E. Backscattered radiation into a transmission ionization chamber: Measurement and Monte Carlo simulation. Applied Radiation and Isotopes, v. 68, p. 586-588, 2010.

- Yoshizumi, M.T., Vivolo, V., Caldas, L.V.E. Preliminary studies of a new monitor ionization chamber. Applied Radiation and Isotopes, v. 68, p. 620-622, 2010.

- Yoshizumi, M.T., Caldas, L.V.E. A new ring-shaped graphite monitor ionization chamber. Nuclear Instruments \& Methods in Physics Research. Section A, Accelerators, Spectrometers, Detectors and Associated Equipment, v. 619, p. 207-210, 2010.

Esses trabalhos, em sua íntegra, estão apresentados a seguir. 